\title{
Data Compilation, Synthesis, and Calculations Used for Organic-Carbon Storage and Inventory Estimates for Mineral Soils of the Mississippi River Basin
}

By Gary R. Buell and Helaine W. Markewich

Chapter A of

Soil-Carbon Storage and Inventory for the Continental United States

Edited by Helaine W. Markewich

Professional Paper 1686-A 


\section{U.S. Department of the Interior \\ Gale A. Norton, Secretary \\ U.S. Geological Survey \\ Charles G. Groat, Director}

\section{U.S. Geological Survey, Reston, Virginia: 2004}

For more information about the USGS and its products:

Telephone: 1-888-ASK-USGS

World Wide Web: http://www.usgs.gov/

Any use of trade, product, or firm names in this publication is for descriptive purposes only and does not imply endorsement by the U.S. Government.

Although this report is in the public domain, permission must be secured from the individual copyright owners to reproduce any copyrighted materials contained within this report.

\section{Library of Congress Cataloging-in-Publication Data}

Buell, Gary R.

Data compilation, synthesis, and calculations used for organic-carbon storage and inventory estimates for mineral soils of the Mississippi River Basin / by Gary R. Buell and Helaine W. Markewich.

p. cm. - (U.S. Geological professional paper ; 1686-A)

Includes bibliographic references.

1. Soils - Carbon content-Mississippi River Watershed — Statistical methods. 2. Carbon cycle (Biogeochemistry)— Mississippi River Watershed—Statistical methods. 3. Carbon sequestration-Mississippi River Watershed—Statistical methods. I. Markewich, Helaine W. II. Title. III. Series.

S592.6.C35B84 2003

$631.4^{\prime} 17-\mathrm{dc} 22$ 


\section{Contents}

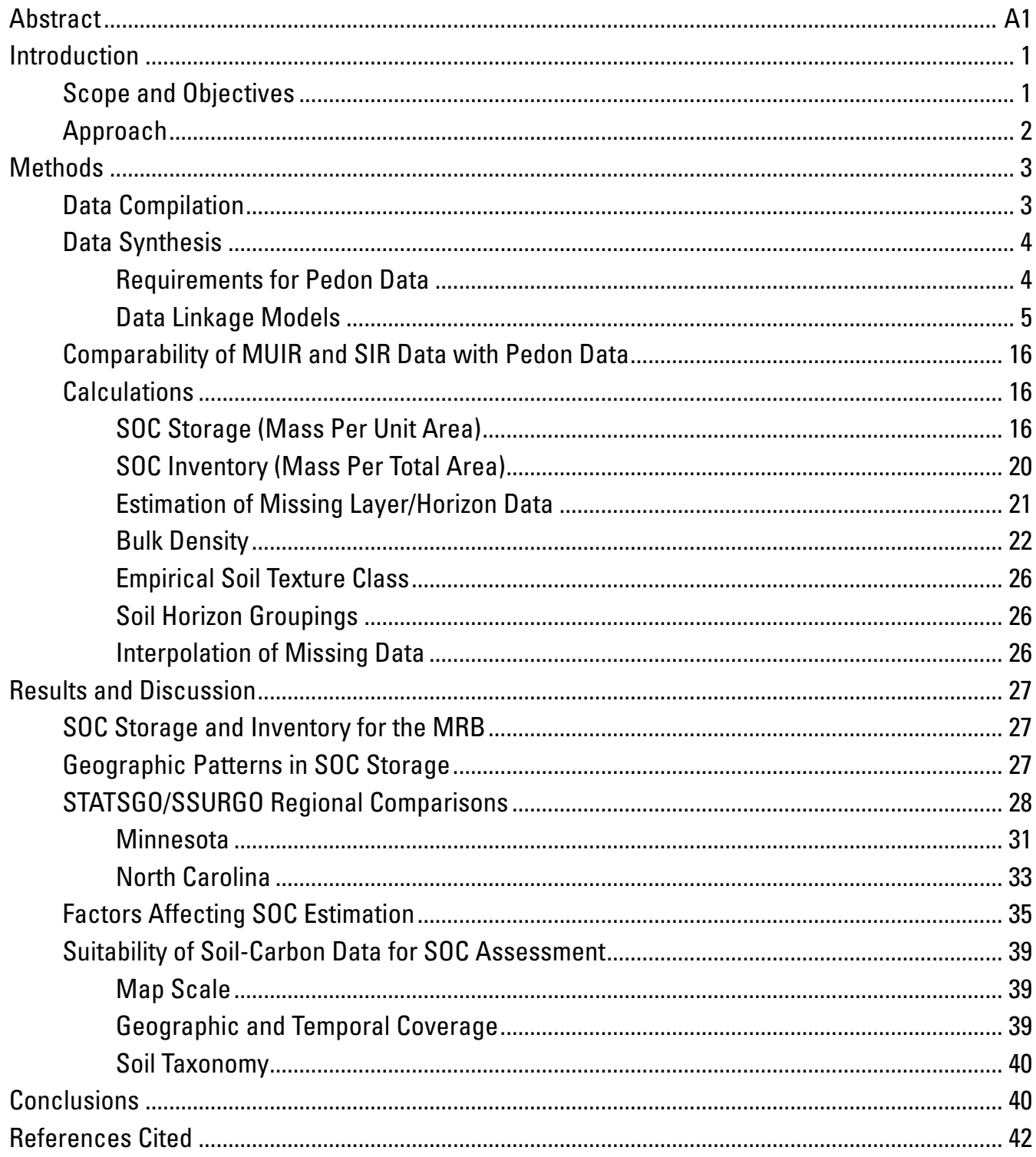

\section{Figures}

1. Map showing U.S. Geological Survey hydrologic regions of the Mississippi River Basin .. A2

2-6. Site-specific soil pedon data sets for:

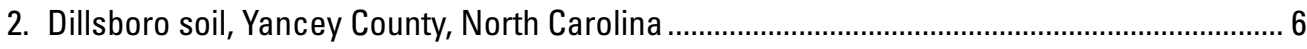

3. Unnamed soil in Carbon County, Montana .............................................................................. 8

4. Cathedral or Cathedral-like soil, Fremont County, Colorado ................................................ 10

5. Memphis soil, Crittenden County, southwestern Kentucky.................................................. 12 
6. Gepp soil, Randolph County, Arkansas

7. Schematic showing a representative pedon profile for a soil series..

8. Maps showing component area-weighted mean coarse-fragment volume for STATSGO and SSURGO map units, Mitchell and Yancey Counties, North Carolina.....

9. Schematic showing the relation between STATSGO map units and STATSGO map-unit components for Mitchell and Yancey Counties, North Carolina

10. Percentage of rock outcrop in STATSGO and SSURGO map units, Mitchell and Yancey Counties, North Carolina

11. Relations among soil bulk density, organic carbon, and clay for selected $A$ and $E$ horizons of soils in the Mississippi River Basin.

12-17. Soil organic carbon storage estimates for mineral soils in:

12. Mississippi River Basin, site-specific data linked to STATSGO map units 28

13. Nicollet, Renville, and Sibley Counties, Minnesota, site-specific data linked to STATSGO map units.

14. Nicollet, Renville, and Sibley Counties, Minnesota, site-specific data linked to SSURGO map units.

15. Mitchell and Yancey Counties, North Carolina, site-specific data linked to STATSGO map units

16. Mitchell and Yancey Counties, North Carolina, site-specific data linked to SSURGO map units

17. Mitchell and Yancey Counties, North Carolina, site-specific data linked to SSURGO map units, calculated by two methods

18. Component area-weighted mean depth to bedrock for STATSGO and SSURGO map units, Mitchell and Yancey Counties, North Carolina

19. Geographic extent of soil orders based on SSURGO taxonomy-Nicollet, Renville, and Sibley Counties, Minnesota, and Mitchell and Yancey

Counties, North Carolina

\section{Tables}

1. Median bulk densities of mineral soils at:

A. 1/3-bar tension moisture content for the standard U.S. Department of Agriculture soil texture classes by soil horizon.

$B$. Oven-dry moisture content for the standard U.S. Department of Agriculture soil texture classes by soil horizon.

2. U.S. Department of Agriculture STATSGO map units with and without site-specific, series-level soil organic carbon data for the U.S. Geological Survey hydrologic regions in the Mississippi River Basin

3-4. Soil organic carbon storage and inventory for the surface meter of mineral soil for:

3. U.S. Geological Survey hydrologic regions and region subbasins in the Mississippi River Basin

4. Selected county areas of the Mississippi River Basin 


\section{Conversion Factors and Datums}

\begin{tabular}{|c|c|c|}
\hline Multiply & By & To obtain \\
\hline \multicolumn{3}{|c|}{ Length } \\
\hline inch (in.) & 2.54 & centimeter $(\mathrm{cm})$ \\
\hline foot $(\mathrm{ft})$ & 0.3048 & meter $(\mathrm{m})$ \\
\hline mile (mi) & 1.609340 & kilometer (km) \\
\hline \multicolumn{3}{|c|}{ Area } \\
\hline square foot $\left(\mathrm{ft}^{2}\right)$ & 0.0929 & square meter $\left(\mathrm{m}^{2}\right)$ \\
\hline square mile $\left(\mathrm{mi}^{2}\right)$ & 2.58999 & square kilometer $\left(\mathrm{km}^{2}\right)$ \\
\hline \multicolumn{3}{|c|}{ Mass } \\
\hline pound, avoirdupois (lb) & 453.59237 & gram $(\mathrm{g})$ \\
\hline pound, avoirdupois (lb) & 0.4536 & kilogram $(\mathrm{kg})$ \\
\hline \multicolumn{3}{|c|}{ Pressure } \\
\hline pound per square foot $\left(\mathrm{lb} / \mathrm{ft}^{2}\right)$ & 47.9 & pascal $(\mathrm{Pa})$ \\
\hline bar & 100,000 & pascal $(\mathrm{Pa})$ \\
\hline bar & 100 & kilopascal (kPa) \\
\hline bar & 0.1 & megapascal (MPa) \\
\hline \multicolumn{3}{|c|}{ Temperature } \\
\hline degrees Fahrenheit $\left({ }^{\circ} \mathrm{F}\right)$ & $5 / 9\left({ }^{\circ} \mathrm{F}-32\right)$ & degrees Celsius $\left({ }^{\circ} \mathrm{C}\right)$ \\
\hline \multicolumn{3}{|c|}{ Concentration } \\
\hline Percent & 10 & grams per kilogram $(\mathrm{g} / \mathrm{kg})$ \\
\hline
\end{tabular}

Vertical coordinate information is referenced to the insert datum name (and abbreviation) here for instance, "North American Vertical Datum of 1988 (NAVD 88)."

Horizontal coordinate information is referenced to the insert datum name (and abbreviation) here for instance, "North American Datum of 1983 (NAD 83)."

Altitude, as used in this report, refers to distance above the vertical datum. 


\title{
Data Compilation, Synthesis, and Calculations Used for Organic-Carbon Storage and Inventory Estimates for Mineral Soils of the Mississippi River Basin
}

\author{
By Gary R. Buell and Helaine W. Markewich
}

\begin{abstract}
U.S. Geological Survey investigations of environmental controls on carbon cycling in soils and sediments of the Mississippi River Basin (MRB), an area of $3.3 \times 10^{6}$ square kilometers $\left(\mathrm{km}^{2}\right)$, have produced an assessment tool for estimating the storage and inventory of soil organic carbon (SOC) by using soil-characterization data from Federal, State, academic, and literature sources. The methodology is based on the linkage of site-specific SOC data (pedon data) to the soil-association map units of the U.S. Department of Agriculture State Soil Geographic (STATSGO) and Soil Survey Geographic (SSURGO) digital soil databases in a geographic information system. The collective pedon database assembled from individual sources presently contains 7,321 pedon records representing 2,581 soil series. SOC storage, in kilograms per square meter $\left(\mathrm{kg} / \mathrm{m}^{2}\right)$, is calculated for each pedon at standard depth intervals from 0 to 10,10 to 20,20 to 50 , and 50 to 100 centimeters. The site-specific storage estimates are then regionalized to produce national-scale (STATSGO) and county-scale (SSURGO) maps of SOC to a specified depth. Based on this methodology, the mean SOC storage for the top meter of mineral soil in the MRB is approximately $10 \mathrm{~kg} / \mathrm{m}^{2}$, and the total inventory is approximately $32.3 \mathrm{Pg}$ ( 1 petagram = $10^{9}$ metric tons). This inventory is from 2.5 to 3 percent of the estimated global mineral SOC pool.
\end{abstract}

\section{Introduction}

Humankind has changed the global carbon cycle by burning fossil fuels and by converting "native" photosynthetic production into "managed" forestry and agriculture for a significant portion of the Earth's surface. Human activity has also transformed much of the land surface itself by converting large areas for human use through urban, suburban, and industrial development. These activities have fundamentally altered the interactions between terrestrial and atmospheric carbon and the sediment/nutrient transport paths across the land surface to the oceans. Understanding these changes and how they affect the carbon cycle are essential to understanding many global environmental problems, particularly the relations between global climate and atmospheric carbon dioxide $\left(\mathrm{CO}_{2}\right)$. What we understand about the interactions among human activities, $\mathrm{CO}_{2}$ cycling, and climate can improve the decisions that result from global environmental policy deliberations.

Presently, climate scientists generally agree that some global warming and changes in rainfall patterns will result from the enhanced greenhouse effect of increasing atmospheric $\mathrm{CO}_{2}$ levels (IPCC, 1995, 2001). Atmospheric warming and changes in precipitation patterns directly and immediately affect the Earth's surface, particularly the soils, which constitute the largest carbon reservoir on the land surface. Blecker and others (1997) presented pedologic and geomorphic evidence for the link between Holocene climate variation, soil formation, and carbon sequestration in the shortgrass steppe soils of northeastern Colorado. U.S. Geological Survey (USGS) investigations of the environmental controls on carbon in soils and sediments of the Mississippi River Basin (MRB) (fig. 1) is a contribution toward understanding the global significance of human influences on terrestrial carbon cycling. Obtaining accurate values for present-day soil organic carbon (SOC) storage and inventory in the MRB is fundamental to this endeavor.

\section{Scope and Objectives}

The Mississippi River is the largest river in North America. Its drainage basin encompasses a $3.3 \times 10^{6} \mathrm{~km}^{2}$ area with large variations in climate, vegetation, land use, and agriculture. The MRB is well studied and includes areas that typify other regions of the Earth's surface that have undergone human development. By examining a variety of spatial scales, including the whole MRB, we can identify those aspects of environmental change that have major effects on carbon, nutrient, and sediment cycles.

Data from several years of investigations in the MRB have allowed us to make progress toward the following objectives: (1) "map" carbon at national, regional, and local scales; (2) calculate present carbon storage at the land surface; (3) identify those areas with the greatest potential to sequester 


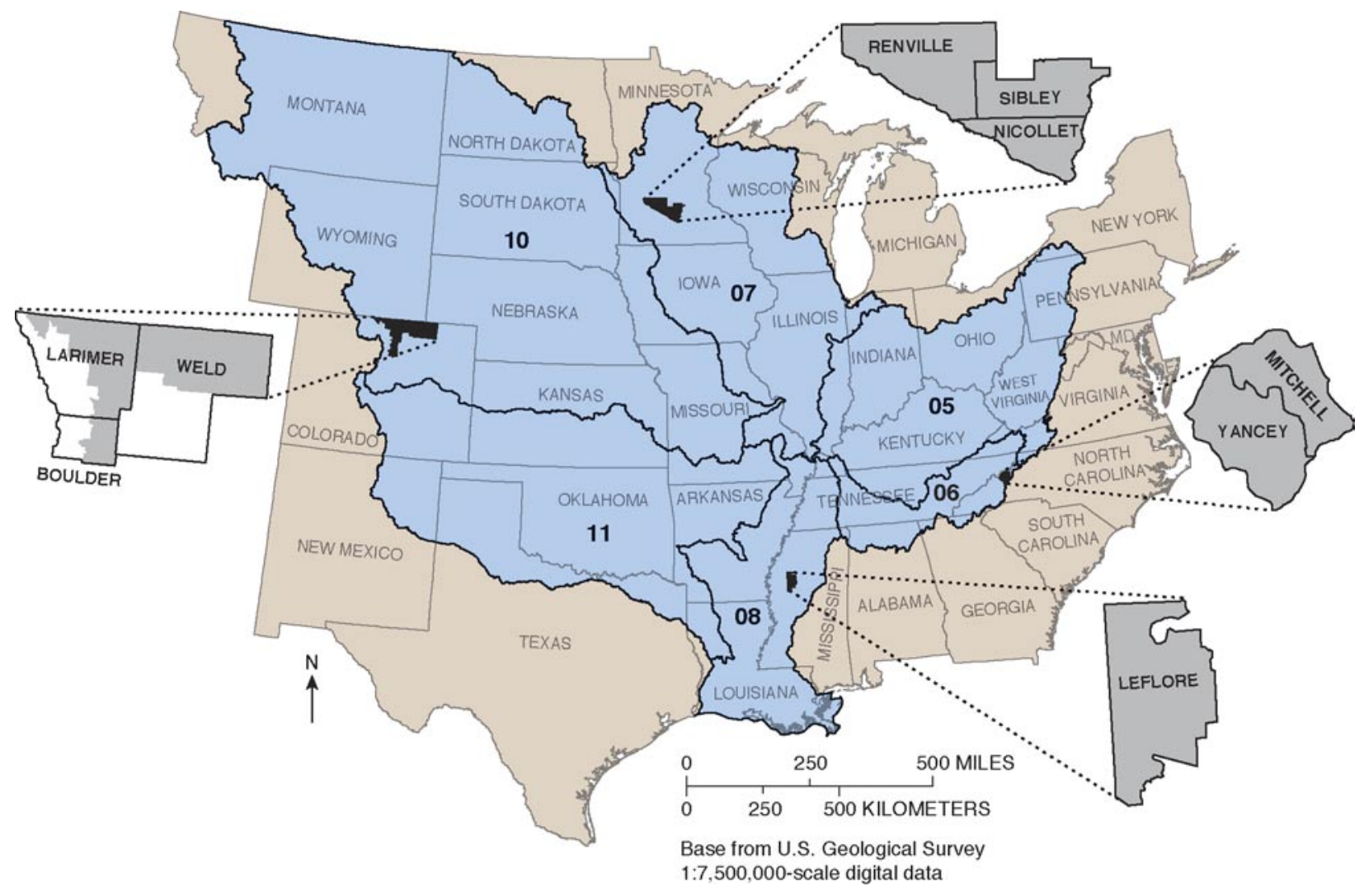

Figure 1. U.S. Geological Survey hydrologic regions (outlined in black, Seaber and others, 1994) of the Mississippi River Basin (MRB) (shown in blue) in the United States. MRB hydrologic regions are numbered: 05, 0hio; 06 , Tennessee; 07, Upper Mississippi; 08, Lower Mississippi; 10, Missouri; and 11, Arkansas-White-Red. Soil organic carbon (SOC) storage and inventory estimates for the hydrologic regions are given in table 3 . See table 4 for the SOC storage estimates for counties (mapped areas of counties shown in gray) in these hydrologic regions.

carbon; and (4) show that many of these areas are coincident with lands targeted by local, State, and Federal agencies for watershed/well-head protection, floodplain/wetland restoration/protection, cropland reserve programs, mammal and bird migration route connection, and urban/suburban greenspace-corridor creation/restoration/connection.

For the MRB, the USGS has begun the following tasks:

- Compilation and synthesis of site-specific data needed to estimate carbon storage and inventory in the soils, reservoir sediment, wetlands, and lakes of the continental United States.

- Characterization of present-day carbon storage by landscape feature and environment.

- Prediction of potential carbon storage for land areas identified as possible reserves for carbon sequestration.

This report presents the approach, methods, and preliminary conclusions for these ongoing efforts directed at obtaining accurate estimates of SOC storage (mass per unit area) and inventory (mass per total area) for the MRB.

\section{Approach}

The first step in completing the tasks listed in the previous section is to estimate the present terrestrial SOC inventory and, thus, provide a baseline for measurement of net changes in SOC inventory related to future changes in land use and climate. The most readily available method for estimation of SOC storage and inventory for the surface meter of any land area in the United States is to use either of two U.S. Department of Agriculture Natural Resources Conservation Service (USDA-NRCS) geographic databases (U.S. Department of Agriculture, 2001a,b) - the State Soil Geographic (STATSGO, 1:250,000) database or the Soil Survey Geographic (SSURGO, 1:24,000) database. These databases are digital soil maps, available within a geographic information system (GIS), which can be used to describe, both geographically and statistically, many soil properties at map scales ranging from national (STATSGO) to county (SSURGO). The STATSGO/SSURGO soil map units are georeferenced polygons comprised of either 1-21 STATSGO or 1-3 SSURGO map-unit components, which are keyed to soil series, the lowest taxonomic classification of a soil. Each map-unit component is assigned a 
percentage of the total map-unit area. Soil series comprising STATSGO map-unit components are characterized by soilattribute and related ancillary data in the USDA-NRCS Soil Interpretations Record (SIR) database (available only as part of STATSGO). SSURGO map-unit components are characterized by a more detailed version of SIR, the USDA-NRCS Map Unit Interpretations Record (MUIR) database (U.S. Department of Agriculture, 2001c). SIR and MUIR are aggregate databases that include variables such as organic matter (from which SOC is calculated), texture, slope, water content, and vegetative cover that describe map-unit components (soil series). Thus, soil properties (such as SOC) can be mapped in a variety of ways by linking series-level soils data to the soil map unit.

Although SIR and MUIR are similar, neither database adequately captures the series-level spatial variability in soil properties that can occur both geographically and with depth in the soil profile. Soil series described in SIR/MUIR generally are represented by five or fewer data records with ranges of values that provide an "average" characterization of the soil. Also, because the SIR and MUIR databases are layer-based rather than horizon-based, some, if not much, of the variation in soil properties with depth is not accurately represented.

Compilation, synthesis, and linkage of site-specific soil data to STATSGO/SSURGO map units provide an empirical alternative to SIR/MUIR-based soil maps. This approach not only provides a greater "ground-truth" component to the analysis but also, where data are sufficient, better captures the spatial variability of many soil properties at the series level. Site-specific soil databases potentially contain many pedon records for a given series and, thus, can provide better definition of the underlying distributions of soil physical and chemical properties. Site-specific data records are hereafter referred to in this report as pedon records or pedon data because the field description and laboratory characterization of the soil samples submitted to the laboratory are based on sampling the soil pedon. The pedon is the smallest physical sampling unit of a soil (generally from 1 to 10 square meters in area and as deep as the soil is formed) required to describe the variability in the properties of that soil at a specific location (Soil Survey Staff, 1999). Pedons generally are sampled by horizon rather than by arbitrary depth increments because soil horizonization provides a physical model for the physical and chemical development of the soil. Thus, the linkage of pedon data to STATSGO/SSURGO map units adds a "degree of confidence" to SOC storage and inventory estimates based on these data.

In this study, estimates of SOC storage and inventory for the MRB and for selected county-level areas within the MRB were calculated by using (1) SIR data linked to STATSGO map units, (2) MUIR data linked to SSURGO map units, (3) pedon data linked to STATSGO map units, and (4) pedon data linked to SSURGO map units. Differences in the SOC estimates based on these approaches are discussed within the context of map scale, map-unit composition and areal representation by component soil series, and series-level representation by data.

\section{Methods}

\section{Data Compilation}

A composite Site-Specific Soil-Carbon (S3C) database, compiled for this study, includes 7,321 soil pedon records obtained from the following sources: (1) USDA-NRCS National Soil Survey Center, Soil Survey Laboratory Characterization (NSSC) database (U.S. Department of Agriculture, 2001d); (2) State databases for Arkansas (E.M. Rutledge, University of Arkansas, Fayetteville, Arkansas, unpub. data, received 2001), Illinois (University of Illinois, 2001), and Louisiana (Schumacher and others, 1988); (3) small published databases (see the included References Cited section); and (4) several small unpublished databases provided by individual researchers. Additions and corrections to the $\mathrm{S} 3 \mathrm{C}$ database are being made on a frequent basis, which allows continual refinement of the SOC storage and inventory estimates.

Upon receipt, data are "standardized" to a consistent format needed for SOC calculations and interpretive analysis. Changes through time in the conventions used for describing soil profiles (Soil Survey Staff, 1951, 1962, 1975, 1986, 1998; Schoeneberger and others, 1998) have produced coding inconsistencies that must be reconciled prior to data analysis. Examples include revisions to soil-horizon nomenclature, measurement of horizon depth relative to the land surface, and designation of lithologic discontinuities in the soil profile. For both organic and mineral soils, revisions made to the pedon data include, but are not restricted to, the following:

1. If pedons do not have assigned latitude and longitude coordinates, sampling locations are georeferenced if there are sufficient locational data available to determine the coordinates. In some cases, the locational data are "exact" in the sense that, with the description given, a specific map location can be determined. Otherwise, there may be township-range-section data available; in which case, an approximate location is assigned based on the centroid of the section or, if given, a smaller quadrant within a section.

2. The top of the A horizon, or mineral surface, is set to the zero-centimeter depth (zero datum) with all depths for both mineral and organic horizons positively offset from this datum. This convention was used until 1993, when the "soil surface" was redefined as the top boundary of the first layer that can support plant growth (Schoeneberger and others, 1998), which may include partially decomposed surface organic horizons (Oe and Oa horizons). The pre-1993 convention was chosen for computational convenience and to support the ecologically based partitioning of SOC into organic and mineral compartments. For organic soils, however, the zero datum is set to the land surface, and, if necessary, horizon depths are adjusted accordingly. 
3. Older horizon nomenclature is converted to currentuse nomenclature (Schoeneberger and others, 1998). Examples include the $\mathrm{G}$ horizon/layer designation (Soil Survey Staff, 1951) that was changed to a subscript $g$ and applied to the $\mathrm{A}, \mathrm{B}$, or $\mathrm{C}$ horizon based on position in the profile; the $\mathrm{A} 2$ horizon changed to an E horizon; and Roman-numeral prefixes that designate lithologic discontinuities changed to Arabic-numeral prefixes.

4. Current-use horizon designations (Schoeneberger and others, 1998) are mapped to more general horizon groups, primarily on the basis of the master and transitional horizon designations. For example, an Ag1 horizon (A horizon, strong gley, first subdivision) and an A3 horizon (A horizon, third subdivision) would be assigned to the A-horizon group; a $\mathrm{Bg} 3$ horizon ( $\mathrm{B}$ horizon, strong gley, third subdivision) and a $2 \mathrm{Bk} 3$ (B horizon with pedogenic accumulation of carbonate developed in the second layer of contrasting material, third subdivision) would be assigned to the B-horizon group. Exceptions to this rule include soil horizons with either cemented or fragipan features. In either of these cases, all horizons with a cemented feature are mapped to "m," and all horizons with a fragipan feature are mapped to "x." The generalized horizon groups are used to aggregate the pedon data for statistical analysis of soil properties that affect SOC such as particle size and bulk density.

5. Either "described as" or "correlated as" soil-series name is assigned to each pedon. If a soil is classed to series when the field description is done, then the "described as" name may later be reviewed and verified during laboratory characterization, and a "correlated as" name assigned. Figure 2 provides an example of this revision for a loam in Yancey County, western North Carolina, that was described and sampled as a Unison series soil and then revised to the Dillsboro series. Where given, correlated series names are used; otherwise, the described name is used.

If the pedon has no series designated, the source of the data is checked to see if the series name was included in a later data revision. Some pedon records are sent to the appropriate State soil scientist to request series classification. However, if no series name is available, every attempt is made to obtain the most detailed taxonomic classification possible. An example of pedon data with no taxonomy is the paleoclimatic/ chronosequence study by Reheis (1987) where 35 pedons were sampled along transects in granitic alluvium representing a transition from mountain-front to basin soils in Carbon County, Montana (data for pedon $\mathrm{RC}-24$ shown in fig. 3). These pedons were georeferenced, located in the Carbon County soil survey (Parker and others, 1975), and then each assigned a soil-series name based on comparison of the pedon data with representative data for that series in the detailed soil map units.

6. Organic-matter (weight percent) and total-carbon (weight percent) values are converted to organic-carbon (weight percent) values, with $\mathrm{pH}$ being considered in the total-carbon to organic-carbon conversion. Organic matter is converted to equivalent organic-carbon content by multiplying the percent organic matter by 0.58 . Although the carbon content of organic matter varies with the source of plant litter and woody debris, 0.58 is a generally accepted "average" value used in this conversion (U.S. Department of Agriculture, 1996; Bowman and Petersen, 1996).

The organic-matter/organic-carbon data used in this paper are based on either the acid-dichromate wet oxidation-reduction (Walkley-Black method; Allison, 1965) or dry-combustion methods (U.S. Department of Agriculture, 1996). The loss-on-ignition (LOI) method, commonly applied to organic soils and freshwater and marine sediments (Bengtsson and Enell, 1986), was not used for analysis of the mineral-soil data presented in this report. Though few studies have been done that relate LOI data to results obtained by wet or dry-combustion techniques, Bengtsson and Enell (1986) report that organic carbon accounts for approximately 40 percent of the actual weight lost on ignition. For noncalcareous soils ( $\mathrm{pH}<7.7$; Bowman and Petersen, 1996), it is assumed that there is negligible carbonate and that results reported as "total carbon" are equivalent to "total organic carbon." If the SOC storage calculation methods presented in this paper were applied to land areas with calcareous soils, the total-inorganic-carbon content of the soil sample (determined as calcium carbonate, U.S. Department of Agriculture, 1996) would need to be subtracted from the total-carbon content to obtain total organic carbon by difference.

7. The pedon data are checked for errors, screened for statistical outliers, and corrections are then applied before analysis. Some of the more common errors include data-entry mistakes in horizon depths, reversal of latitude and longitude coordinates, misspellings of soil-series names, and misplaced decimal points.

\section{Data Synthesis}

\section{Requirements for Pedon Data}

The first decisions made in this study relate to database design and use- - how to get the best use of the data to meet the study objectives. The list of conceptual or "philosophical" questions includes: 
- What depth intervals should be used for SOC storage computations?

- How reliable are the data and what criteria have to be met for the data to be used?

- Should a data set for a pedon be used if the data are incomplete? If so, then what values should be used for the missing data, and how are these values determined? Figures 2-6 give examples of pedon data sets that have varying quantities of missing data that must be estimated or interpolated if these pedons are to be used for SOC storage calculations.

- How representative are the data? For example, should data for a map unit component (soil series) be used if the number of pedons for which data are available is less than some minimum number? If the data are used, then in what way - mean, median, mode, and so on?

- How can data for pedons that are not classed to series be used? These pedons generally are classed to family, but occasionally only to a higher taxonomic level such as subgroup, great group, suborder, or order.

- How can pedon data that are layer-based rather than horizon-based be used in the analysis?

- What is there to learn about SOC distribution from sitespecific data linked to SSURGO that differs from the results of linking site-specific data to STATSGO? Are there "scale" effects? To what extent are scale effects related to differences in map-unit composition?

The answers to these and other questions have largely determined the direction of this study and continue to do so as more data are acquired.

\section{Data Linkage Models}

This study used a mapping approach to quantify SOC storage (mass per unit area) and inventory (mass per total area) for the MRB and for selected county areas within the MRB (fig. 1). The storage/inventory estimates are based on linking the STATSGO/SSURGO map units with (1) the aggregate soils data provided with STATSGO/SSURGO in the SIR/ MUIR databases and (2) the S3C pedon data. The aggregatedata linkage is straightforward and is based on the relational table design of the STATSGO and SSURGO databases. Each map unit has a set of associated data tables in the aggregate database that can be linked to the map unit, a map-unit component, or a depth layer within a map-unit component. There is a one-to-one correspondence between a map-unit component and the associated component data and between the depth layers of a map-unit component and the associated layer data. This method is comparable to that used by Bliss and oth- ers (1995) to develop a SOC inventory for the United States. To facilitate comparisons between SOC estimates based on aggregate data with those based on pedon data, each map-unit component with its associated layer records is computationally treated as a pseudo pedon. SOC storage values are first calculated for standardized depth intervals from 0 to 10 centimeters (cm), 10 to $20 \mathrm{~cm}, 20$ to $50 \mathrm{~cm}$, and 50 to $100 \mathrm{~cm}$ for both pseudo pedons (SIR and MUIR databases) and actual pedons ( $\mathrm{S} 3 \mathrm{C}$ database) where the required data are available. The data required for calculation of SOC storage include the volume occupied by the intact soil, soil bulk density (either 1/3-bar or oven-dry), and weight percent of either organic matter, organic carbon, or total carbon.

Because the STATSGO/SSURGO map-unit components generally are based on soil series, the simplest and most direct method for linking S3C-derived SOC data to the map units is by soil series. The pedon-data linkage differs slightly from the aggregate-data linkage in that selected percentiles of SOC distributions by soil series are used for all map-unit components of a given series. The 50th percentile was chosen for this study to accommodate the series-level bias in available pedon data. Only 5 percent of the 2,500+ soil series for which pedon data are available is represented by 10 or more pedons, and 25 percent of the series are represented by only one pedon. If there were sufficient pedon data available to accurately describe the series-level variability in soil properties for the map area of interest, then other percentiles could be chosen. The interpretation of results based on the linkage of different percentiles is discussed in some detail later in this report.

Total SOC storage values for each map-unit are then calculated as the area-weighted component sums. For map units with partial representation by data, the summed SOC storage values are divided by the fraction of the map unit represented by data. This adjustment assumes that the "unsampled" area of the map unit is similar to the "sampled" area. SOC inventories are then calculated for each map area (for example, the MRB or selected county areas) by applying the map-unit SOC storage values to the total map-unit areas and then summing the map-unit inventories for all of the map units in the map area. For map areas with "no-data" map units, the summed SOC inventory values are divided by the fraction of the map area represented by map units with at least partial data representation. This adjustment for the larger map area is the same adjustment that is made for individual map units with the assumption that the unsampled area has a similar SOC composition to that of the sampled area.

Map units with no-data representation are not mapped and appear blank in the accompanying maps. Also, map units with a component area-weighted mean depth to bedrock less than the deepest interval midpoint are not mapped. For example, if SOC were being mapped to a depth of 1 meter, map units with a mean depth to bedrock less than $75 \mathrm{~cm}$ (midpoint from 50 to $100 \mathrm{~cm}$ ) are not mapped and would appear blank. If SOC were being mapped to a 0.5 -meter depth, the cutoff depth would be $35 \mathrm{~cm}$ (midpoint from 20 to $50 \mathrm{~cm}$ ). 


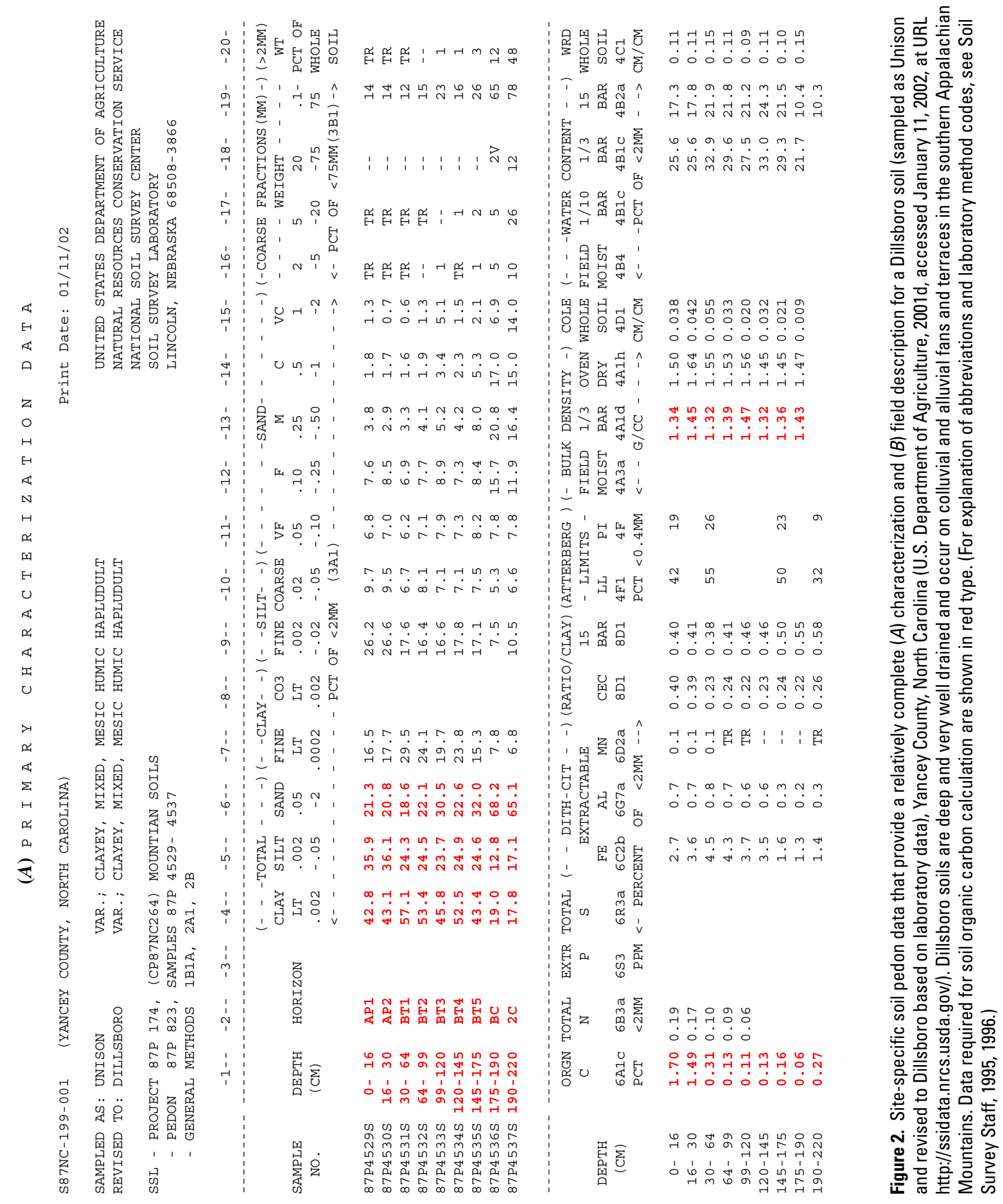



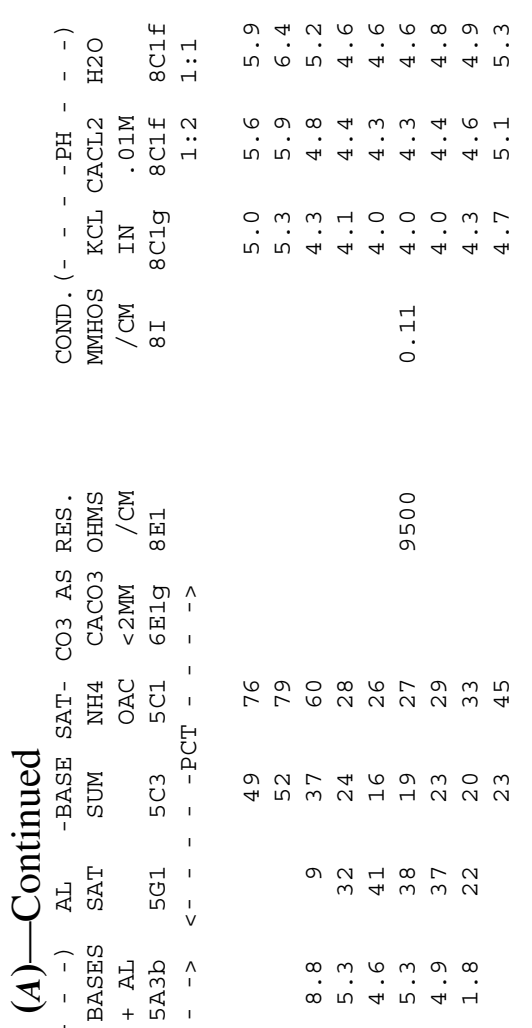

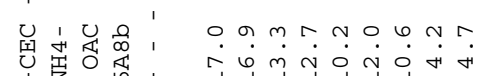

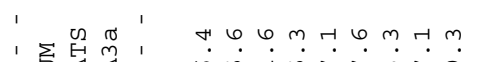
L品U,

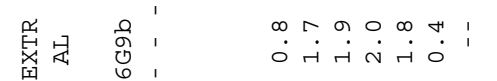

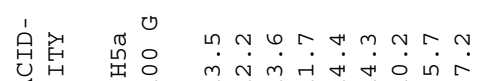

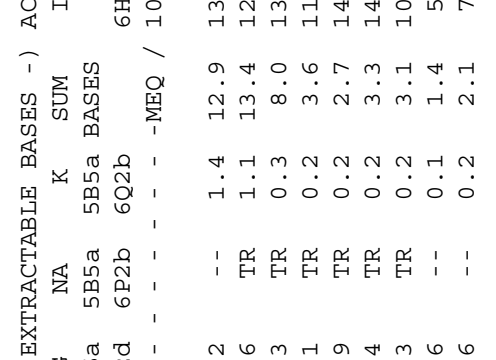

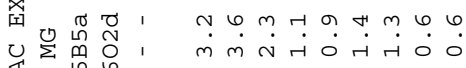

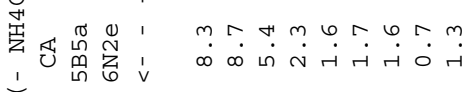

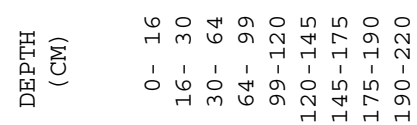
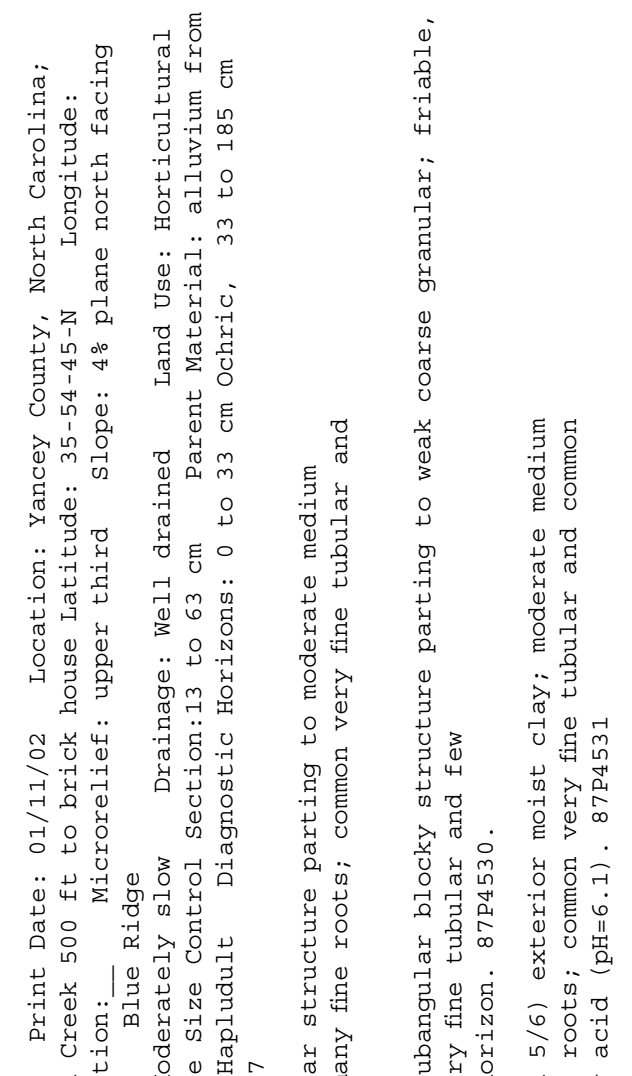

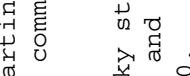

항

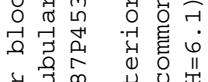

更

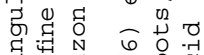

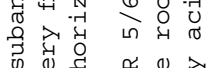

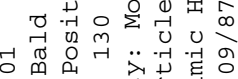

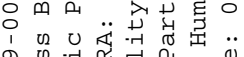

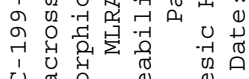

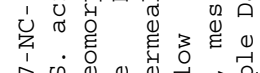

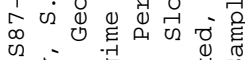

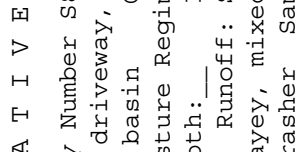

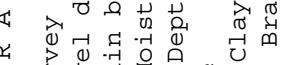

«

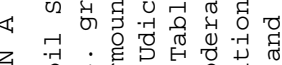

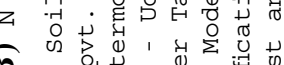

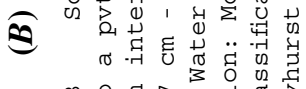

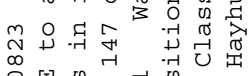

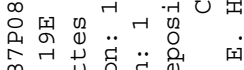

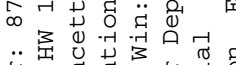

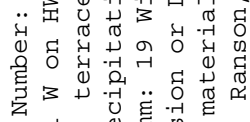

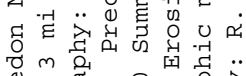

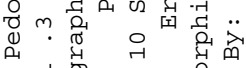

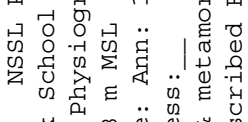

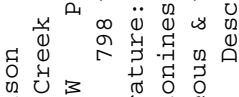

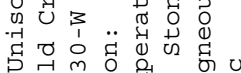

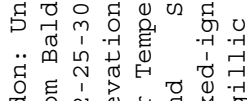

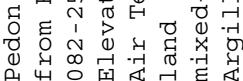

मै द्व

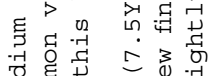

造变

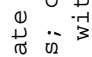

다워

焉

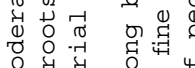

足荡

है

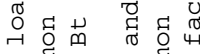

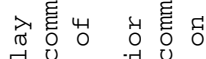

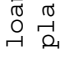

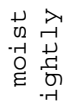

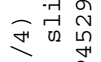

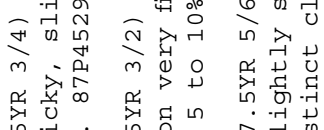

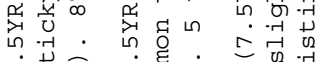

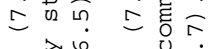

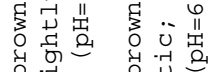

단 $\overrightarrow{0}$

तु

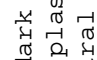

है

है

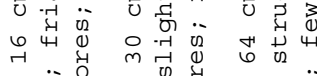

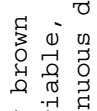

告

प्र

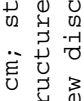

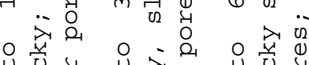

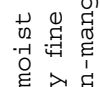

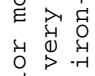

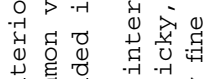

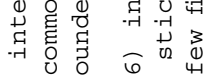

in

는

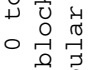

1 嵌

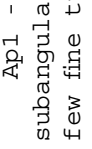

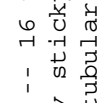

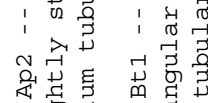

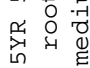

둔

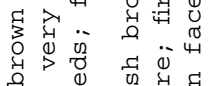

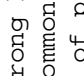

$\begin{array}{lll}0 & 0 \\ 4 & 0 & 0 \\ 02 & 0 & 0 \\ 0 & 0 & 0 \\ 0 & 0 & 0\end{array}$

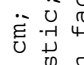

on 0

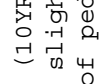

है हो

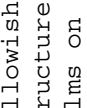

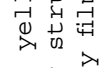

突究焉

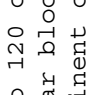

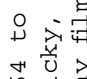

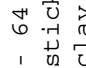

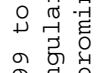

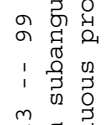

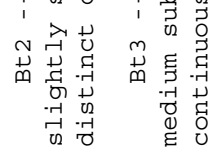

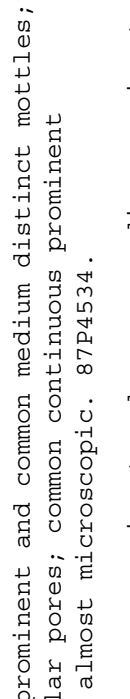

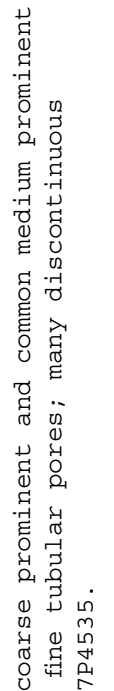

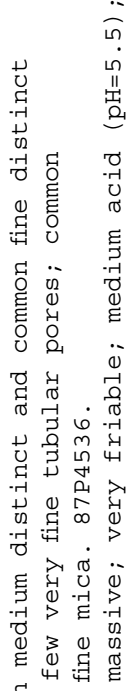

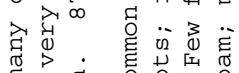

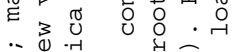

究焉水

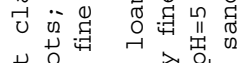

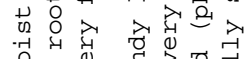

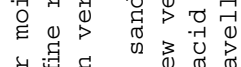

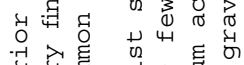

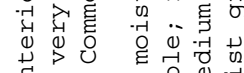

न्न 3 - 4.

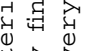

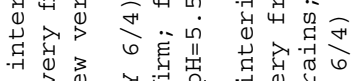

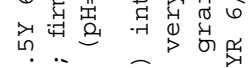

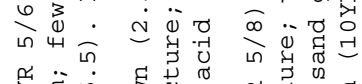

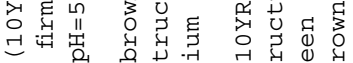

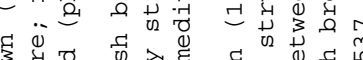

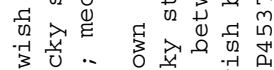

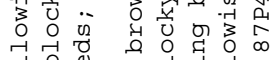

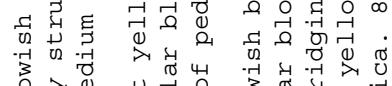

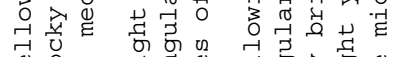

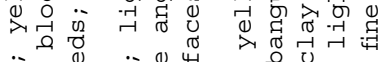

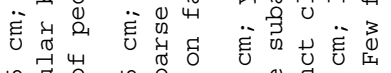

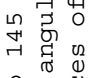

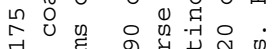

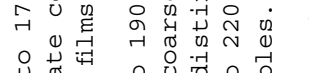

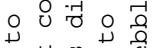
弪劣

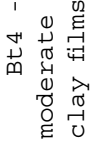



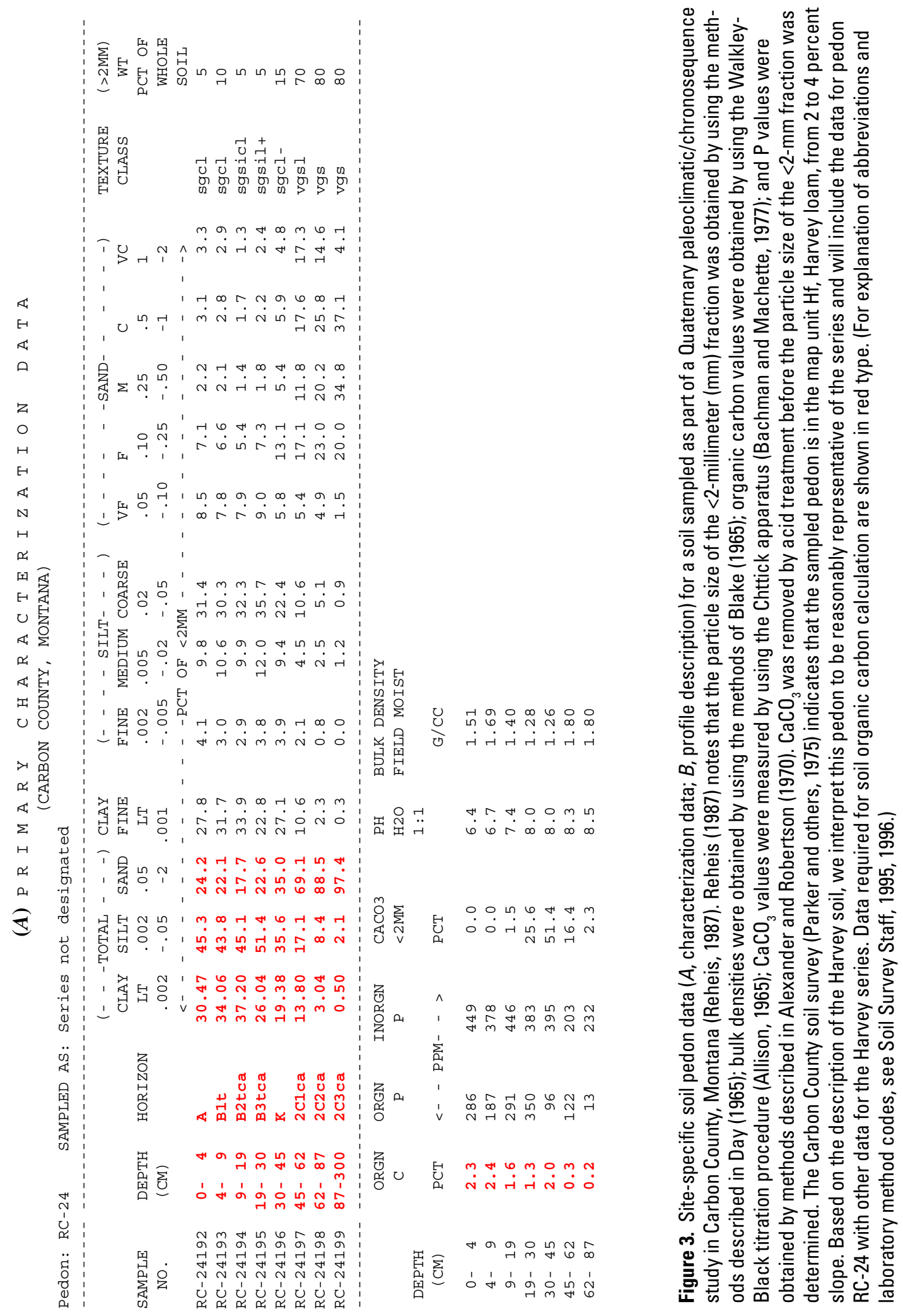


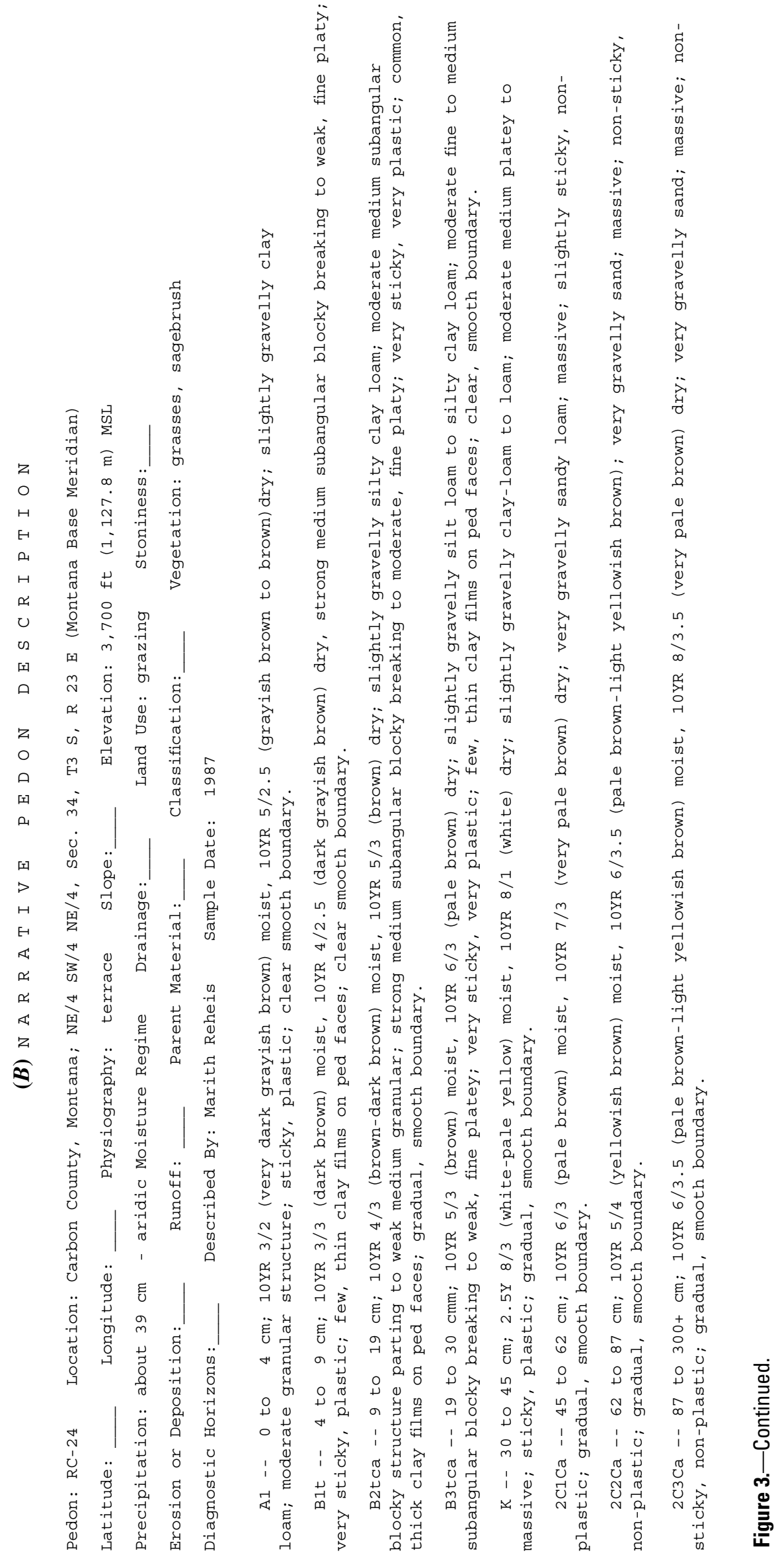




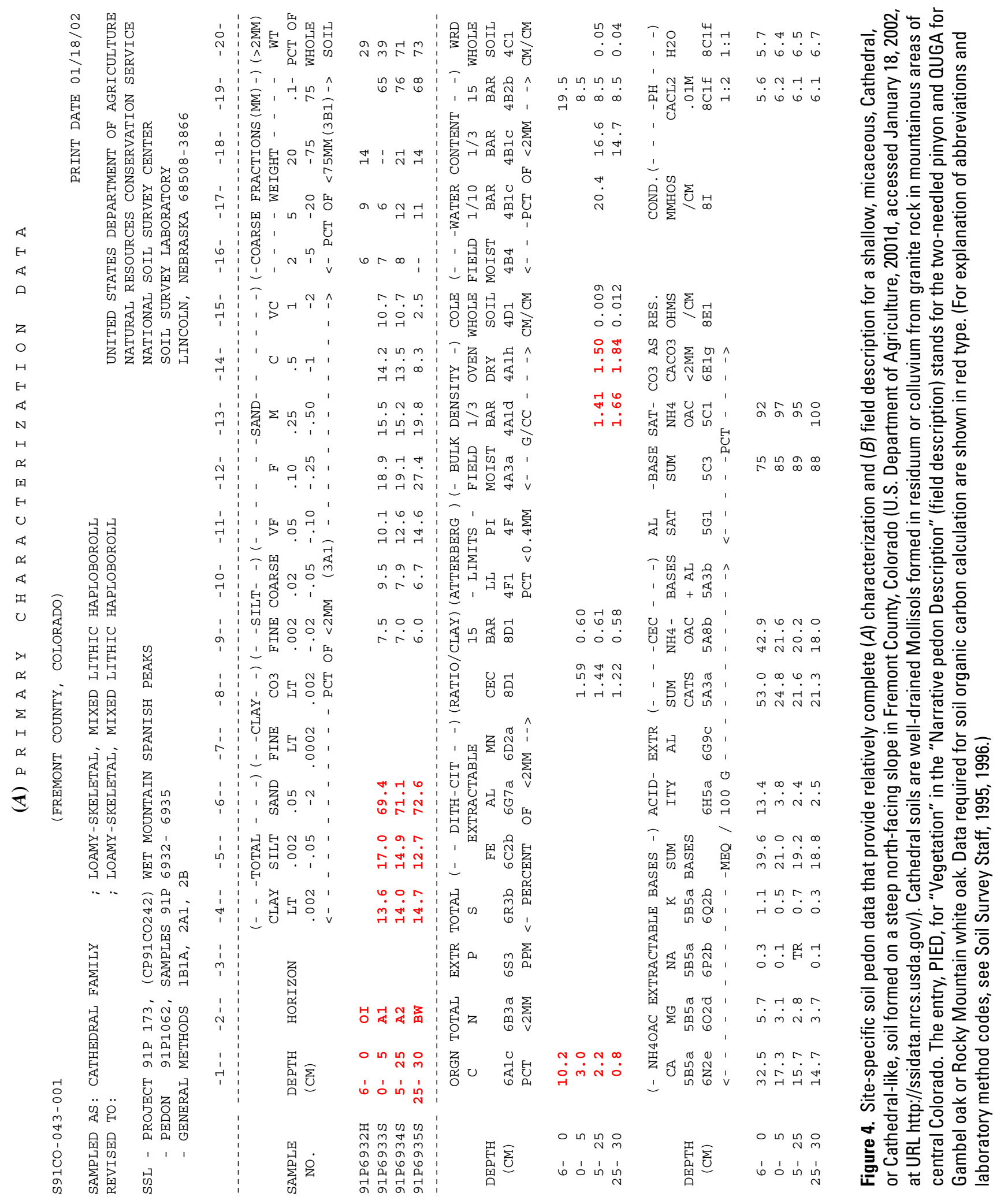




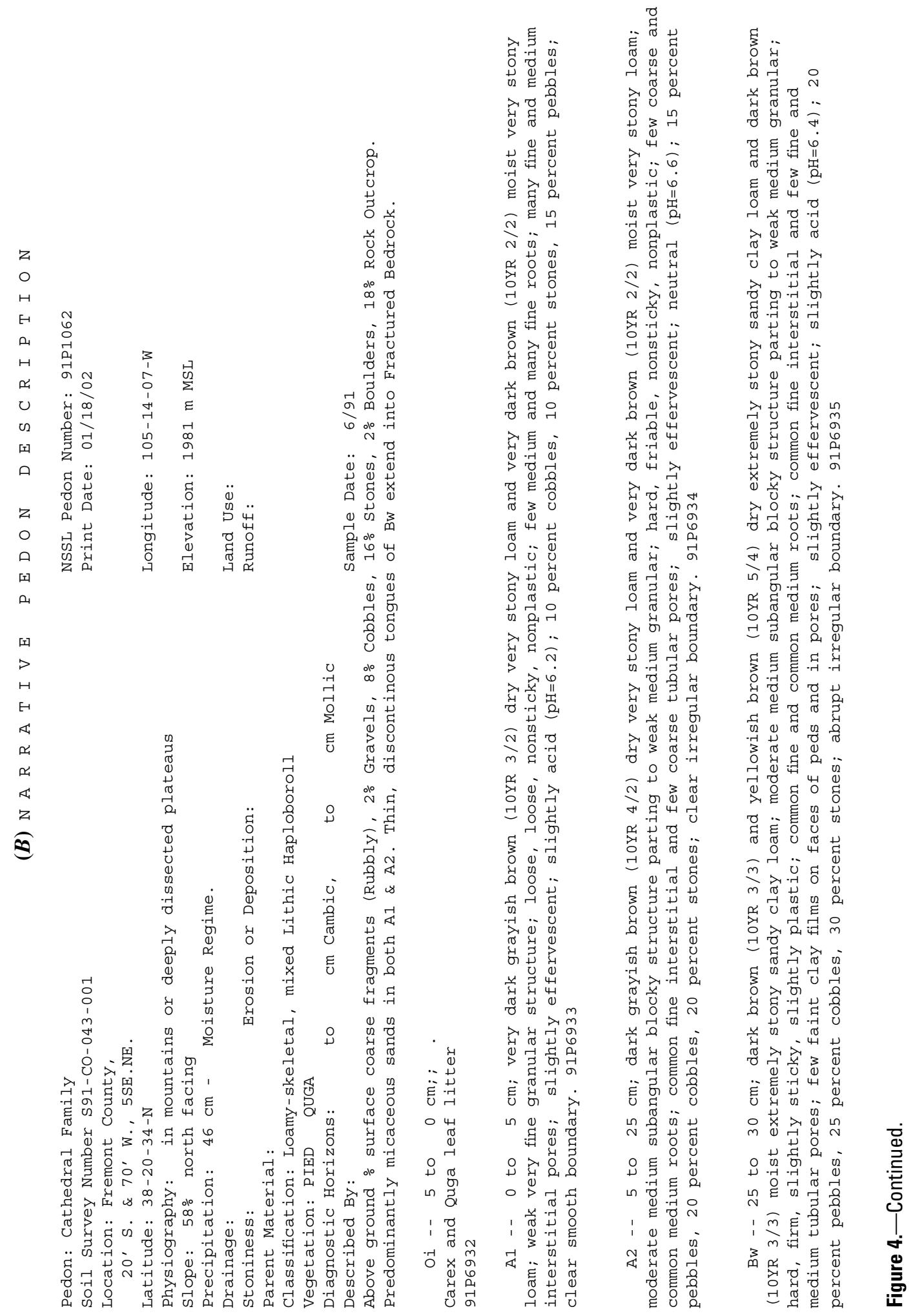




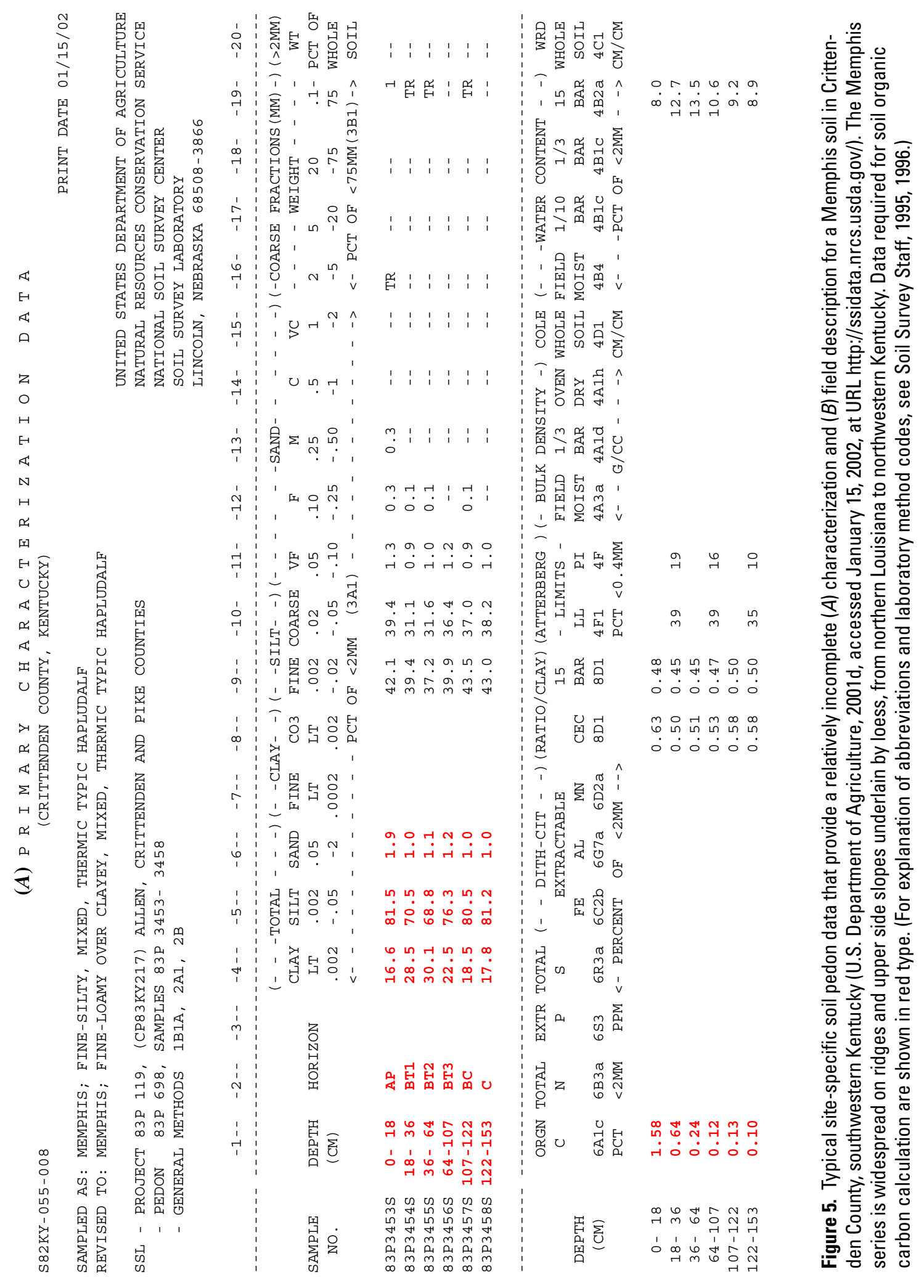




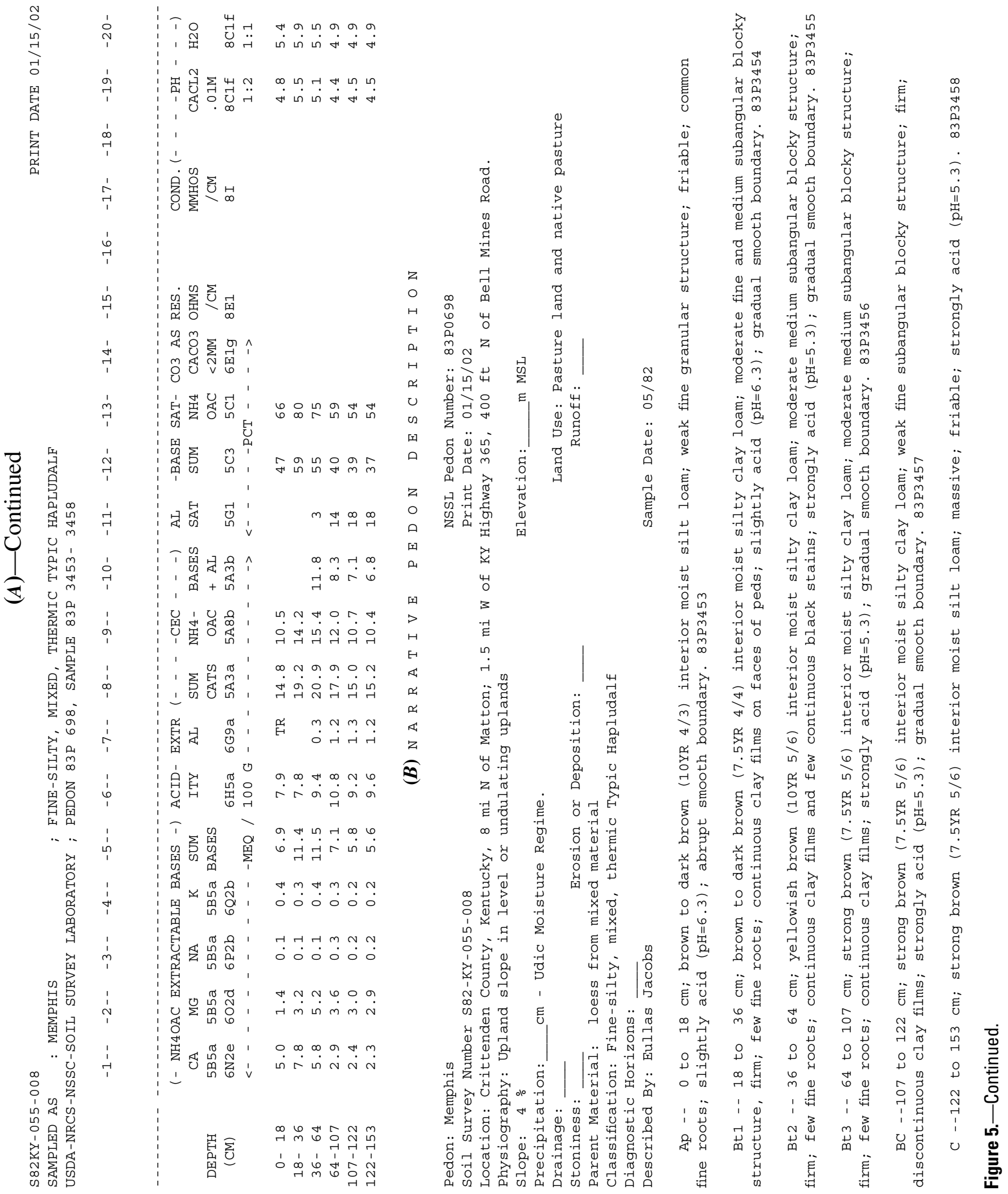



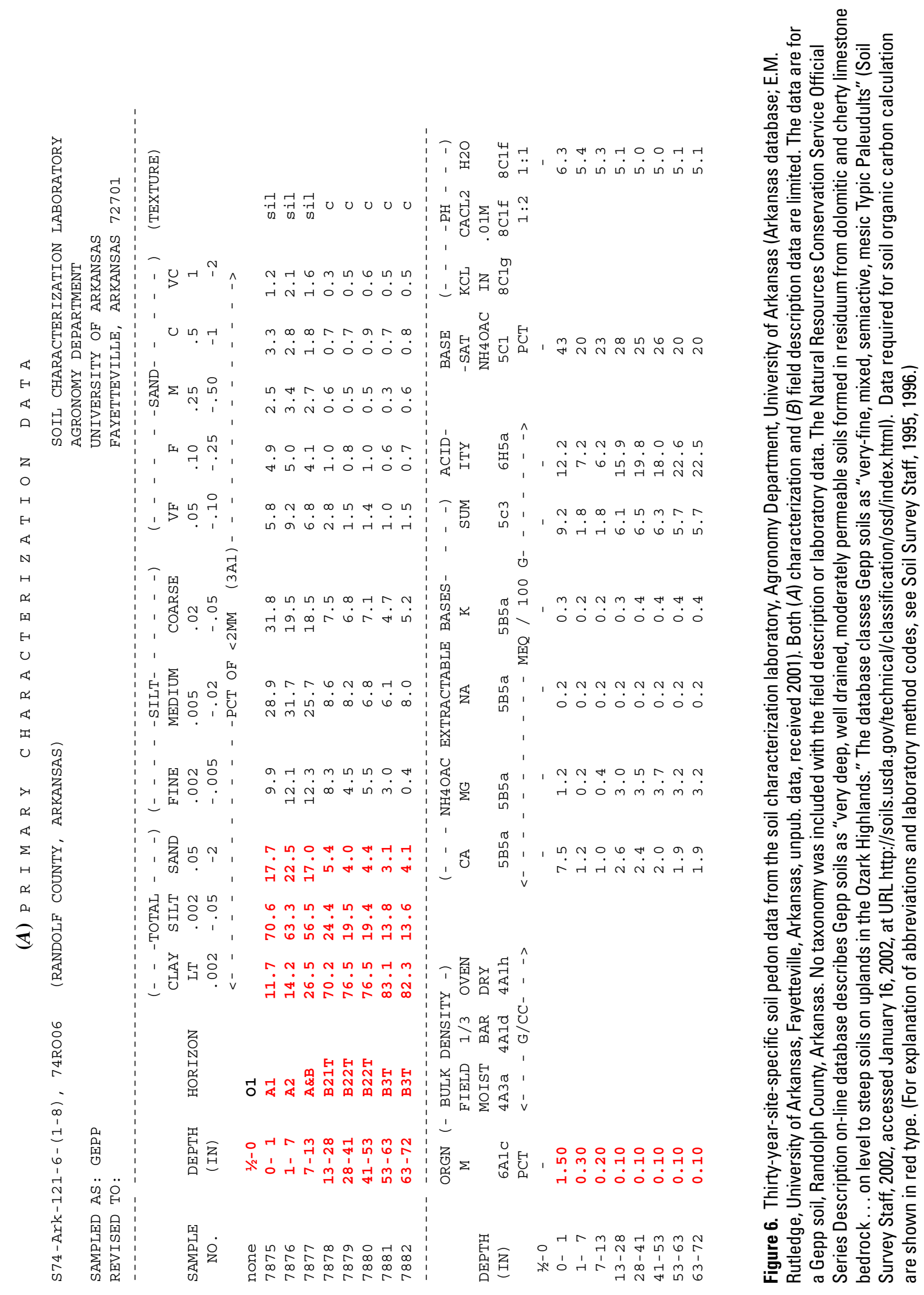


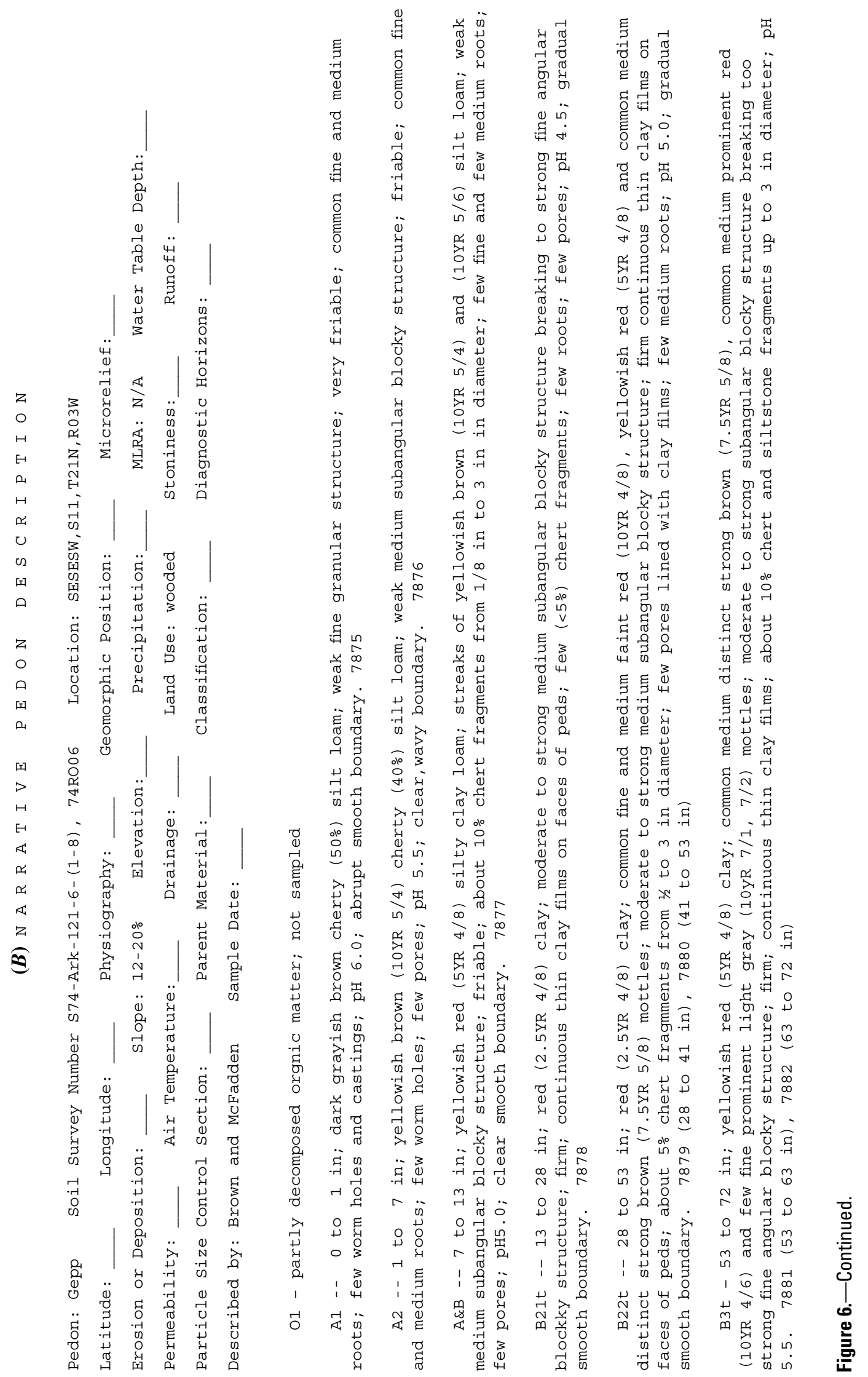




\section{Comparability of MUIR and SIR Data with Pedon Data}

One of the fundamental differences between SIR/MUIR data and pedon data relates to the aggregate nature of the SIR/MUIR soil-interpretation records. There are relatively few interpretation records for each soil series represented in the map-unit components of STATSGO/SSURGO, compared to the potentially large number of records that may be available for a given soil series in the pedon database. Where there are multiple interpretation records, differences in values for soil properties typically represent the series-level variation associated with landscape position and geographic location (that is, soil-series phases). Because SSURGO is intended as a "local-use" database and land-management tool, there is more regional variation built into MUIR than in SIR. Both SIR and MUIR data are intended to represent the "typical" or characteristic ranges of the physical and chemical properties of the soils in each series represented in a map unit. Therefore, ranges based on representative, or typical, minimum and maximum values for each soil property are reported in the SIR/MUIR layer table records (the layer-specific portion of the soil-interpretation record). However, within individual interpretation records, there may not be a consistent derivation of the values reported for each soil property. Some properties may not have been measured for a particular series, in which case, "typical" values for a similar series may be used, or values for that soil property may be derived from local expert knowledge.

The site-specific pedon data have sample-specific values for each soil property, as the analyses are done on individual samples. In this study, the map-unit component, with its associated interpretation record, is viewed as a pseudo pedon that is representative of the soil series at the geographic location of the map unit. Consistent with this view, all "raw" data used in SIR/MUIR component-level calculations are based on the midpoint of the range of values reported for each soil property (equivalent to both the median and the mean). The pseudo-pedon model allows for computational consistency in the calculation of SOC storage values so that statistical comparisons can be made between calculations based on aggregate data (SIR/MUIR interpretation records) and those based on pedon data.

\section{Calculations}

\section{SOC Storage (Mass Per Unit Area)}

SOC storage is calculated for the 0 to 10,10 to 20,20 to 50 , and 50 to $100 \mathrm{~cm}$ standard depth intervals. A schematic showing a representative pedon profile for a soil series is shown in figure 7. The schematic for a STATSGO/SSURGO component pseudo-pedon profile would be similar to the diagram in figure 7 , except that horizons would be replaced by arbitrary depth layers-layer 1,0 to $15 \mathrm{~cm}$; layer 2, 15 to 50 $\mathrm{cm}$; and so on. Values for the cumulative depth intervals of 0 to 20, 0 to 50 , and 0 to $100 \mathrm{~cm}$ are then computed by summing the appropriate standard depth intervals.

Depth intervals used for SOC mass computations are "standardized" to permit geographic analysis of SOC storage. Horizon depths (pedon data) and layer depths (SIR/MUIR data) are quite variable because they are based on sampling strategies designed to characterize the soils accurately. Horizon thicknesses (and, therefore, depths to horizon boundaries) vary across all levels of taxonomy as a result of differences in soil development. The horizon-based sampling done to characterize an individual pedon of a soil series produces depth intervals consistent with the pedon horizon boundaries. Layer thicknesses of STATSGO/SSURGO components are loosely based on "typical" horizon thicknesses of the component soil series.

As storage is a soil property, an adjustment is also made for the volume in the soil profile occupied by coarse fragments greater than 2 millimeters $(\mathrm{mm})$ in diameter. For example, if 30 percent of the profile volume is occupied by coarse fragments, the storage value is multiplied by 0.70 . There can be considerable difference between the STATSGO and SSURGO "views" of coarse-fragment volume. Figure 8 shows the percentage of the total volume to a depth of 1 meter occupied by rock (measured as the component area-weighted mean coarsefragment volume) for Mitchell and Yancey Counties, North Carolina ( $A$, STATSGO; $B$, SSURGO). The south-to-northtrending ridge where Mt. Mitchell is located is shown with a 20 to 30 percent coarse-fragment volume in the STATSGO view whereas, in the SSURGO view, this same area is shown with a 40 to 55 percent coarse-fragment volume. Although many of the pedon records in the $\mathrm{S} 3 \mathrm{C}$ database have the requisite data for calculation of coarse-fragment volume, there are insufficient site-specific data for coarse-fragment volume to apply consistently to all of the soil series in the MRB portion of STATSGO and SSURGO. Therefore, the median coarsefragment volume values derived from SIR and MUIR are used for storage and inventory calculations based on pedon data as well as for those based on SIR/MUIR aggregate data.

Incremental SOC mass for each pseudo-pedon layer (SIR/MUIR databases) or pedon horizon (S3C database) is computed as

$$
\text { MI }=\rho_{\mathrm{b}} * 10 *\left(\mathrm{~d}_{\mathrm{bh}}-\mathrm{d}_{\mathrm{th}}\right) *(\mathrm{oc} / 100) * \mathrm{f}_{\mathrm{s}}
$$
where

$$
\begin{aligned}
\text { MI }= & \begin{array}{l}
\text { incremental SOC mass, in kilograms per square } \\
\text { meter }\left(\mathrm{kg} / \mathrm{m}^{2}\right) \text { (total matrix, organic carbon) }
\end{array} \\
\rho_{\mathrm{b}}= & \begin{array}{l}
\text { soil bulk density, in grams per cubic centimeter } \\
\left(\mathrm{g} / \mathrm{cm}^{3}\right)
\end{array} \\
10= & \text { factor for conversion from } \mathrm{g} / \mathrm{cm}^{3} \text { to } \mathrm{kg} / \mathrm{m}^{2} \\
\mathrm{~d}_{\mathrm{bh}}= & \text { depth of soil layer/horizon bottom, in centimeters } \\
\mathrm{d}_{\mathrm{th}}= & \text { depth of soil layer/horizon top, in centimeters } \\
\text { oc }= & \text { soil organic carbon concentration, in weight percent } \\
\mathrm{f}_{\mathrm{s}}= & \text { fraction of the profile volume occupied by soil }
\end{aligned}
$$




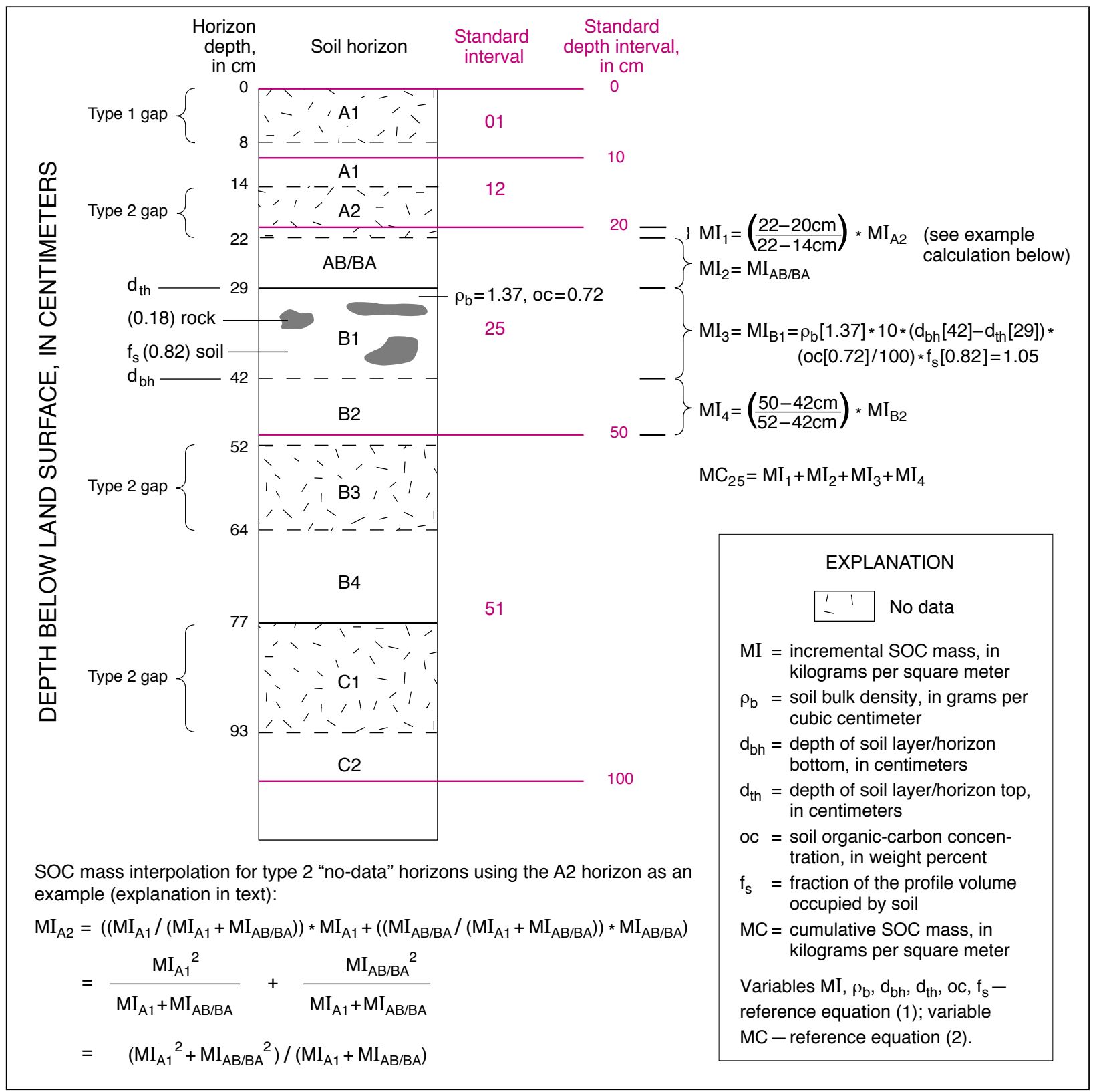

Figure 7. Representative pedon profile for a soil series. The 0 to 8 centimeter $(\mathrm{cm})$ section of the $A 1$ horizon was not sampled for organic carbon and represents a type $1 \mathrm{gap}$ (surface horizon with no data). This section is assigned the soil organic carbon (SOC) value calculated for the 8 to $14 \mathrm{~cm}$ section of the $A 1$ horizon. The $A 2, B 3$, and $C 1$ horizons represent type 2 gaps-intermediate horizons not sampled for organic carbon. SOC values assigned to these horizons are calculated as the mass-weighted mean of the SOC values for the overlying and underlying horizons (examples given above). The standard depth intervals from 0 to 10, 10 to 20,20 to 50, and 50 to $100 \mathrm{~cm}$ are delineated in red. Incremental (MI) and cumulative (MC) SOC mass calculations for the 20- to $50-\mathrm{cm}$ standard depth interval are shown in the figure.

As an example, the incremental SOC mass for the B1 horizon ( 29 to $42 \mathrm{~cm}$ ) illustrated in figure 7 is computed where $\rho_{\mathrm{b}}=$ $1.37 \mathrm{~g} / \mathrm{cm}^{3}, \mathrm{oc}=0.72$ percent, and $\mathrm{f}_{\mathrm{s}}=0.82$ :

$$
\begin{aligned}
& \mathrm{MI}_{\mathrm{B} 1}=\left(1.37 \mathrm{~g} / \mathrm{cm}^{3}\right) * 10 *(42 \mathrm{~cm}-29 \mathrm{~cm}) *(0.72 \% \\
& \quad / 100 \%) * 0.82=1.05 \mathrm{~kg} / \mathrm{m}^{2}
\end{aligned}
$$

Cumulative SOC mass for each standard depth interval, $h h$, is then computed as where

$$
\mathrm{MC}_{h h}=\left(\sum_{\mathrm{i}=1}^{\mathrm{n}} \mathrm{MI}_{\mathrm{i}}\right) *\left(\mathrm{t}_{h h} / \mathrm{f}_{h h}\right)
$$

$\mathrm{MC}_{h h}=$ cumulative SOC mass for the standard depth interval $h h$, in kilograms per square meter

$\mathrm{n} \quad=$ the total number of complete and/or partial soil layers or horizons within the standard depth interval 

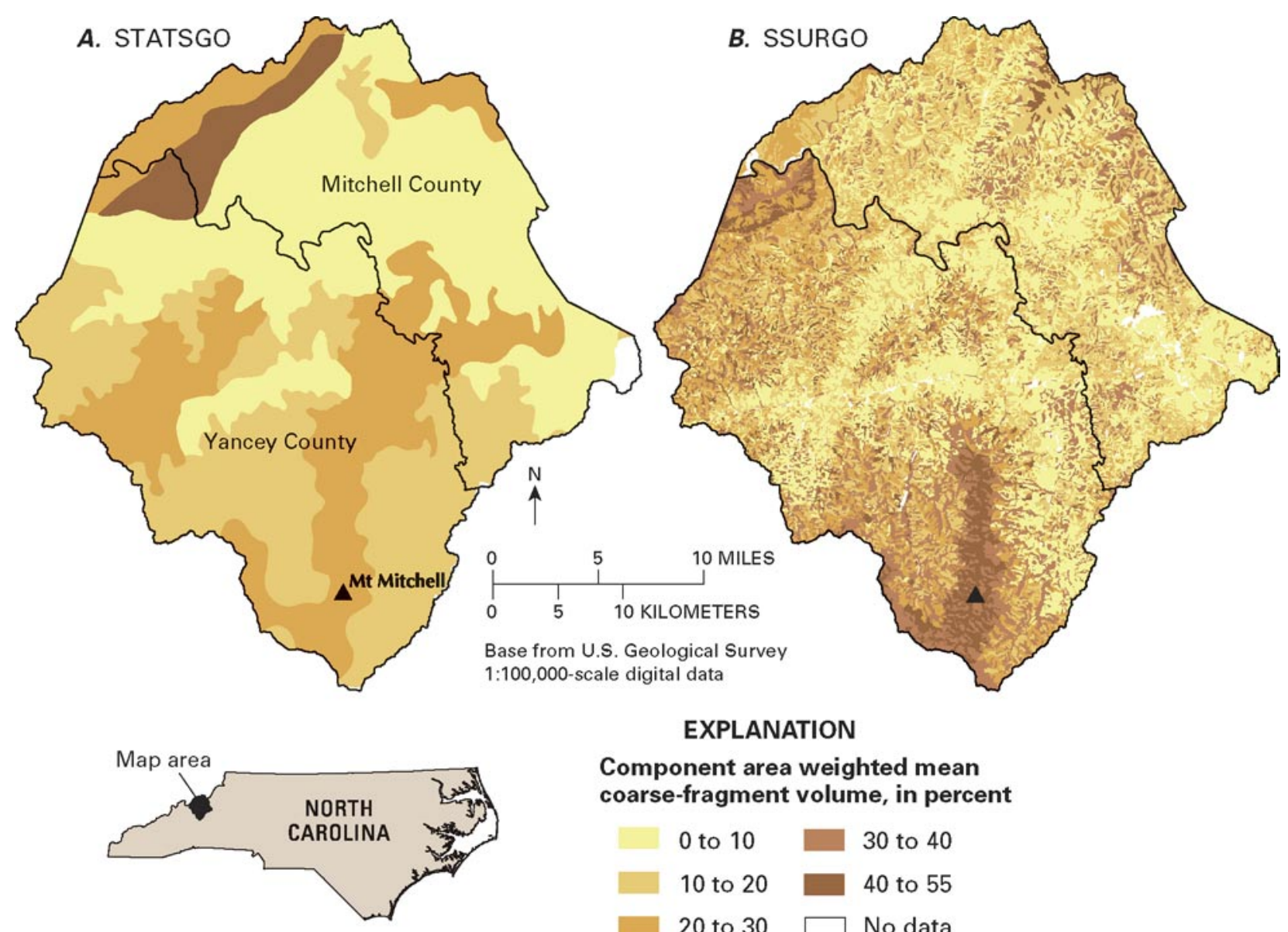

\section{EXPLANATION}

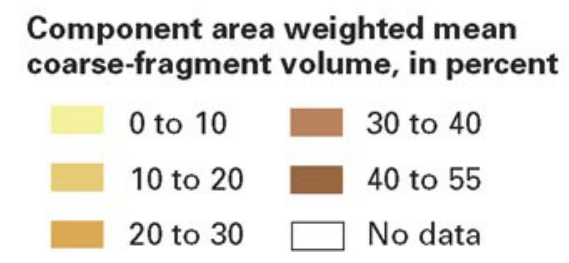

Figure 8. Component area-weighted mean coarse-fragment volume, depth interval from 0 to 100 centimeters, for $(A)$ STATSG0 map units and (B) SSURGO map units, Mitchell and Yancey Counties, North Carolina.

$\mathrm{i}=$ the $\mathrm{i}^{\text {th }}$ complete or partial soil layer/horizon within the standard depth interval

$\mathrm{MI}_{\mathrm{i}}=$ incremental SOC mass (equation (1)) for the $\mathrm{i}^{\text {th }}$ complete or partial soil layer/horizon within the standard depth interval, in kilograms per square meter

$\mathrm{t}_{h h}=$ standard interval thickness, in centimeters

$\mathrm{f}_{h h}=$ standard interval thickness represented by data, in centimeters

The following values are used for $h h: 01,0$ to $10 \mathrm{~cm} ; 12$, 10 to $20 \mathrm{~cm} ; 25,20$ to $50 \mathrm{~cm} ; 51,50$ to $100 \mathrm{~cm} ; 02,0$ to 20 $\mathrm{cm} ; 05,0$ to $50 \mathrm{~cm}$; and 10,0 to $100 \mathrm{~cm}$. The adjustment made to $\mathrm{MC}_{h h}$ by the ratio $\mathrm{t}_{h h} / \mathrm{f}_{h h}$ accounts for any unsampled portion of the standard interval. In practice, this adjustment is only relevant for the deepest interval, as the shallower interval gaps are filled in by a mass-weighted interpolation of data for the adjacent boundary layers. In making this adjustment for the deepest layer, the SOC mass calculated for part of the standard interval is simply applied to the rest of the interval. Values for MC, which are specific to individual records in the MUIR, SIR, or S3C databases, form the basis for all subsequent SOC calculations for soil map-unit components (fig. 9C), soil map units (fig. 9B), and larger geographic areas such as counties (fig. $9 A$ ).

The calculation of cumulative SOC mass for the standard depth interval from 20 to $50 \mathrm{~cm}\left(\mathrm{MC}_{25}\right)$ is shown for the representative pedon profile illustrated in figure 7. The SOC mass calculated for each horizon is assumed to be uniformly distributed. Therefore, the SOC mass for any horizon that overlaps a standard depth interval boundary is apportioned to the adjacent standard intervals in proportion to the fraction of the total horizon thickness in each standard interval. Using the example for $\mathrm{MI}_{4}$ (fig. 7), $8 \mathrm{~cm}$ of the 10-cm-thick B2 horizon is in the 20 to $50 \mathrm{~cm}$ standard depth interval. Therefore, $8 / 10$ ( 80 percent) of the SOC mass for that horizon is assigned to the 20 to $50 \mathrm{~cm}$ standard interval (see accompanying equation for the calculation of $\mathrm{MI}_{4}$, fig. 7). Although potentially confusing, dual subscripting is used for the incremental SOC mass (MI) to avoid propagation of unnecessary variables. Horizon subscripts are used when MI is calculated for a soil horizon. Numeric subscripts are used when MI is calculated for a partial or complete soil layer or horizon within a standard depth interval as input to the cumulative-mass calculation for that standard interval. In both cases, the mass computations are the same, as described in equation (1). 


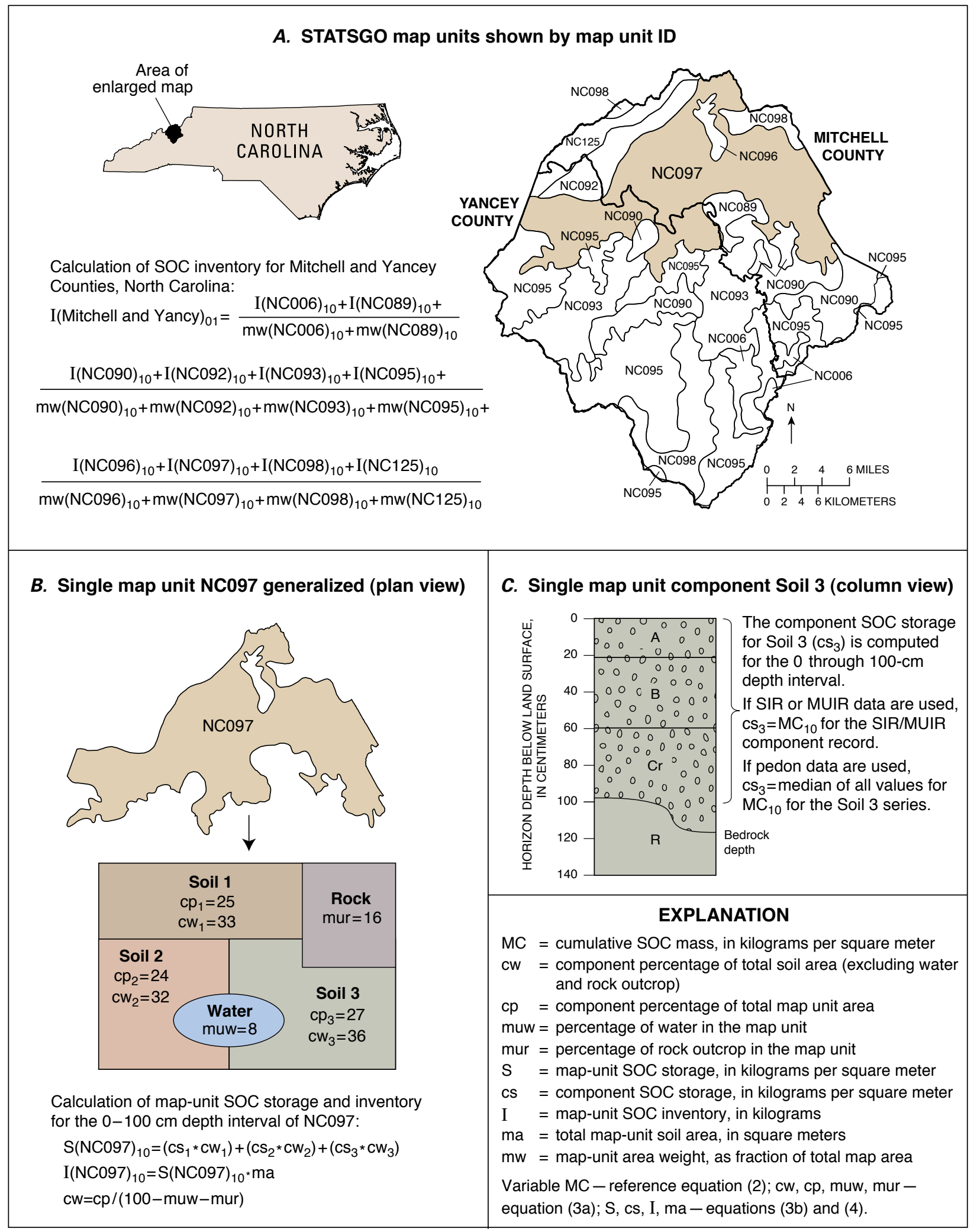

Figure 9. Schematic showing the relation between STATSGO map units $(A)$ and STATSGO map unit components $(B)$ for Mitchell and Yancey Counties, North Carolina. Calculation of soil organic carbon (SOC) inventory for these counties is shown in $A$; calculation of SOC storage and inventory for map unit NCO97 is shown in $B$ and $C$. 


\section{SOC Inventory (Mass Per Total Area)}

SOC inventory for each STATSGO/SSURGO map unit is computed as the area-weighted sum of the SOC storage values for all of the map-unit soil components (fig. 9B). The area weights for each soil component are computed on a total soil base, adjusted for the percentage of water and rock outcrop in the map unit, according to the equation

$$
\mathrm{cw}_{\mathrm{j}}=\mathrm{cp}_{\mathrm{j}} /(100-\text { muw }- \text { mur })
$$

where

$$
\begin{aligned}
& \mathrm{cw}_{\mathrm{j}}= \\
& \mathrm{cp}_{\mathrm{j}}=\underset{\text { percentage of total map-unit area occupied by }}{\text { are }} \\
& \text { the } \mathrm{j}^{\text {th }} \text { map-unit soil component }
\end{aligned}
$$

muw $=$ percentage of water in the map unit

mur $=$ percentage of rock outcrop in the map unit

The STATSGO/SSURGO database structure represents water bodies, areas of rock outcrop, and soil as separate map-unit components and assigns each of them areal percentages of the total map unit. Geographic distribution of rock outcrop is shown for Mitchell and Yancey Counties, North Carolina, in figure 10 ( $A$, STATSGO; $B$, SSURGO). As an example, the soil base for the STATSGO map units shown in medium brown $(10 A)$ would be adjusted from 100 percent to somewhere between 90 and 95 percent (rock outcrop varies between 5 and 10 percent for these map units).

In the example in figure 9B, the area weight for "Soil 3" would be computed as follows: STATSGO map unit NC097 is 8 percent water and 16 percent rock outcrop. Soil 3 occupies 27 percent of the total map-unit area. Therefore, the area weight for Soil 3 is

$$
\mathrm{cw}_{\text {Soil3 }}=27 \% /(100 \%-8 \%-16 \%)=0.36
$$

Soil 3 occupies 27 percent of the total map-unit area but 36 percent of the total soil area in the map unit. As indicated in figure $9 B$, the map-unit illustration presents a "generalized plan view" rather than the actual map-unit composition because there are no water components present in any of the STATSGO map units for Mitchell and Yancey Counties, North Carolina.

The equations for map-unit SOC storage (S) and inventory (I) are

$$
\begin{aligned}
& \mathrm{S}_{h h}=\left(\sum_{\mathrm{j}=1}^{\mathrm{n}} \mathrm{cs}_{\mathrm{j}} * \mathrm{cw}_{\mathrm{j}}\right) / \sum_{\mathrm{j}=1}^{\mathrm{n}} \mathrm{cw}_{\mathrm{j}} \\
& \mathrm{I}_{h h}=\mathrm{S}_{h h} * \mathrm{ma}
\end{aligned}
$$

where

$\mathrm{S}_{h h}=$ map-unit SOC storage for the standard depth interval $h h$, in kilograms per square meter

$\mathrm{n}=$ total number of components in the map unit

$\mathrm{j}=\mathrm{j}^{\text {th }}$ map-unit component

$\mathrm{cs}_{\mathrm{j}}=$ SOC storage for the $\mathrm{j}^{\text {th }}$ map-unit component, in kilograms per square meter (computed as the term MC, equation (2))

$$
\begin{aligned}
& \mathrm{cw}_{\mathrm{j}}=\text { area weight for the } \mathrm{j}^{\text {th }} \text { map-unit component } \\
& \mathrm{I}_{h h}=\begin{array}{l}
\text { map-unit } \mathrm{SOC} \text { inventory for the standard } \\
\text { depth interval } h h, \text { in kilograms }
\end{array} \\
& \mathrm{ma}=\text { total map-unit soil area, in square meters }
\end{aligned}
$$

Calculation of SOC storage and inventory for the generalized STATSGO map unit NC097 is schematically shown in figure $9 B$ and $9 C$ ). Values for $\mathrm{MC}_{h h}$ (cumulative SOC mass for standard depth intervals, equation (2)) are used for the component storage $\left(\mathrm{cs}_{\mathrm{j}}\right)$; and, therefore, $\mathrm{S}$ and I assume the same subscripts, $h h$. Thus, map-unit storage and inventory are computed for the 0 to 10,10 to 20,20 to 50 , and 50 to $100 \mathrm{~cm}$ intervals of soil and, by summation, for the 0 to 20,0 to 50 , and 0 to $100 \mathrm{~cm}$ intervals of soil. Three separate computations of $\mathrm{S}_{h h}$ and $\mathrm{I}_{h h}$ are made, the first based on SIR data (STATSGO layer tables), the second on MUIR data (SSURGO layer tables), and the third on S3C data. For the first two cases (SIR and MUIR data), $\mathrm{MC}_{h h}$ calculations are based on the available data for the matching component record in the STATSGO/SSURGO layer tables. This analysis is the intended use of the soil-attribution data as described in the user manuals distributed with the STATSGO and SSURGO databases (U.S. Department of Agriculture, 1994, 1995). When SOC storage values assigned to map-unit components are derived from pedon data, series-level median values of $\mathrm{MC}_{h h}$ are linked to the map units by component soil series.

Total SOC inventory for a larger geographic area such as a county, drainage basin, or the MRB is computed by summing the inventories of all of the map units in that area and then dividing the inventory sum by the sum of the area weights for all of the map units with data:

$$
\begin{aligned}
\mathrm{I}_{\text {total }} & =\sum_{\mathrm{k}=1}^{\mathrm{n}} \mathrm{I}_{\mathrm{k}} / \sum_{\mathrm{k}=1}^{\mathrm{n}} \mathrm{mw}_{\mathrm{k}} \\
\text { where } & =\text { total SOC inventory for the area, in kilograms } \\
\mathrm{I}_{\text {total }} & =\text { SOC inventory for the } \mathrm{k}^{\text {th }} \text { map unit, in kilograms } \\
\mathrm{I}_{\mathrm{k}} & =\text { total number of map units in the area } \\
\mathrm{n} & =\mathrm{k}^{\text {th }} \text { map unit } \\
\mathrm{k} & \text { area weight for the } \mathrm{k}^{\text {th }} \text { map unit with data, } \\
\mathrm{mw}_{\mathrm{k}}= & \text { calculated as the fraction of the total map } \\
& \text { area }
\end{aligned}
$$

The inventory adjustment for unsampled area accounts for "no-data" map units by applying the values for map areas with SOC data to those map areas with no SOC data. As an example, calculation of the STATSGO-based SOC inventory for Mitchell and Yancey Counties, North Carolina, is schematically shown in figure $9 A$.

In practice, $\mathrm{I}_{\text {total }}$ usually is converted to units of metric tons ( 1 metric ton $=1,000$ kilograms $)$, teragrams $\left(1 \mathrm{Tg}=10^{9}\right.$ kilograms), or petagrams ( $1 \mathrm{Pg}=10^{12}$ kilograms) to make the numbers more "user-friendly" and scale-appropriate. 

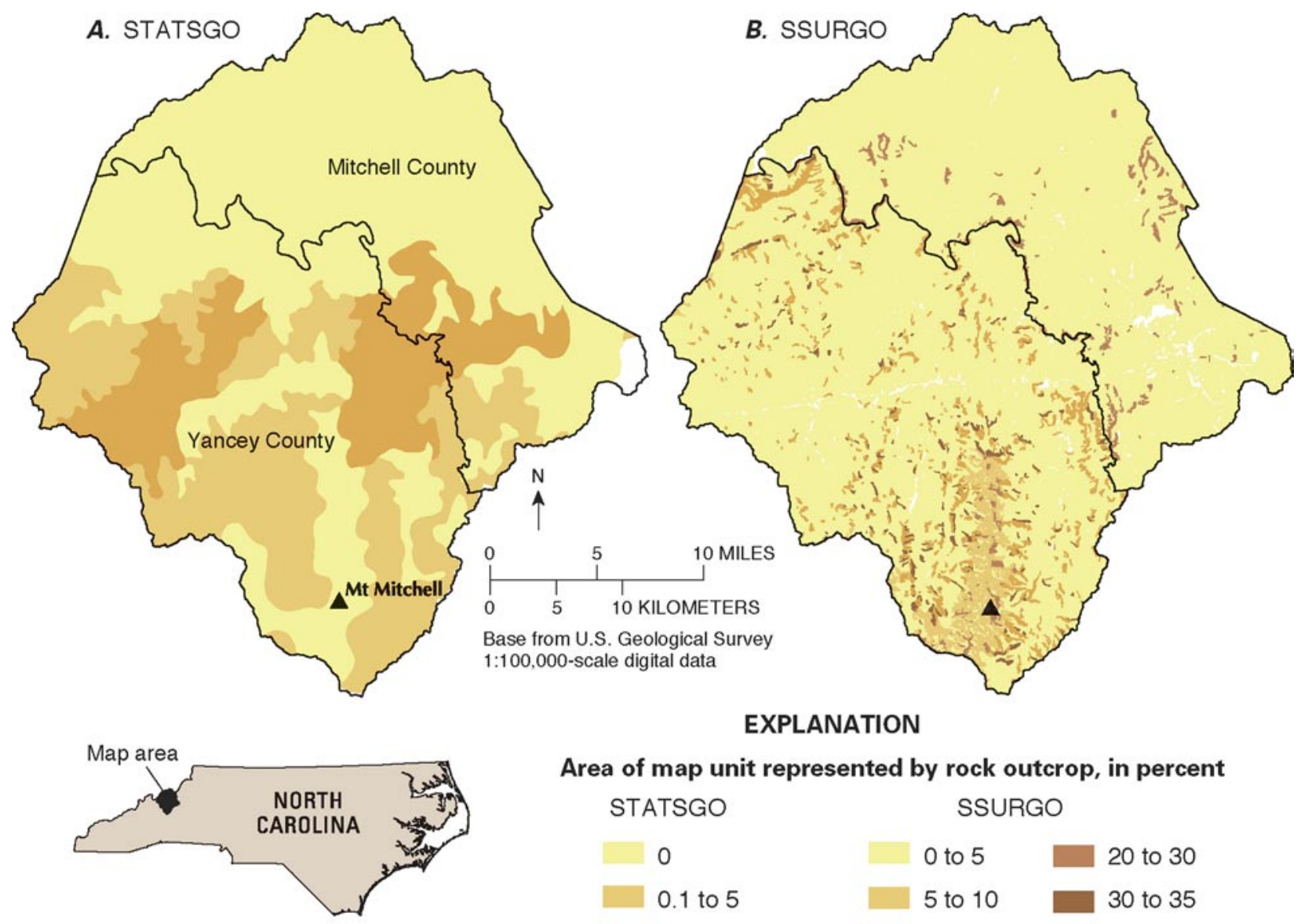

EXPLANATION

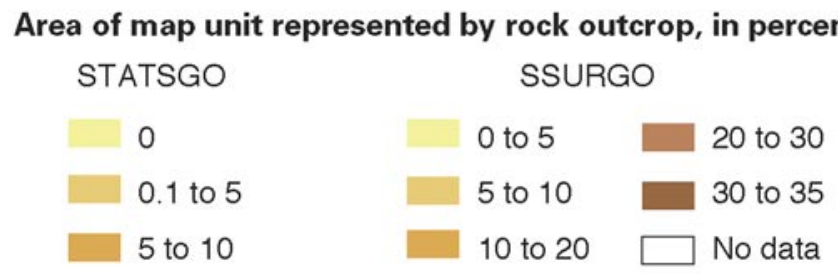

No data

Figure 10. Percentage of rock outcrop in (A) STATSGO and (B) SSURGO map units, Mitchell and Yancey Counties, North Carolina.

\section{Estimation of Missing Layer/Horizon Data}

The calculation of mass accumulation in a soil profile requires consistent data for all of the layer or horizon intervals in the profile. However, much of the available pedon data have some missing values for total carbon/organic carbon/organic matter, bulk density, or particle size (percent sand, silt, and clay). If pedons with missing data are to be used in SOC calculations, these data gaps need to be resolved. Figures 2 and 4 (U.S. Department of Agriculture, 2001d) show relatively complete data sets for a Dillsboro loam pedon sampled in Yancey County, western North Carolina, and a Cathedral sandy-loam pedon sampled in Fremont County, central Colorado. Bulk-density, particle-size, and organic-carbon data are present for most of the sampled horizons-the exceptions are no bulk-density measurements for the $2 \mathrm{C}$ horizon of the Dillsboro pedon or for the Oi and A1 horizons of the Cathedral pedon. Figure 3 (Reheis, 1987) shows a complete data set for an alluvial soil in Carbon County, Montana, that was not classed to series. Although the data set is complete in terms of data needed for SOC calculation, field-moist bulk density was measured rather than 1/3-bar or oven-dry bulk density. Figure 5 (U.S. Department of Agriculture, 2001d) and figure
6 (Arkansas database; E.M. Rutledge, University of Arkansas, Fayetteville, Arkansas, unpub. data, received 2001) show more typical incomplete data sets for a Memphis silt-loam pedon sampled in the Loess Hills of southwestern Kentucky (Crittenden County) and a Gepp silt-loam pedon sampled in the Ozark Highlands of northeastern Arkansas (Randolph County). Particle-size and organic-carbon data are present for all the horizons, but no bulk-density measurements were made.

If no carbon measurement (organic carbon, organic matter, or total carbon) was made for a layer/horizon, then that data record was "deleted" from the analysis prior to calculation of SOC storage for the pseudo pedon (SIR/MUIR databases) or pedon (S3C database). In some instances, a layer/horizon was not sampled at all. Although organic carbon can be estimated by regression on other soil properties such as bulk density, particle size, and moisture content (Jobbágy and Jackson, 2000), this approach was not chosen because of the large errors typically associated with such regression models. Also, for layers/horizons that were not sampled or for which there were none of the requisite data, the regression approach could not be used. Because the result of deleting "no-carbon data" layer/horizon records is a discontinuous soil profile, 
some method has to be selected to interpolate or "fill in" the gaps. In this study, linear mass interpolation of the SOC quantities in adjacent layers/horizons was chosen. There are three types of gap conditions associated with discontinuous profiles (fig. 7): (1) no data or sample for the surface layer/horizon, (2) no data or sample for an intermediate layer/horizon, and (3) no data for the basal layer/horizon. For profiles with type 1 gaps, the SOC value for the underlying layer/horizon is applied to the missing layer/horizon. Type 2 gaps have adjacent layers/horizons with SOC values. Therefore, in this case, a mass-weighted mean SOC value based on the values for the adjacent layers/horizons is applied to the missing layer/horizon (reference equation for the A2 horizon, lower left corner of fig. 7). In this study, type 3 gaps are not interpolated-no storage is assigned below the deepest layer/horizon with an SOC value.

When a layer/horizon record includes carbon data but no bulk-density data, then bulk-density values are estimated from statistical distributions of bulk-density measurements for combinations of empirical soil texture class and soil horizon (tables $1 A$ and $1 B$ ). The empirical soil texture class is computed from the available particle-size data for total sand, silt, and clay (Soil Survey Staff, 1993; Schoeneberger and others, 1998). If particle-size data are not available, the field-texture class is used. Both of these topics are discussed in greater detail in the next section.

\section{Bulk Density}

Bulk density, the mass per unit volume of a substance, is a required measurement for the calculation of SOC storage from carbon-concentration data. However, bulk density is one of the more difficult soil properties to measure, is requested less often when samples are submitted for characterization, and, therefore, is more likely to be missing from pedon records. The three most widely used methods for measuring bulk density are made across a decreasing range of soil moisture content from (1) field-moist (the natural condition of the soil when sampled) to (2) 1/3-bar (sample desorbed to 1/3-bar tension moisture content, weighed, oven-dried at 105 degrees Celsius $\left({ }^{\circ} \mathrm{C}\right)$, and then weighed again) to (3) ovendry (sample oven-dried at $105^{\circ} \mathrm{C}$ and then weighed) (U.S. Department of Agriculture, 1996). For a given volume of intact soil, the field-moist bulk-density measurement provides the closest approximation to the actual mass of soil at the time of sampling. However, 1/3-bar measurements are used in this study as an approximation of the field condition because these measurements are made at a consistent and operationally defined moisture content and, therefore, provide data suitable for regional comparisons. SOC storage and inventory data for pedon records used in this study are based on 1/3-bar bulkdensity measurements. SOC storage and inventory estimates based on oven-dry bulk-density values would be biased high because the oven-dry determination is based on the oven-dry volume of the sample rather than the 1/3-bar equilibrated volume (based on a comparison of the values in tables $1 A$ and
$1 B)$. SOC storage calculations for the layer records in the SIR and MUIR databases are based on "moist bulk density." It is not clear from the documentation for STATSGO and SSURGO whether this measure relates to a field-moist or 1/3-bar moisture content. In this report, the assumption is made that the STATSGO/SSURGO bulk-density data are equivalent to 1/3-bar bulk density.

Horizon records with missing bulk-density values were assigned values based on the statistical distributions of bulk density by texture class and horizon. This method incorporates the variation of bulk density with clay and organic-matter content (fig. 11) and also with texture class and soil horizon (tables $1 A$ and $1 B$ ). Tables $1 A$ and $1 B$ present the median bulk-density values for mineral soils at $1 / 3$-bar tension (table $1 A$ ) and oven-dry (table $1 B$ ) moisture content for the standard USDA soil texture classes and selected USDA soil horizons. 1/3-bar bulk-density values decrease from sandy to clayey soils and generally are higher for B horizons than for A or $\mathrm{C}$ horizons. Oven-dry bulk-density values are higher than 1/3-bar values for sandy and clayey soils. Oven-dry clays have the highest values. The B-horizon "bulge" is less evident with oven-dry values than with 1/3-bar values - the oven-dry values generally do not decrease going from $\mathrm{B}$ horizons to $\mathrm{C}$ horizons. Both 1/3-bar and oven-dry bulk-density values are higher for plow layers (Ap horizons) than for undisturbed A horizons.

Figure 11 shows the relations among 1/3-bar bulk density and clay (column 1), 1/3-bar bulk density and organic carbon (column 2), and organic carbon and clay (column 3), for selected groups of $\mathrm{A}$ and $\mathrm{E}$ horizons. Empirical trends in the data (11A and 11B; Schumacher and others, 1988; Pettry and Switzer, 1999; U.S. Department of Agriculture, 2001d; University of Illinois, 2001) show that bulk density increases with increasing clay content and decreases with increasing organiccarbon content. Clay and organic carbon have opposite effects on soil bulk density and generally vary inversely (fig. $11 \mathrm{~A}$ and $B$, column 3). $A$ shows data for $\mathrm{A}$ and $\mathrm{E}$ horizons in the $\mathrm{S} 3 \mathrm{C}$ database with a 15-bar water content of 10-12 percent; $B$, 18-20 percent. The wetter soils $(B)$ have somewhat higher clay and organic-carbon contents.

Exceptions to these general trends are shown in $11 C, D$, and E. C (Bowman and Petersen, 1996; U.S. Department of Agriculture, 2001d) and $D$ (U.S. Department of Agriculture, 2001d; Kansas State University, 2002) show data for soil series in the Central Great Plains region of the United States, and $E$ for Sharkey series clays in the Mississippi River alluvial valley (Schumacher and others, 1988; Pettry and Switzer, 1999; E.M. Rutledge, University of Arkansas, Fayetteville, Arkansas, unpub. data, received 2001; U.S. Department of Agriculture, 2001d). For the native shortgrass prairie soils depicted in $11 C$, bulk density decreases slightly as both clay and organic-carbon content increase, and there is a positive association between clay and organic carbon. There is no apparent relation between either clay and bulk density or clay and organic carbon for the native tallgrass prairie soils at the Konza Prairie Long-Term Ecological Research (LTER) Site 


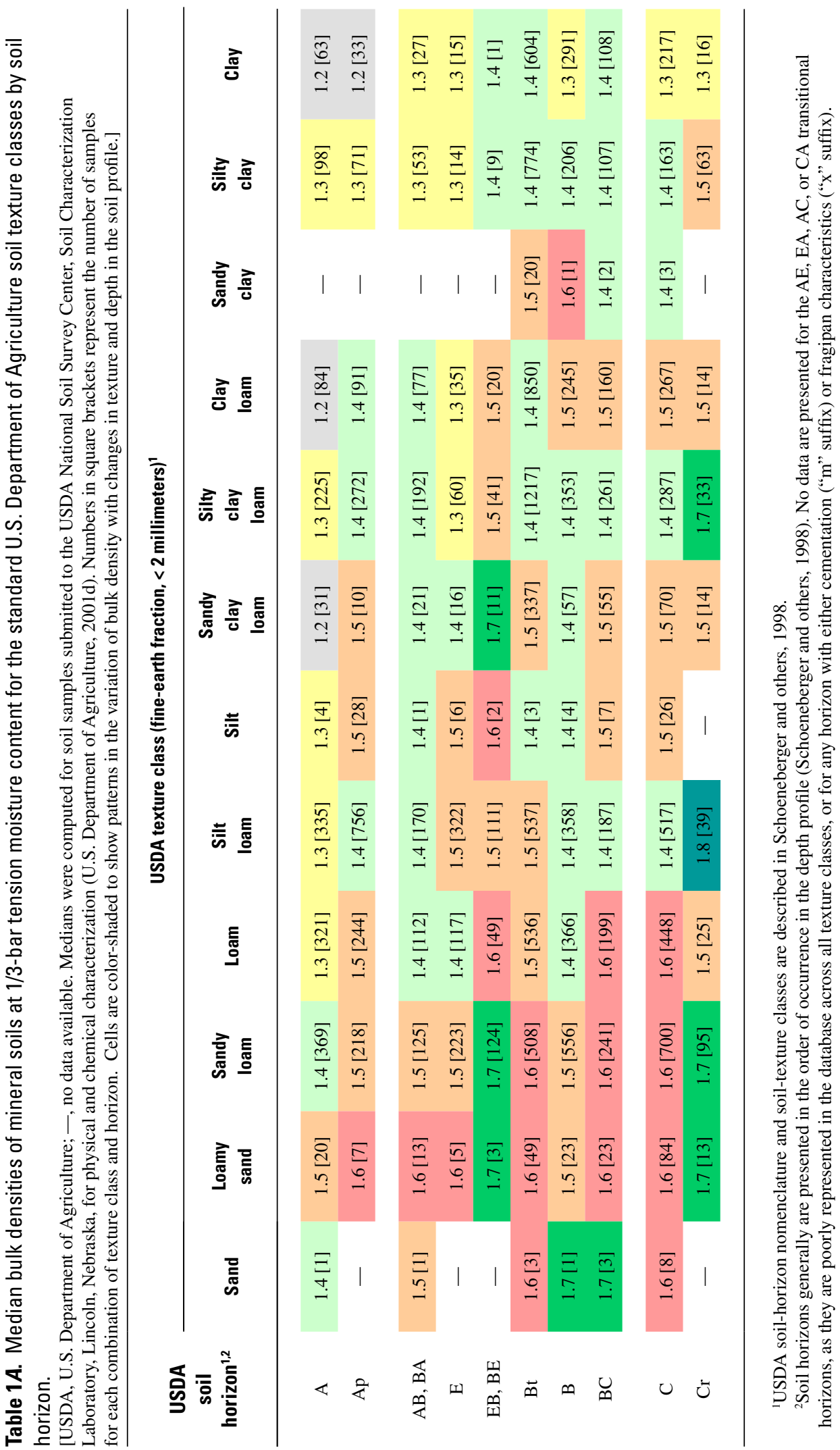




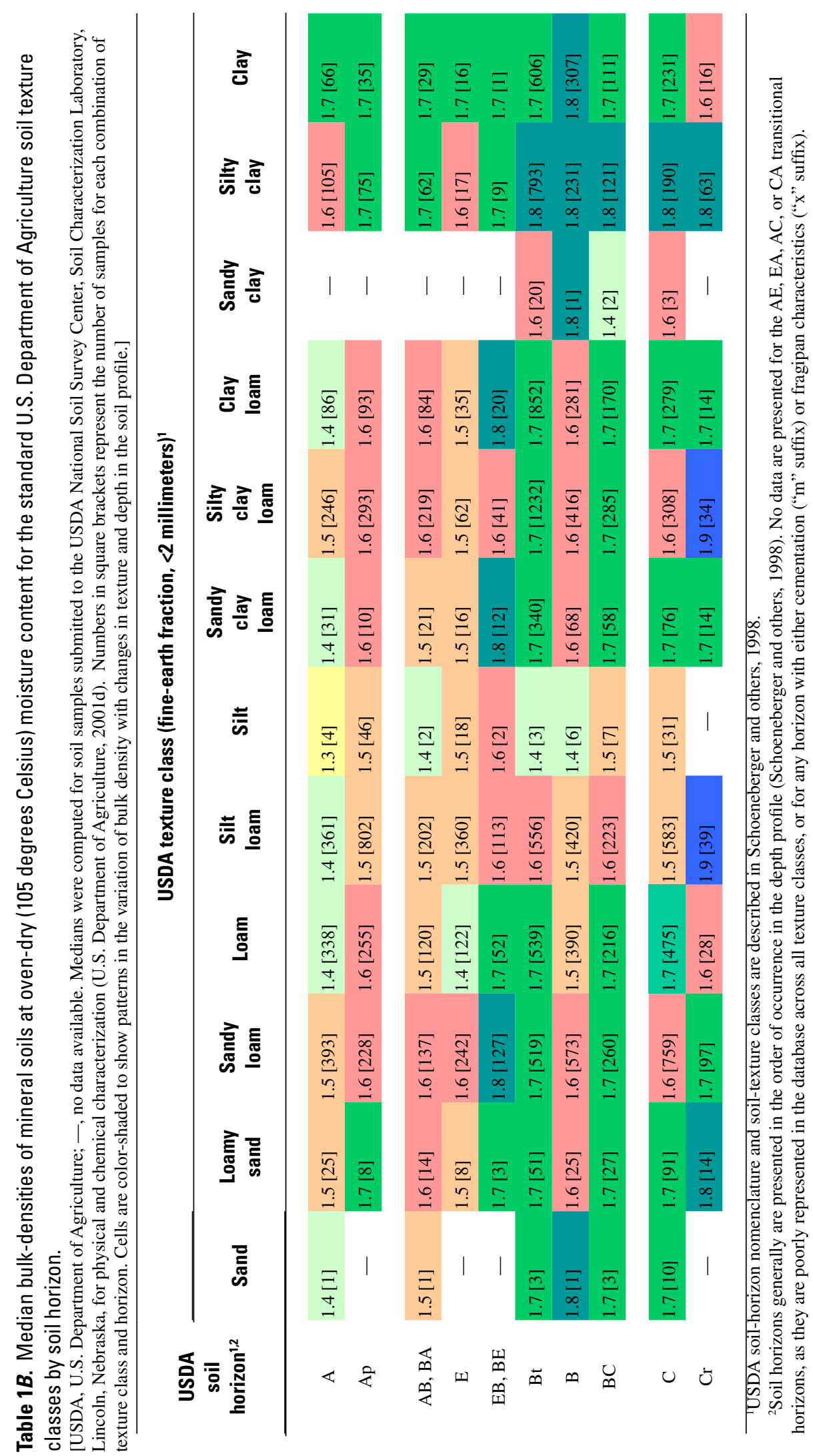


A. Mississippi River Basin soils, 10-12\% SWC15
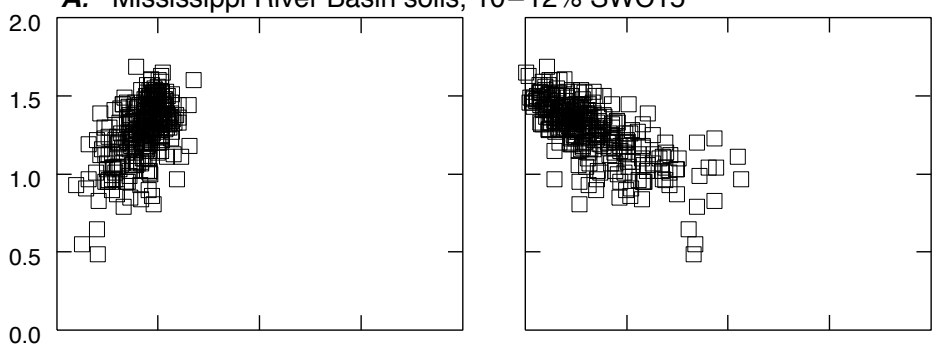

B. Mississippi River Basin soils, 18-20\% SWC15

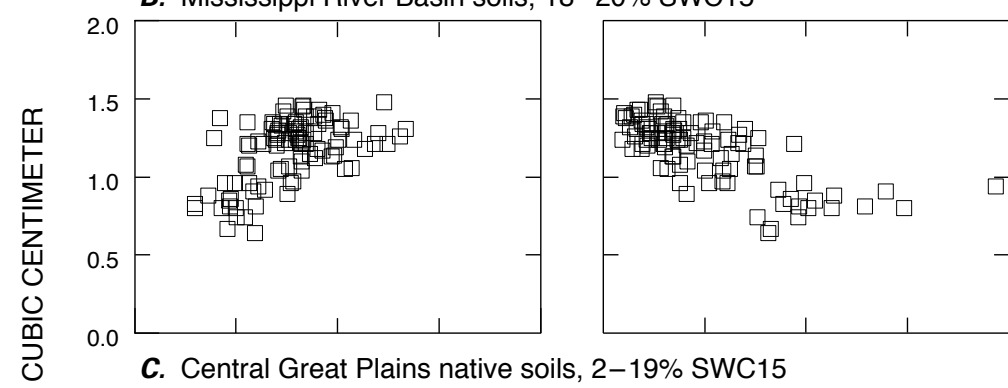

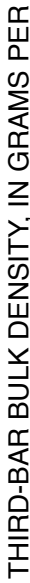

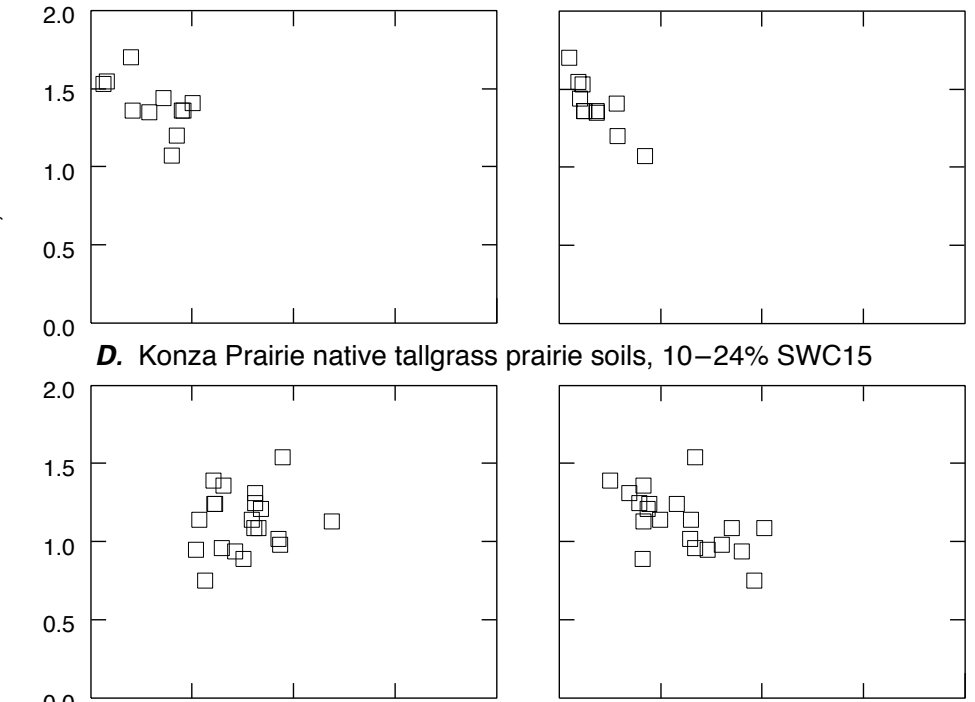

E. Lower Mississippi River valley Sharkey clay soils, 11-46\% SWC15
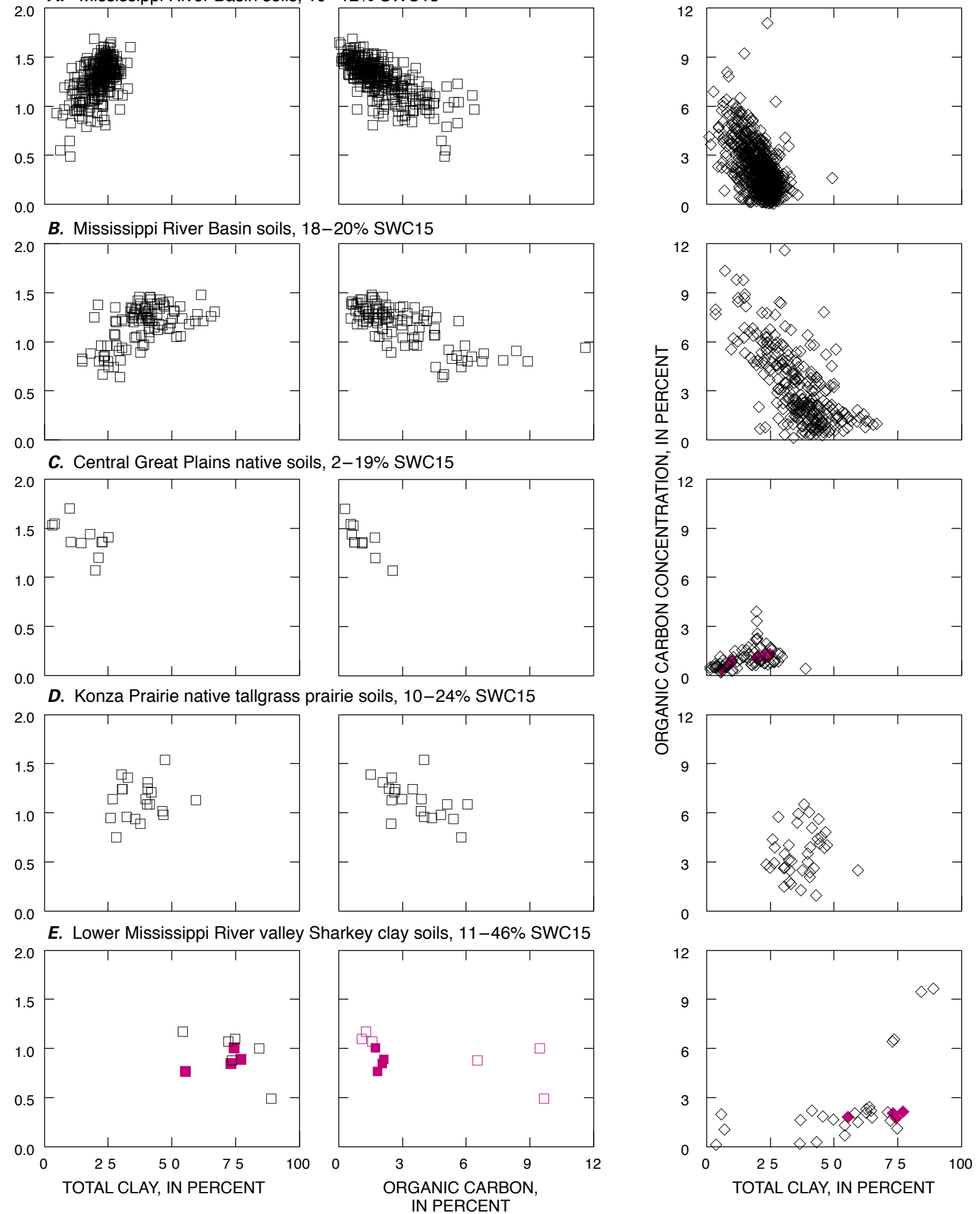

Figure 11. Relations among soil bulk density (samples equilibrated to 1/3-bar (0.033 Mpa) tension moisture content), organic carbon, and clay for selected $A$ and $E$ horizons of soils in the Mississippi River Basin. $A$ and $B$, Schumacher and others, 1988; Pettry and Switzer, 1999; U.S. Department of Agriculture, 2001d; University of Illinois, 2001. C, Bowman and Petersen, 1996; U.S. Department of Agriculture, 2001d. D, U.S. Department of Agriculture, 2001d; Kansas State University, 2002. E, Schumacher and others, 1988; E.M. Rutledge, University of Arkansas, Fayetteville, Arkansas, unpub. data, received 2001; Pettry and Switzer, 1999; U.S. Department of Agriculture, 2001d. Open symbols-S3C database; solid red symbols-Bowman and Petersen, 1996 (C); Pettry and Switzer, 1999 (E). 
in eastern Kansas $(D)$. However, as with $A-C$, bulk density decreases with increasing organic-carbon content. The Sharkey clays $(E)$ show trends similar to those depicted in $C$ - slight decreases in bulk density with increasing clay and organic carbon content and an apparent positive association between clay and organic carbon.

The data shown in $C-E$ are much smaller subsets of data than those used for $A-B$ because they were selected to represent soils formed under similar environmental conditionsnative shortgrass prairie $(C)$, native tallgrass prairie $(D)$, and cultivated/native Sharkey clay $(E)$. The apparent exceptions to the effects of clay and organic carbon on soil bulk density may be real or, possibly, artifacts of smaller sample sizes. However, the large variance in all of the scatterplots shown in figure 11 illustrates the problems encountered in predicting bulk density from other soil properties.

Horizon records with missing bulk-density values were assigned the median values for combinations of texture class and soil horizon (tables $1 A$ and $1 B$ ) to minimize the bias associated with variable data coverage. Most of the available pedon data typically are biased toward more productive agricultural soils, and, therefore, texture classes such as sand, loamy sand, and sandy clay are underrepresented in the data. Also, there are some combinations of texture class and horizon that occur less frequently than others. With sample sizes less than or equal to 10 , the confidence intervals for the 25th and 75th percentiles (which define the interquartile range of a distribution) will overlap the confidence intervals for the 50th percentile (median) - in other words, the boundaries of the interquartile range are not significantly different from the median (Helsel and Hirsch, 1992).

As STATSGO/SSURGO records have a layer-based, rather than horizon-based, data structure, layer records with missing bulk-density values were assigned the median values of bulk-density distributions by texture class only. Bulk-density and particle-size data (used to estimate empirical texture class) from the SIR/MUIR databases were used to estimate missing bulk-density values in STATSGO/SSURGO layer records.

\section{Empirical Soil Texture Class}

The empirical soil texture classes and subclasses for each pedon horizon were computed from the percentages of sand, silt, and clay according to the definitions given in the U.S. Department of Agriculture Handbook 18 (Soil Survey Staff, 1993). Where particle-size data were available, the empirical texture classes were used to group the data (rather than field-determined texture classes) to provide a more consistent approach to estimating bulk density. Although subclasses for the sands, loamy sands, and sandy loams were determined, only the classes were used in the analysis.

\section{Soil Horizon Groupings}

Soil horizon groupings used to determine bulk-density values for pedon horizon records with missing data are based on the current master and transitional soil horizons and, to a lesser extent, the horizon suffixes (Schoeneberger and others, 1998). A level of generalization was chosen so that sufficient detail was maintained in the horizon designations to reproduce the typical variation in bulk density with depth. The following groupings of master/transitional horizons and horizon suffixes were used in the analysis of bulk density by horizon (bulkdensity data for the more commonly occurring groupings are shown in bold and presented in tables $1 A$ and $1 B$ ):

$$
\begin{aligned}
& \text { organic horizons-Oa, Oe, Oi, Op, Oae, Oei } \\
& \text { solum horizons- }-\mathbf{A}, \mathbf{A p}, \mathbf{E}, \mathrm{AE}, \mathbf{A B}, \mathrm{AC}, \mathrm{EC}, \mathbf{B}, \mathbf{B t}, \mathbf{E B}, \\
& \text { BE, and BC } \\
& \text { parent-material-C and } \mathbf{C r}
\end{aligned}
$$$$
\text { dominant horizon suffixes- } \mathrm{m} \text { and } \mathrm{x}
$$

For transitional horizons such as the Oei, $\mathrm{AB}$, or $\mathrm{BE}$ horizons, dominance was ignored. Thus, the $\mathrm{AB}$ grouping includes all combinations of $\mathrm{A}$ and $\mathrm{B}$ horizons- $\mathrm{AB}$ (A dominant with some $\mathrm{B}$ characteristics), $\mathrm{A} / \mathrm{B}$ (discrete, intermingled $\mathrm{A}$ and $\mathrm{B}$, mostly A), BA (B dominant with some A characteristics), and B/A (discrete, intermingled A and B, mostly B). Numerical prefixes (lithologic discontinuities), numerical suffixes (master-horizon subdivisions), and primes (horizon suffix denoting multiple occurrences of identical horizons) also were ignored-for example, B, 2B, 2B2, and $\mathrm{B}^{\prime}$ are all included in the B grouping. All horizons with strong cementation (" $\mathrm{m}$ " horizon suffix) were grouped together because of the dominant effect cementation has on bulk density, and all fragic horizons (" $x$ " horizon suffix) were similarly grouped.

\section{Interpolation of Missing Data}

Soil-carbon maps based on linkage of data to STATSGO/ SSURGO map units predictably will have "no-data" areas, both at the level of the map unit and at smaller scales (larger land areas), such as counties or river basins. These "spatial data gaps" result from a lack of data for some or all of the component series in some soil map units and, to avoid underestimation of carbon mass, must somehow be accounted for in calculations of SOC inventory. In this study, the unsampled areas of each map unit or larger land area were assumed to be "represented" by the sampled areas. Area weights for the sampled components in each map unit were used to apportion SOC storage to the unsampled portion of the map unit according to equation (3b). If entire map units were unsampled, area weights for the sampled map units in a larger land area were similarly used to apportion SOC inventory to the unsampled 
portion of the land area according to equation (5). The errors produced by this approach increase both with more unsampled area and more spatial heterogeneity in soil properties, particularly organic matter and bulk density.

\section{Results and Discussion}

The presentation of material in the preceding sections of this report has focused entirely on data collection and management and calculation methods for the estimation of carbon storage and inventory. Although this report is not interpretive, results for selected geographic areas are presented and discussed from an interpretive perspective, as the geographic interpretation of soil-carbon data provides a good framework for evaluating strengths and weaknesses associated with different soil-carbon data sources.

\section{SOC Storage and Inventory for the MRB}

SOC storage and inventory for the surface meter of mineral soil were calculated and mapped for the six USGS hydrologic regions in the MRB (fig. 12, tables 2 and 3) by using the linkage of soil pedon data to STATSGO map units. The linkage was based on the 50th percentile of SOC storage for each soil series to generate a "series-typical" soil-carbon map. Organic horizons of mineral soils were excluded because of insufficient data, and, because the geographic extents of "native" versus "disturbed" (such as eroded or mined), areas have not been delineated for soil series that would have developed organic surface horizons under predevelopment conditions.

At the MRB scale, the pedon-to-STATSGO data linkage results in from 95 to 98 percent of the geographic area by region being mapped (table 2). For example, STATSGO map units that have partial or complete representation by soil-carbon data account for 97 percent of the $410,700 \mathrm{~km}^{2}$ in the Ohio River Basin (region 05) and 98 percent of the 1,301,000 km² in the Missouri River Basin (region 10). A STATSGO map unit is considered to be "represented by data" if at least one of the component soil series has available pedon data. As each mapunit component is assigned a percentage of the total map-unit area, the sum of these percentages for all the components with pedon data gives the total percentage of the map unit that is represented by data. Although the level of MRB geographic coverage is 95 percent or higher, the data coverage for individual map-units is much lower. With the exception of the Lower Mississippi Basin, the 50th percentile for the percent of map-unit area represented by data ranges from 71 to 77 percent (table 2). For example, half of the 2,169 STATSGO map units in the Ohio River Basin have 75 percent or more of the mapunit area represented by data. This percentile is 95 percent for the Lower Mississippi Basin, largely because of the pedon data available from the Arkansas and Louisiana databases (E.M. Rutledge, University of Arkansas, Fayetteville, Arkansas, unpub. data, received 2001; Schumacher and others, 1988).

SOC storage for mineral soils within the MRB varies by hydrologic region from $7.1 \mathrm{~kg} / \mathrm{m}^{2}$ in the Tennessee River Basin to $12.5 \mathrm{~kg} / \mathrm{m}^{2}$ in the Upper Mississippi Basin (table 3, 50th percentile) and SOC inventory from $752 \mathrm{Tg}$ in the Tennessee River Basin to 13,900 Tg in the Missouri River Basin. The basinwide mean SOC storage for the MRB is approximately $10.0 \mathrm{~kg} / \mathrm{m}^{2}$, and the total SOC inventory for the MRB is $32,300 \mathrm{Tg}(32.3 \mathrm{Pg})$. Recent estimates of global SOC inventory for mineral soils (surface meter only) range from 1,115 Pg (Adams and others, 1990) to 1,219 Pg (Eswaran and others, 1993), which would place the MRB inventory somewhere between 2.7 and 2.9 percent of the global mineral-soil SOC pool. The MRB coonstitutes approximately 2.6 percent of the global land area.

One of the strengths of the pedon-to-STATSGO data linkage as an approach to carbon-inventory assessment is the potential availability of pedon data. The more data that are available for a given soil series, the better the characterization of individual map-unit components. However, in its present state, the S3C database is highly skewed-46 percent of the 2,581 series for which SOC storage in the surface meter of soil could be calculated are represented by 1 pedon, 12 percent by 5 or more pedons, and only 5 percent by 10 or more pedons.

Given the high series-level spatial variability in soil organic matter and, to a lesser extent, bulk density, SOC values based on a small number of pedons $(n \leq 5)$ may not be representative of that series. For example, if 100 pedons were sampled at sites statistically located to represent a Grenada silt loam in northwestern Mississippi, an SOC value based on these samples could be quite different from an SOC value based on only 4 or 5 pedons. A 5-pedon median could, for example, be biased to the 25 th or 75 th percentile of a distribution based on 100 pedons selected to spatially represent the Grenada series. The effects of sample size and bias on pedon-based estimates of SOC storage and inventory can be semiquantitatively described by looking at the interquartile (from 25th to 75th percentile) ranges of these estimates-from 8.6 to $11.7 \mathrm{~kg} / \mathrm{m}^{2}$ for MRB storage and from 27.7 to $37.6 \mathrm{Pg}$ for MRB inventory (table 3). With variable sample sizes and unknown bias, the interquartile range provides a probable window for the "actual" median SOC storage and inventory.

\section{Geographic Patterns in SOC Storage}

Geographic variation in SOC storage for mineral soils within the MRB is shown in figure 12. Regionally, higher storage values occur in the formerly glaciated areas of southern Minnesota and northwestern Iowa, the loess-derived soils of the Upper Midwest (eastern Iowa, northern Illinois and 


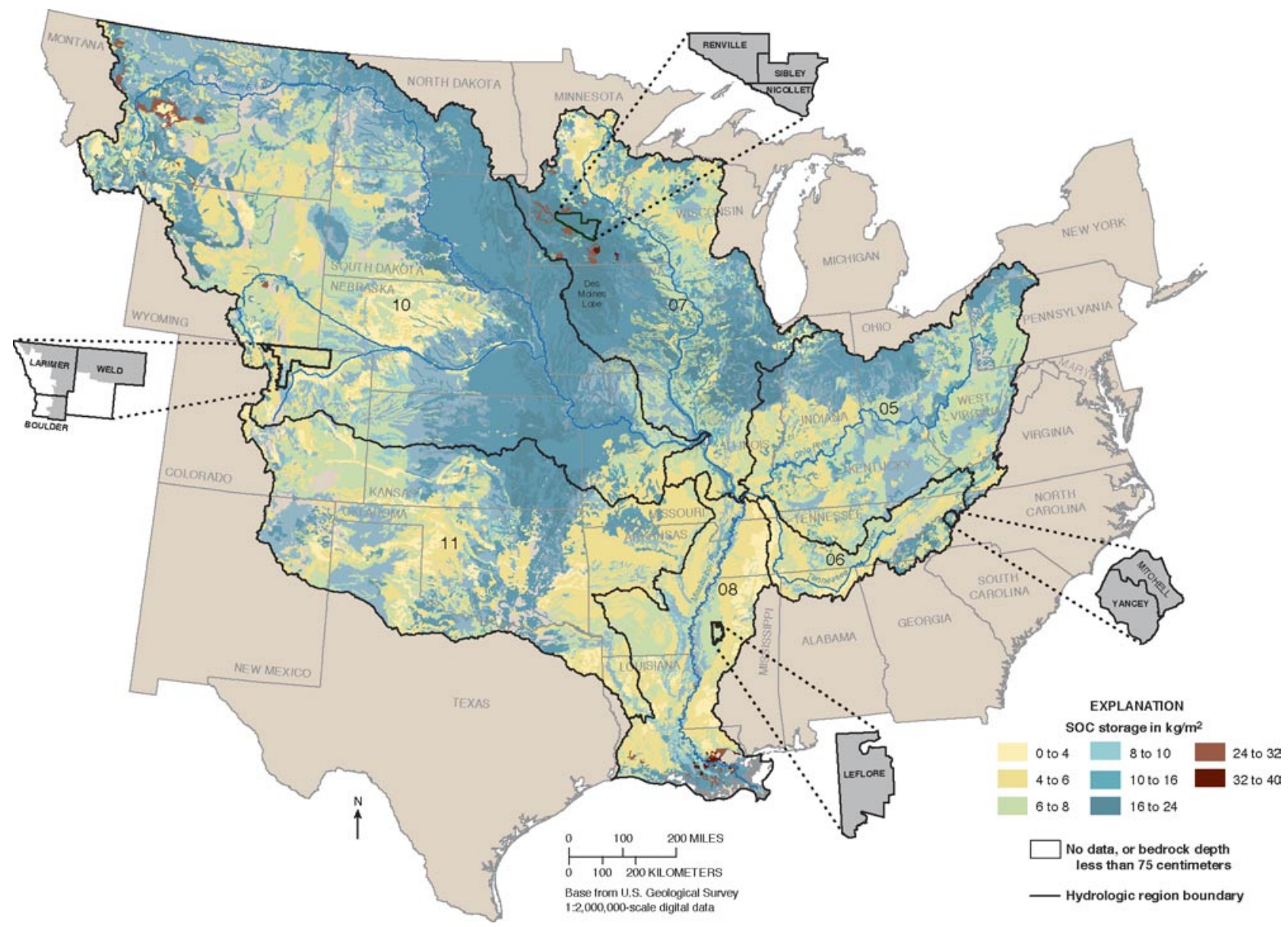

Figure 12. Soil organic carbon (SOC) storage estimates, depth interval from 0 to 100 centimeters, for mineral soils in the Mississippi River Basin. Storage estimated by linking site-specific data for 7,321 pedons (representing 2,581 soil series) to STATSG0 map units. USGS hydrologic regions (Seaber and others, 1994) named by region number are shown in figure 1. The three-county area outlined in Minnesota and the two-county area outlined in North Carolina are shown in figures 13 and 14 (Minnesota) and figures 15 and 16 (North Carolina). SOC storage and inventory estimates for county areas (mapped areas of counties shown in gray) outlined in Colorado, Minnesota, and North Carolina are given in table 4.

Indiana, and west-central Ohio), and the eastern portion of the Central Great Plains (eastern Nebraska/Kansas). SOC storage values in these areas typically range from 10 to $24 \mathrm{~kg} / \mathrm{m}^{2}$. The highest SOC storage values are more limited in geographic extent and are associated with depressional wetlands in southern Minnesota (from 32 to $40 \mathrm{~kg} / \mathrm{m}^{2}$ ), coastal marshes in southern Louisiana (from 32 to $40 \mathrm{~kg} / \mathrm{m}^{2}$ ), and high-elevation montane forests in the northern Rocky Mountains (from 24 to $32 \mathrm{~kg} / \mathrm{m}^{2}$, Montana and Wyoming).

Geomorphic controls of geographic patterns in SOC storage are evident in comparisons between erosional and depositional environments within the MRB. Alluvial soils, in particular, stand out as areas of both higher and lower carbon storage than the adjacent uplands. Soils formed in alluvium along tributaries to the Missouri River in eastern Nebraska and western Iowa and along tributaries to the Platte River in central Nebraska have higher carbon storage than the adjacent upland soils. This pattern also holds for many of the floodplains along the larger rivers in the MRB, such as the Missis- sippi, Missouri, and Ohio. Although less common, there are exceptions to this pattern. Alluvial soils along the Platte River in eastern Nebraska, the Missouri River in northwestern Missouri, and along the small streams draining the Des Moines Lobe in northwestern Iowa have lower carbon storage than do the adjacent upland soils.

\section{STATSG0/SSURGO Regional Comparisons}

SOC maps for selected county areas within the MRB (figs. 13-16) and comparative estimates of SOC storage and inventory (table 4) were produced by linking aggregate and site-specific soil-carbon data to both STATSGO and SSURGO to examine the effects of data source and map scale on the variability in estimates of SOC storage and inventory. The SOC maps were produced by using pedon-to-STATSGO (PDSG) and pedon-to-SSURGO (PDSS) data linkages (50th percentile). Storage/inventory estimates presented in table 4 are based on the PDSG and PDSS linkages (25th, 50th, 


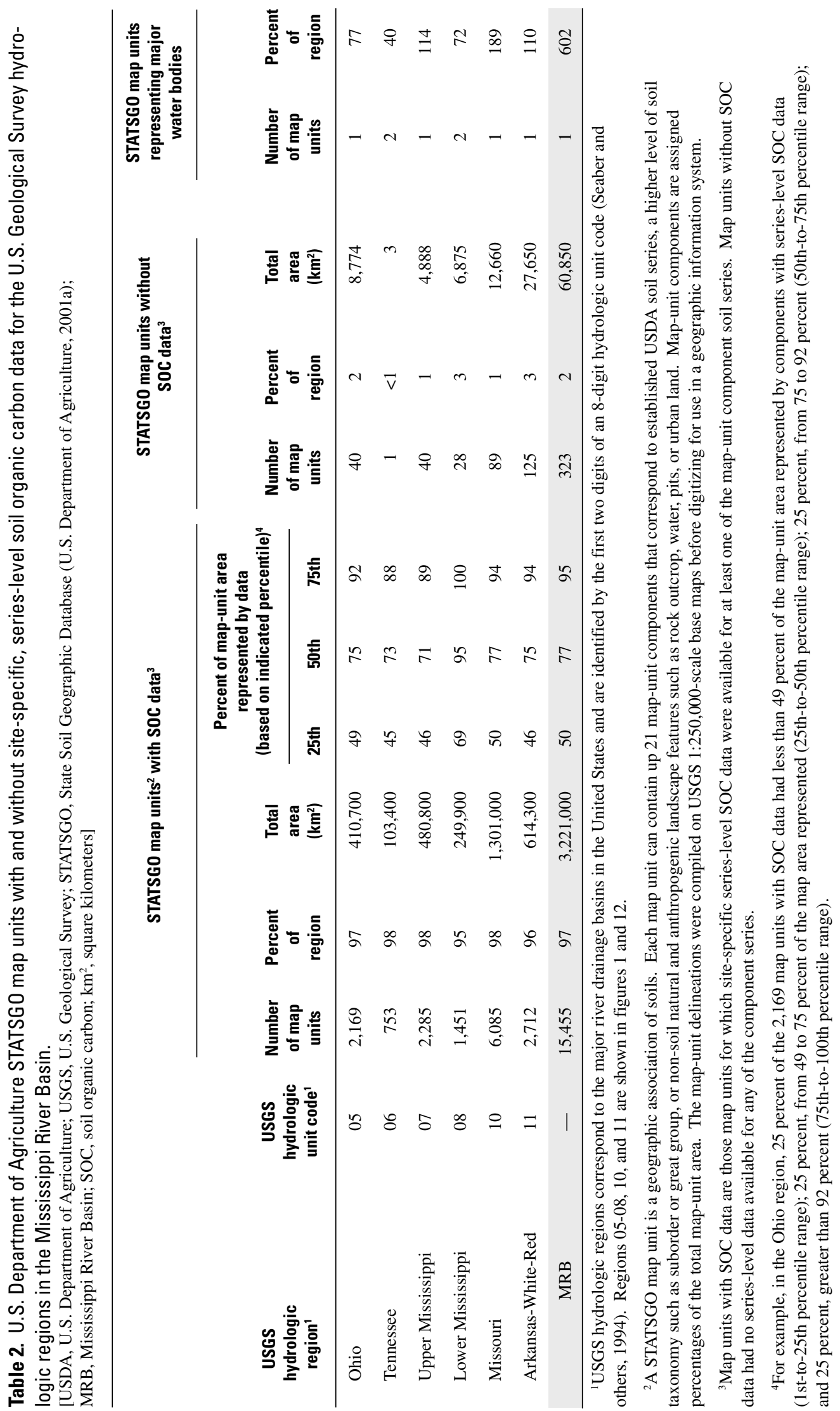




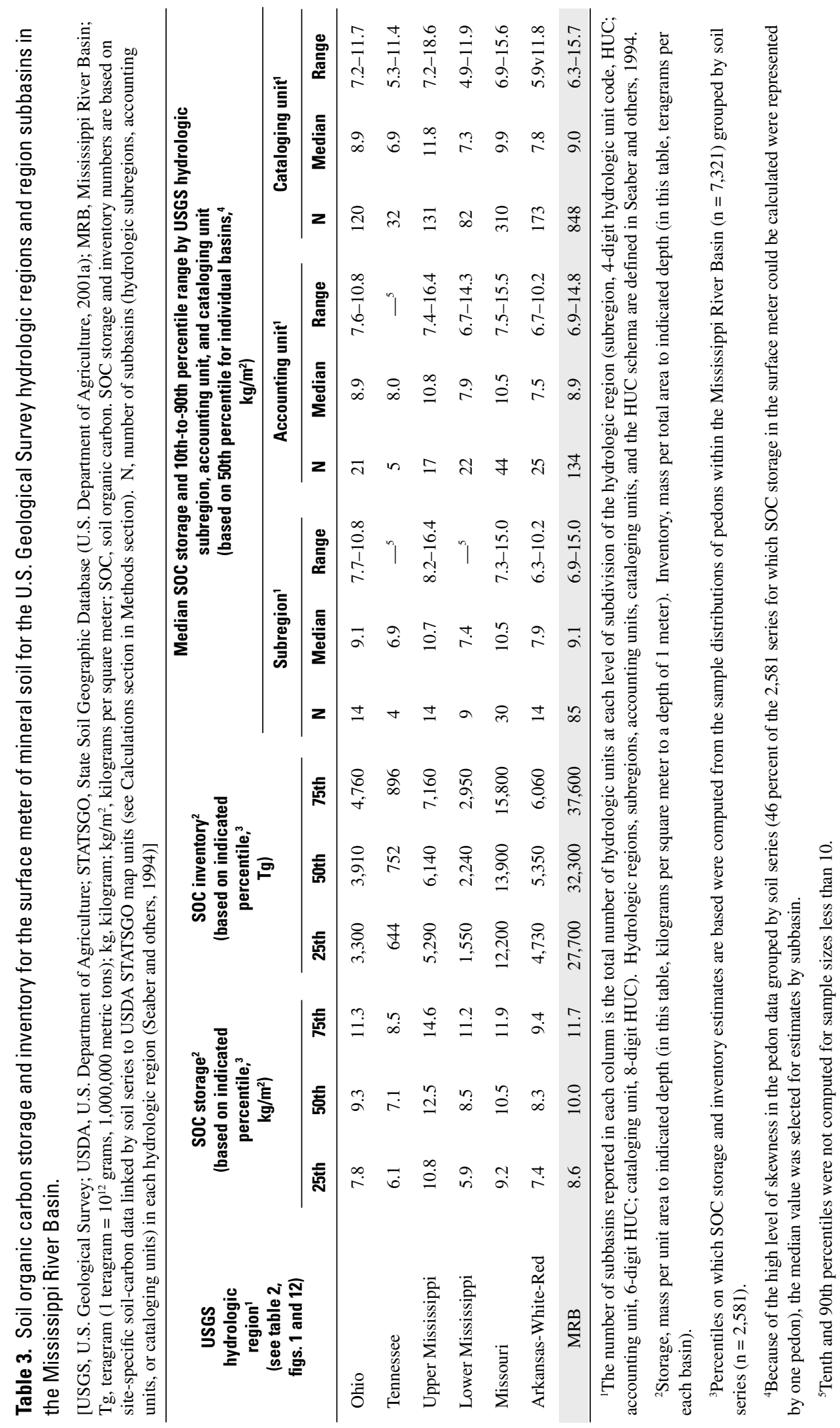


and 75th percentiles) and, additionally, on STATSGO-toSTATSGO (SGSG) and SSURGO-to-SSURGO (SSSS) linkages (50th percentile).

Four county areas-representing different physiographic, geomorphic, and ecological settings - were selected for comparison (figs. 1 and 12):

\section{Portions of Boulder, Larimer, and Weld Counties,} Colorado - The eastern half of Boulder County, the eastern two-thirds of Larimer County, and the northern half of Weld County are included in the USDA SSURGO database (shaded area in Colorado county inset, figs. 1 and 12). The eastern two-thirds of this area (eastern Boulder and eastern Larimer Counties and northern Weld County) is located in the Colorado Piedmont and High Plains sections of the Central Great Plains physiographic province (Fenneman, 1931). Native vegetation is predominantly shortgrass prairie—buffalo grass, grama, wheatgrass, and needlegrass; shrubs - sagebrush and rabbitbrush; and scattered trees (Central High Plains ecoregion; Bailey and Cushwa, 1981; Bailey, 1995). The western third (central Boulder and central Larimer Counties) is located in the Southern Rocky Mountains physiographic province (Fenneman, 1931). Vegetation zones in this area, largely defined by an east-to-west increase in elevation and moisture, transition from grassland to woodland (ponderosa pine, pinyon-juniper association, or scrub oak) to montane (ponderosa pine on lower, drier slopes and Douglas fir on higher, wetter slopes) to subalpine (Engelmann spruce and subalpine fir) to alpine tundra (Northern Parks and Ranges ecoregion; Bailey and Cushwa, 1981; Bailey, 1995).

\section{Nicollet, Renville, and Sibley Counties,} Minnesota - All three counties are in the Western Lake section of the Central Lowland physiographic province (Fenneman, 1938). Nicollet, Renville, and all but the far northeastern portion of Sibley County are in the North Central Glaciated Plains ecoregion (Bailey and Cushwa, 1981). Native vegetation is characterized by mixed deciduous forest (dominated by oak and hickory) and tallgrass prairie (big and little bluestem, switchgrass, and Indian grass; Bailey, 1995). Northeastern Sibley County is in the Morainal-Oak Savannah ecoregion (Bailey and Cushwa, 1981) with native vegetation dominated by oak-hickory forest with interspersed maple and basswood (Bailey, 1995).

3. Leflore County, Mississippi - Leflore County is located in the east-central portion of the Mississippi Alluvial Plain section of the Coastal Plain physiographic province (Fenneman, 1938). The Mississippi Alluvial Plain is almost coincident with the Mississippi Alluvial Basin ecoregion (Bailey and Cushwa, 1981). Native vegetation in this ecoregion is bottomland deciduous forest (green and Carolina ash, elm, cottonwood, sugarberry, sweetgum, water tupelo, oak, and bald cypress; Bailey, 1995). Much of this area, with the exception of isolated wetlands and catfish ponds, is now cultivated for soybeans, cotton, mixed row crops, and small grains or seasonally flooded for rice production.

4. Mitchell and Yancey Counties, North Carolina - The Mitchell-Yancey county area is located in the Southern Blue Ridge physiographic province (Fenneman, 1938) or the Blue Ridge Mountains ecoregion (Bailey and Cushwa, 1981). As with the Colorado counties, vegetation patterns are defined by vertical zonation related to changes in temperature and moisture with elevation. Coves and valleys are dominated by mixed oak-pine forest at lower elevations and oak forest at mid-elevations. At higher elevations, oaks are replaced by northeastern forest species (birch, beech, maple, elm, red oak, basswood, hemlock, and white pine). The highest elevation ridges and peaks are predominantly spruce-fir forest and meadows (Bailey, 1995).

Scale-related differences in the modeled geographic distribution and relative quantity of soil carbon are discussed by using selected Minnesota and North Carolina counties as examples. All spatial data sets have intrinsic scales that relate to sampling density and generally can be abstracted to smaller scales. For example, are the regional patterns for a larger geographic area, as depicted by SSURGO, similar to those depicted by STATSGO? It is shown that the smallscale $(1: 250,000)$ regional distribution of soil carbon depicted by mapping SOC data to STATSGO is comparable to that produced by mapping the same data to SSURGO, at least for county-sized land areas. The large-scale (from 1:12,000 to $1: 63,360)$ differences in soil-carbon distribution are shown to be primarily associated with differences between the two databases in map-unit size and composition-SSURGO map units are much smaller in area than STATSGO map units, have no more than three components, and typically have only one or two components. SSURGO can be viewed as a close approximation to a series-level database.

\section{Minnesota}

The STATSGO-based (fig. 13) and SSURGO-based (fig. 14) SOC storage maps for Nicollet, Renville, and Sibley Counties show similar geographic patterns at the STATSGO scale but markedly different patterns at the SSURGO scale. On a countywide basis, storage/inventory values based on the PDSG linkage are comparable to those values based on the PDSS linkage-19 $\mathrm{kg} / \mathrm{m}^{2}$ storage, $100 \mathrm{Tg}$ inventory, PDSG linkage; $20 \mathrm{~kg} / \mathrm{m}^{2}$ and $106 \mathrm{Tg}$, PDSS linkage (table 4). Based on the PDSG data linkage (fig. 13A), soils in the upland areas of all three counties have SOC storage values ranging from 16 to $24 \mathrm{~kg} / \mathrm{m}^{2}$. Alluvial soils along the Minnesota River in Renville and western Nicollet Counties have higher SOC storage (from 24 to $32 \mathrm{~kg} / \mathrm{m}^{2}$, fig. $13 A$ and $13 B$ ) than those in the adjacent uplands, whereas the soils along the Minnesota River in eastern Nicollet and Sibley 


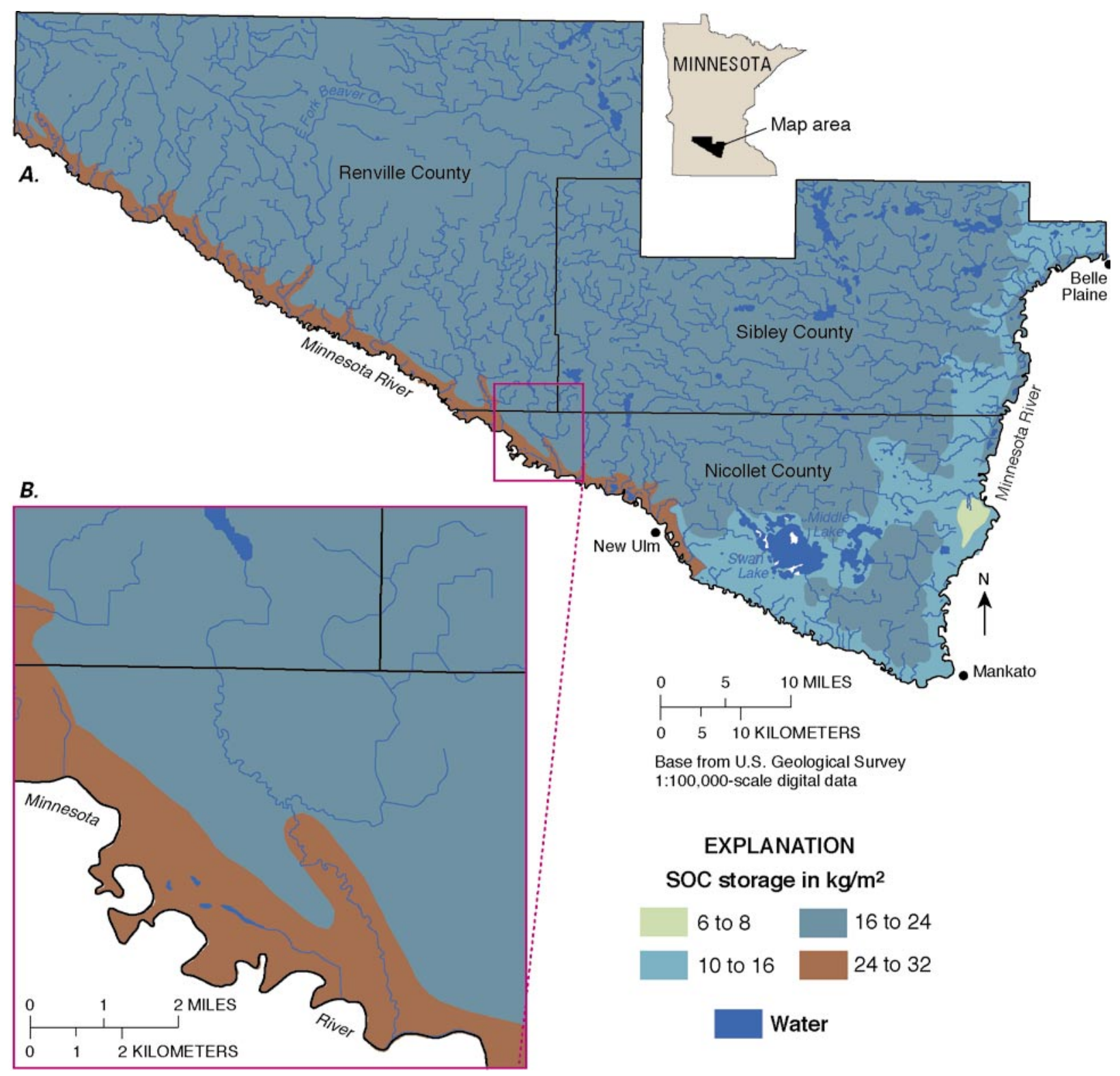

Figure 13. (A) Soil organic carbon (SOC) storage, depth interval from 0 to 100 centimeters, for mineral soils in Nicollet, Renville, and Sibley Counties, Minnesota. Storage estimated for site-specific data linked to STATSGO map units. Data are for soils classed to the series level. $(B)$ Area outlined in $A$ showing relatively high SOC storage values for map units along the Minnesota River.

Counties and surrounding Middle and Swan Lakes in Nicollet County have lower SOC storage (from 10 to $16 \mathrm{~kg} / \mathrm{m}^{2}$, fig. 13A) than those in the adjacent uplands.

By comparison, the PDSS data linkage produces a map with comparable SOC storage values (from 16 to $24 \mathrm{~kg} / \mathrm{m}^{2}$ ) for all but the northwestern section of Renville County but with different large-scale patterns and some smaller scale regional differences (fig. 14A). Alluvial soils located along the Minnesota River in Nicollet and Sibley Counties are similarly mapped with lower storage values (from 10 to $16 \mathrm{~kg} / \mathrm{m}^{2}$ ) than those assigned to the adjacent uplands. However, many of the alluvial SSURGO map units for near-channel portions of the
Minnesota River flood plain have no pedon data for any of the component series (shown in fig. 14A, and in greater detail in $14 C$ ); these areas appear white on the map. Numerous small wetlands located in closed and poorly drained depressions have storage values from 32 to $40 \mathrm{~kg} / \mathrm{m}^{2}$. The part of Renville County north and west of the East Fork Beaver Creek tributary to the Minnesota River has much higher SOC storage when pedon data are linked to SSURGO map units than when linked to STATSGO map units. Based on linkage to SSURGO, SOC storage in this area varies from 32 to $52 \mathrm{~kg} / \mathrm{m}^{2}$ (fig. 14A). When pedon data are linked to STATSGO, SOC storage varies from 16 to $24 \mathrm{~kg} / \mathrm{m}^{2}$ (fig. 13A). 


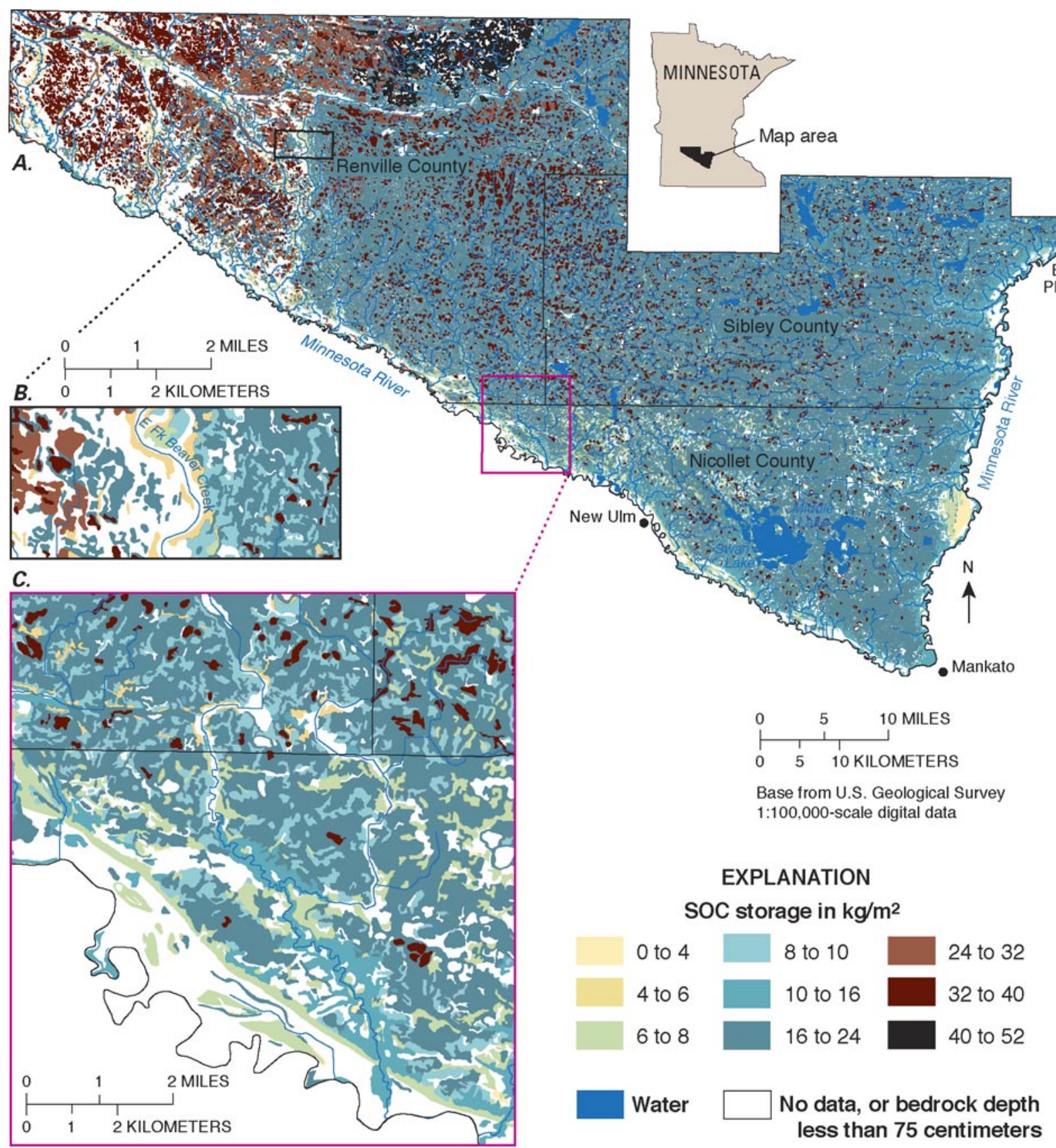

Figure 14. $(A)$ Soil organic carbon $(S O C)$ storage, depth interval from 0 to 100 centimeters, for mineral soils in Nicollet, Renville, and Sibley Counties, Minnesota. Storage was estimated by linking site-specific data to SSURGO map units. Data are for soils classed to the series level. Generally, areas with SOC storage values $>40$ kilograms per square meter $\left(\mathrm{kg} / \mathrm{m}^{2}\right)$ are associated with poorly drained, closed depressions. $(B)$ Area outlined in A, area near a north-south-trending stream channel in Renville County. (C) Area outlined in A that includes parts of Nicollet, Renville, and Sibley Counties.

\section{North Carolina}

Spatial variability in the distribution of soil carbon is much greater in Mitchell and Yancey Counties, North Carolina, (fig. 15-STATSGO and fig. 16-SSURGO) than in Nicollet, Renville, Sibley Counties, Minnesota (fig. 13-STATSGO and fig. 14-SSURGO). As with Minnesota, the STATSGO-scale geographic patterns in SOC data linked to STATSGO map units are comparable to those patterns produced by linking
SOC data to SSURGO map units. High-elevation peaks and ridges and the upstream portions of low-order watersheds have the greatest carbon storage (from 16 to $24 \mathrm{~kg} / \mathrm{m}^{2}$, STATSGO, fig. 15; from 24 to $32 \mathrm{~kg} / \mathrm{m}^{2}$, SSURGO, fig. $16 C$ ). Lower SOC storage values (from 4 to $6 \mathrm{~kg} / \mathrm{m}^{2}$ ) generally are associated with low- to mid-elevation coves and valleys.

Differences between the STATSGO-based SOC map (fig. 15 ) and the SSURGO-based SOC map (fig. 16) relate primarily to elevation, slope, and aspect controls on temperature and 


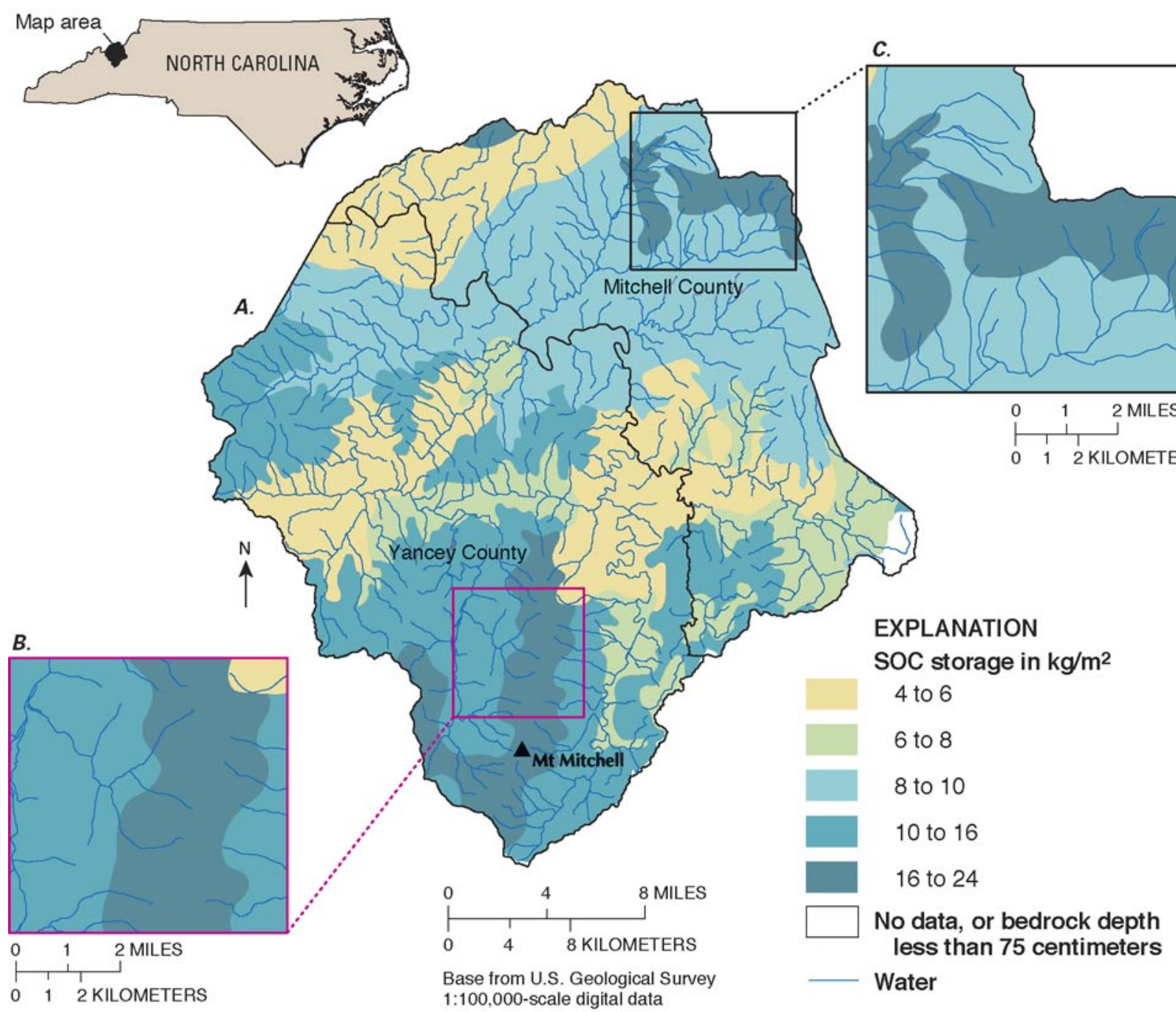

Figure 15. (A) Soil organic carbon (SOC) storage, depth interval from 0 to 100 centimeters, for mineral soils in Mitchell and Yancey Counties, North Carolina. Storage estimated by linking site-specific data to STATSGO map units. Data are for soils classed to the series level. (B) Area outlined in $A$ showing greater SOC storage values for soils on a north-south-trending ridge, 2,800-6,684 feet (ft) (853-2,037 meters $(\mathrm{m})$ altitude). (C) Area outlined in $A$ showing SOC storage values for soils on mountain slopes $\left(4,000-6,300 \mathrm{ft}(1,219-1,920 \mathrm{~m})\right.$ altitude) between 8 and 24 kilograms per square meter $\left(\mathrm{kg} / \mathrm{m}^{2}\right)$.

moisture and to bedrock depth. Higher-elevation, north-tonortheast-facing slopes generally have greater SOC storage values (from 16 to $32 \mathrm{~kg} / \mathrm{m}^{2}$ ) than do the south-to-southwestfacing slopes (from 4 to $16 \mathrm{~kg} / \mathrm{m}^{2}$ ), as the northern aspect is cooler and wetter than the southern aspect. The difference in SOC storage with slope aspect is shown in detail in figure $16 B$ (north-trending ridge of Mt. Mitchell) and 16C (high-elevation area, 4,000-6,300 ft, in northeastern Mitchell County).

Because of the way thin soils (depth $<1 \mathrm{~m}$ ) are dealt with when SOC storage is calculated, many of the high-elevation SSURGO map units are displayed white (no SOC data, fig. $16 B$ and $16 C$ ). Although pedon data may be available for series locations with soil depths greater than 1 meter, for this exercise, if the area-weighted mean depth of the map unit is less than 75 $\mathrm{cm}$ (the midpoint of the 50 to $100 \mathrm{~cm}$ depth interval), then the 0 to $100 \mathrm{~cm} \mathrm{SOC}$ value for that map unit is set to missing.
However, if the purpose of the storage/inventory calculation is soil-carbon accounting rather than comparison of calculation results based on different SOC data sources, then it is appropriate to include shallow soils in the accounting if the data are available for the entire soil profile (that is, from surface to bedrock). The difference in approach is shown for Mitchell and Yancey Counties, North Carolina (fig. 17), using site-specific SOC data linked to SSURGO map units. The ridgetop soils in the Mt. Mitchell area and along the northwestern border of both counties are not mapped if the shallow soils (depth to bedrock $<75 \mathrm{~cm}$ ) are excluded (fig. 17A). By comparison, when these soils are included (fig. 17B), the SOC storage for the Mt. Mitchell area varies from 10 to $16 \mathrm{~kg} / \mathrm{m}^{2}$, and SOC storage for the area along the northwestern border of both counties varies from 4 to $6 \mathrm{~kg} / \mathrm{m}^{2}$. The geographic distribution of shallow soils by mean depth to bedrock for Mitchell and 


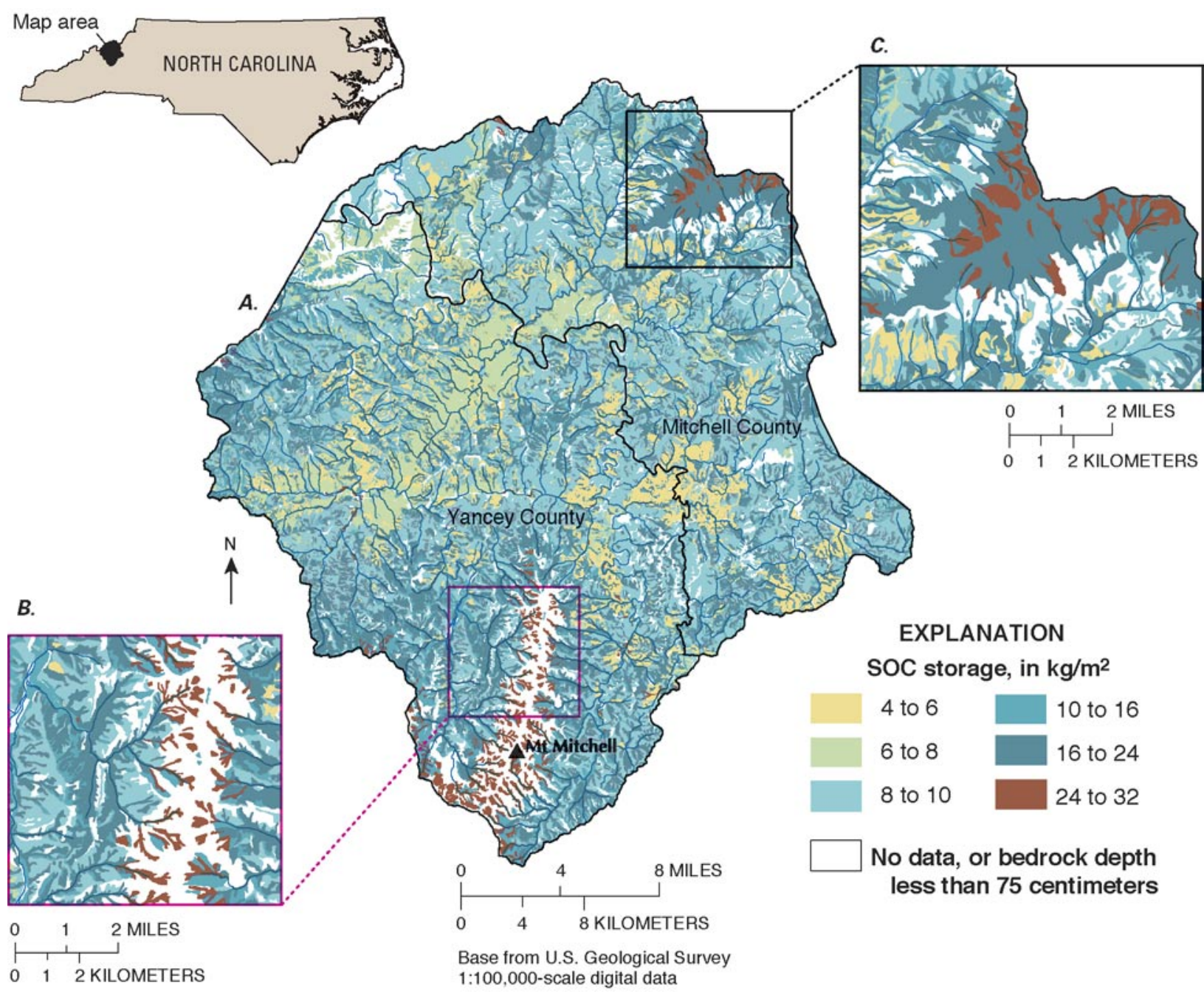

Figure 16. (A) Soil organic carbon (SOC) storage, depth interval from 0 to 100 centimeters, for mineral soils in Mitchell and Yancey Counties, North Carolina. Storage estimated by linking site-specific data to SSURGO map units. Data are for soils classed to the series level. (B) Area outlined in $A$ showing greater SOC storage values for soils on north-facing slopes than for those on south-facing slopes; slopes have about 3,000 feet (ft) (900 meters (m)) relief. (C) Area outlined in $A$ showing SOC storage values for mountain slopes $(4,000-6,300 \mathrm{ft}(1,219-1,920 \mathrm{~m})$ altitude) from 16 to 32 kilograms per square meter $\left(\mathrm{kg} / \mathrm{m}^{2}\right)$.

Yancey Counties is shown in figure 18. If the SOC mapping to a depth of 1 meter is done based on STATSGO (fig. 18A), no map units are excluded. However, the SSURGO-based mapping excludes the areas shown in bright yellow (fig. 18B, depth to bedrock from 44 to $75 \mathrm{~cm}$ ). Adding these shallow soils to the 1-meter inventory increases the total SOC inventory for Mitchell and Yancey Counties from 13.4 Tg to $14.4 \mathrm{Tg}$. Therefore, by difference, the shallow, high-elevation, ridgetop and upper slope soils in these two counties have an SOC inventory of approximately $1 \mathrm{Tg}$.

Most of the shallow, montane soils in Mitchell and Yancey Counties, as well as those developed in similar environmental settings in other geographic areas, are forest soils-an important terrestrial reservoir when considering carbon sequestration from a management perspective. Recent modeling efforts suggest that forest ecosystems are a significant terrestrial carbon sink in the northern hemisphere (Goodale and others, 2002).

Scientific studies of carbon cycling in terrestrial ecosystems will take a completely different approach to soil depth than that taken for development of calculation or accounting methods. Although arbitrary depth intervals certainly could be used in functional studies of carbon cycling, a horizon-based approach makes more sense since soil horizons develop in response to ecosystem function.

\section{Factors Affecting SOC Estimation}

Areawide estimates of SOC storage and inventory were calculated for the selected county areas in Colorado, Minnesota, Mississippi, and North Carolina (table 4) to provide a basis for examining the effects of different soil-carbon data 


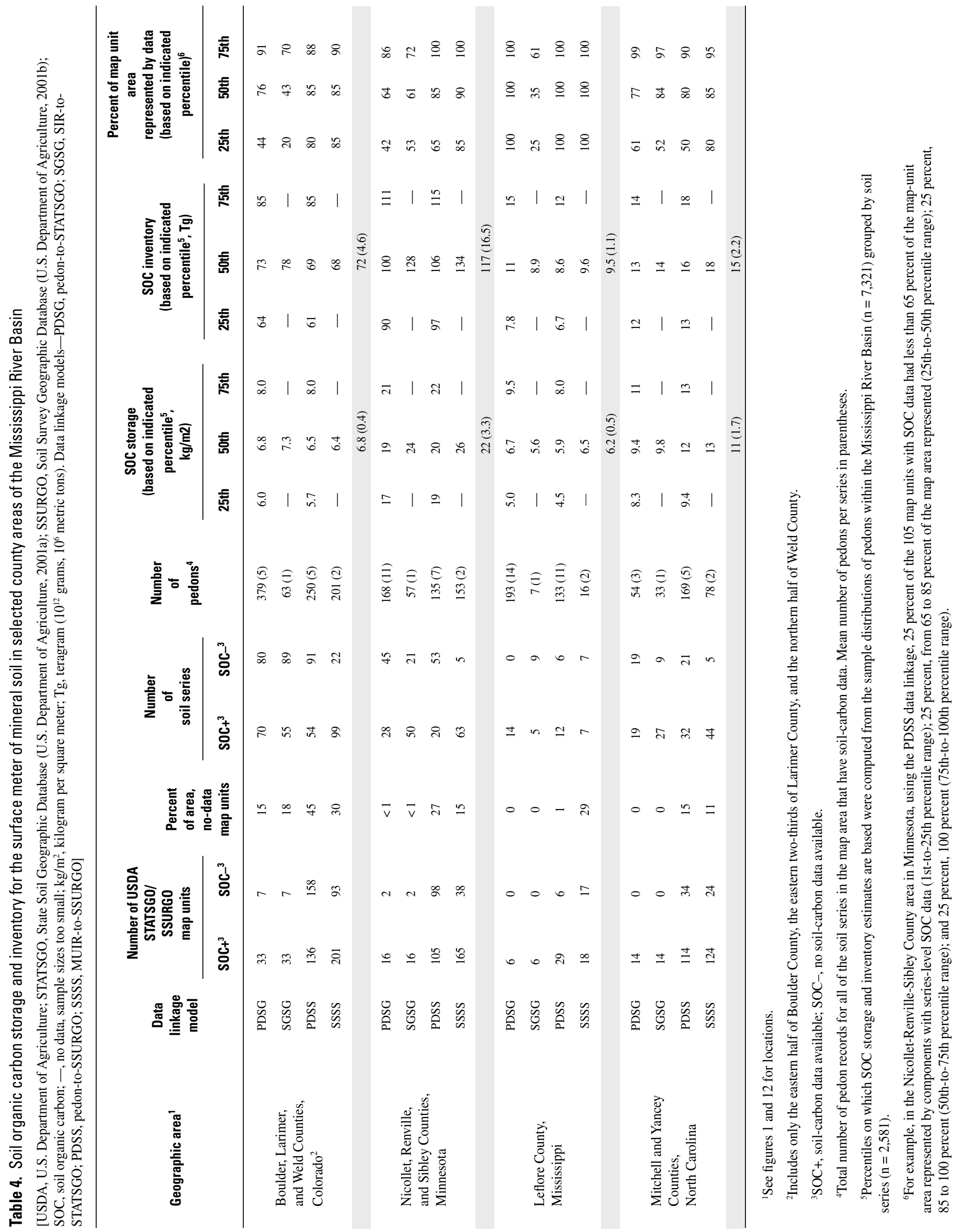



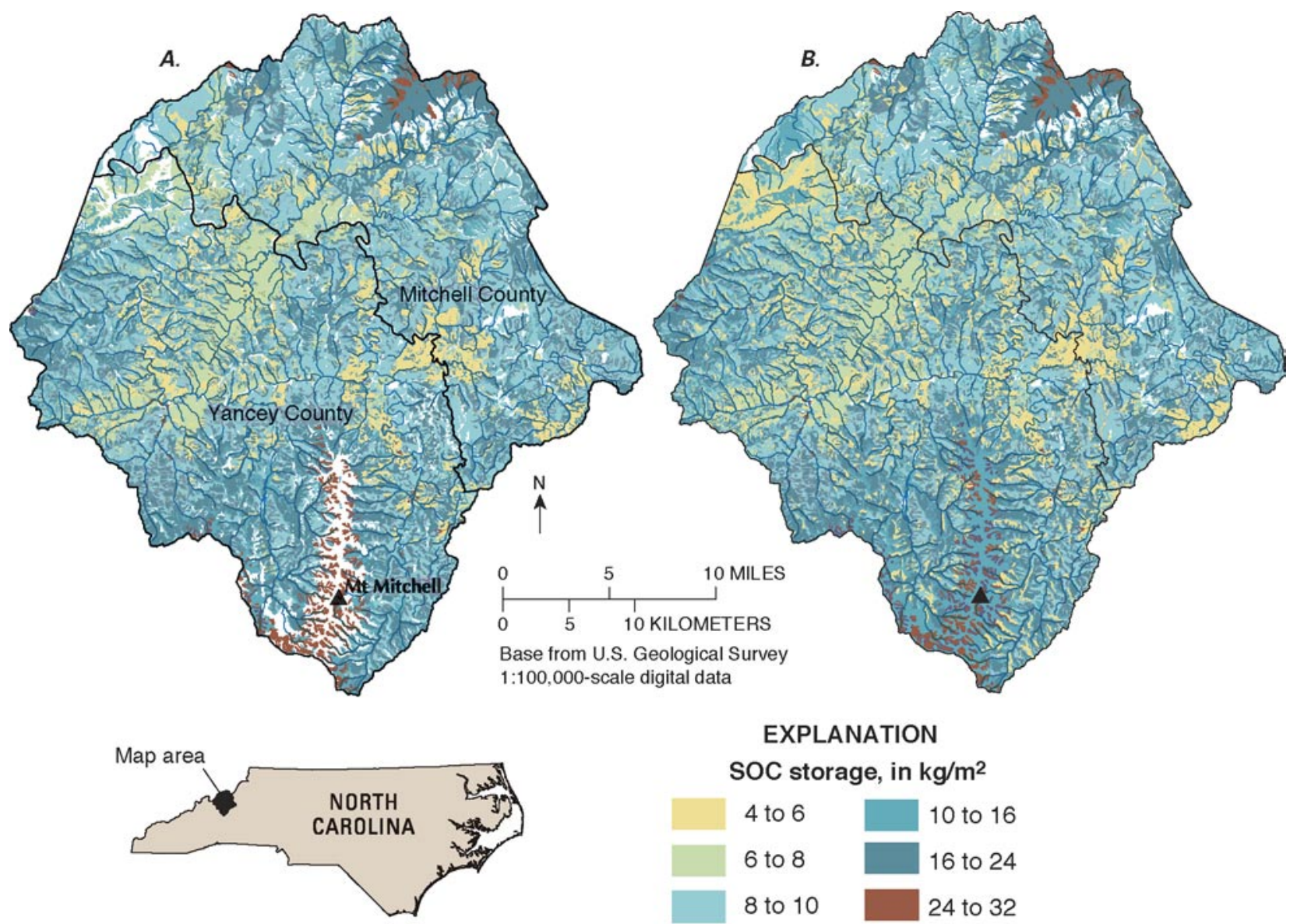

\section{EXPLANATION}

SOC storage, in $\mathrm{kg} / \mathrm{m}^{2}$

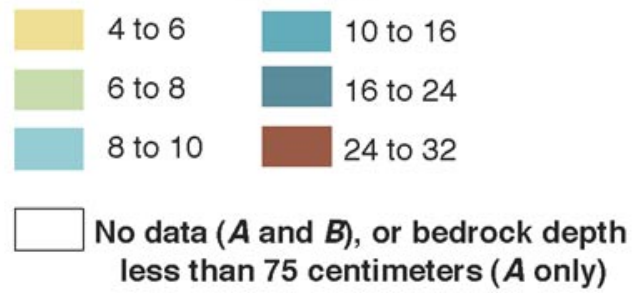

Figure 17. (A) Soil organic carbon (SOC) storage, depth interval from 0 to 100 centimeters, for mineral soils in Mitchell and Yancey Counties, North Carolina. Storage estimated by linking site-specific data to SSURGO map units. Data are for soils classed to the series level. No-data areas, shown in white, include map units for which there are no data or for which depth to bedrock is $<75 \mathrm{~cm}$. $(B)$ Same as $A$, except that areas shown in white include only those map units for which there are no data. Carbon storage for shallow soils (depth to bedrock $<75 \mathrm{~cm}$ ) is mapped in $B$ as long as there are SOC data available for the entire soil profile from the surface to bedrock. If the primary purpose of the SOC inventory is soil-carbon accounting rather than comparison of SOC data sources, $B$ presents a more appropriate scenario.

sources, different map scales, and scale-related differences in map-unit taxonomy. Nicollet, Renville, and Sibley Counties, Minnesota, have the greatest areawide SOC storage, with values ranging from $19 \mathrm{~kg} / \mathrm{m}^{2}$ (PDSG linkage model) to 26 $\mathrm{kg} / \mathrm{m}^{2}$ (SSSS linkage model) and a mean storage $( \pm 1$ standard deviation, based on four linkage models) of $22 \pm 3.3 \mathrm{~kg} / \mathrm{m}^{2}$; followed by Mitchell and Yancey Counties, North Carolinamean storage, $11 \pm 1.7 \mathrm{~kg} / \mathrm{m}^{2}$; Boulder, Larimer, and Weld Counties, Colorado- $6.8 \pm 0.4 \mathrm{~kg} / \mathrm{m}^{2}$; and Leflore County, Mississippi- $6.2 \pm 0.5 \mathrm{~kg} / \mathrm{m}^{2}$ (table 4). For these areas, there is no systematic bias in which linkage model gives the highest or lowest estimate of SOC storage.

Several measures of "data completeness" were chosen to help quantify the differences in SOC estimates by data linkage model: (1) the number of STATSGO/SSURGO map units with and without SOC data, (2) percent of area represented by map units without SOC data, (3) the number of soil series with and without SOC data, (4) the number of pedons or pseudo pedons contributed to the map by each data linkage, and (5) the percent of map-unit area represented by data. The range of estimates for each geographic area and the errors associated with each estimate are functions of these factors, all of which deal with different aspects of data availability (that is, map-unit representation by data, soil-series representation by data, and scale-related differences in map-unit taxonomy).

All but 4 of the 16 linkage models (PDSG and SGSG for Mississippi and North Carolina) resulted in some number of map units for which no component-level soil-carbon data were available. In other words, there are no available site-specific pedon data for any of the component series in the map unit or there are no available STATSGO/SSURGO layer data or both. As stated earlier in Methods section, the error in estimates of 

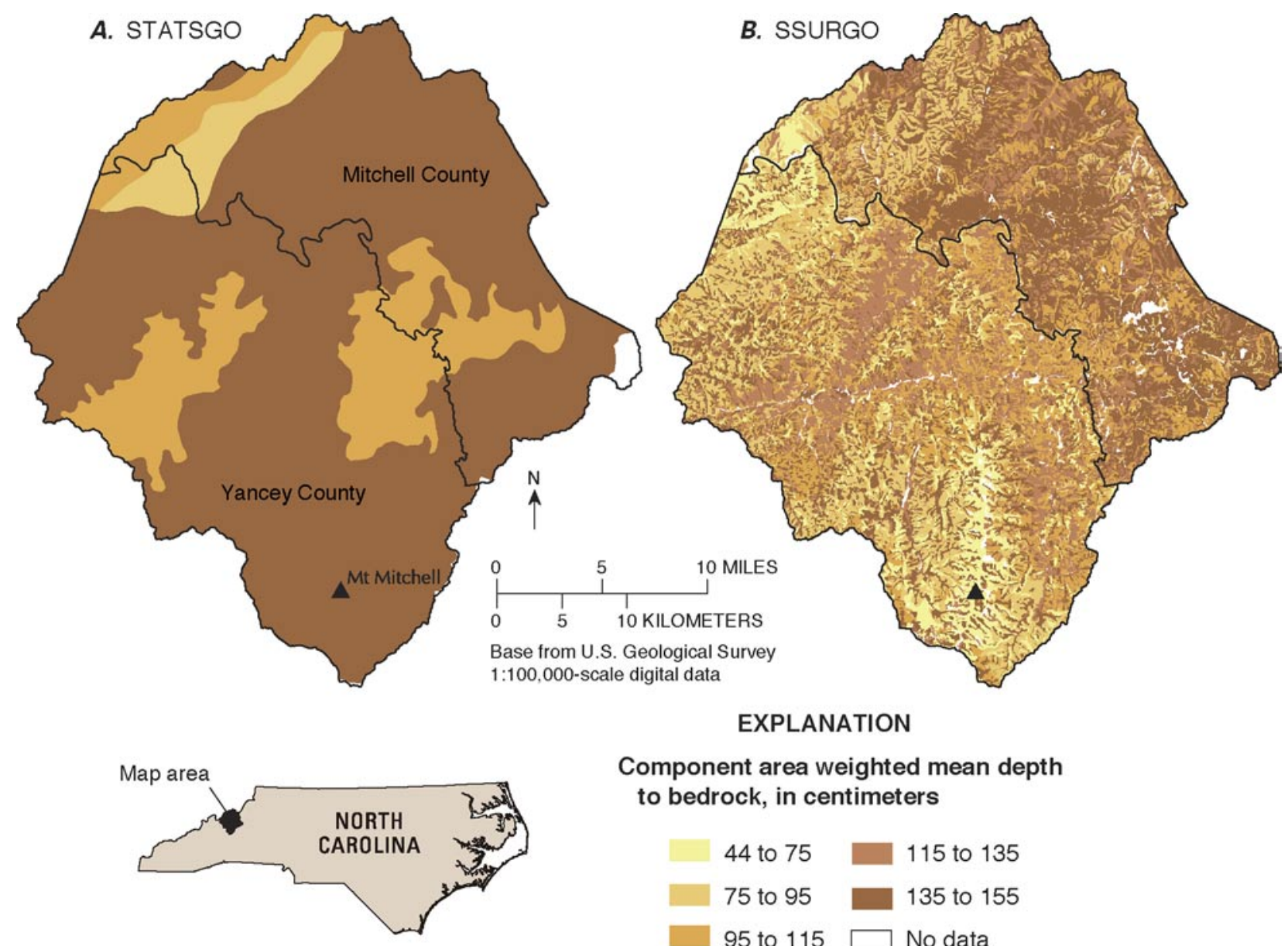

\section{EXPLANATION}

\section{Component area weighted mean depth} to bedrock, in centimeters

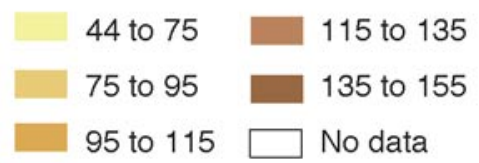

Figure 18. Component area-weighted mean depth to bedrock for (A) STATSGO and (B) SSURGO map units, Mitchell and Yancey Counties, North Carolina.

SOC inventory for areas with no-data map units varies with the amount of unmapped area and with how representative the mapped area is of the unmapped area. The greater the number of no-data map units and/or the larger the unmapped area, the greater the potential error. In general, both the number of no-data map units and the percentage of unmapped area were greater for SSURGO linkages than for STATSGO linkages.

This trend does not infer that STATSGO-based estimates of inventory for the Colorado area (table 4), for example, are better or more accurate than SSURGO-based estimates. If pedon data are linked to STATSGO, 15 percent of the area (represented by 7 of 41 map units) is unmapped, whereas, if these same data are linked to SSURGO, 45 percent of this same area (represented by 158 of 294 map units) is unmapped. However, greater geographic coverage with STATSGO may be more than offset by the greater local-scale accuracy of SSURGO. SSURGO map units have a maximum of three component soil series and, in many cases, relate directly to single series, as contrasted with STATSGO map units, which can have a maximum of 21 component soil series. Depending on the availability and representativeness of data for com- ponent series, STATSGO map units have a larger potential variance in estimates of map-unit properties than do SSURGO map units.

The number of soil series without available soil-carbon data and the number of pedons or pseudo pedons per series affect the accuracy of an SOC map at the component level rather than the map-unit level. Major geographic components with missing soil-carbon data, for example, generally will have a much greater effect on map accuracy than will minor components with missing data. Larger numbers of pedons per series tend to increase map accuracy, provided these pedons represent the series-level spatial variability in soil carbon. In many cases, the no-data soil series outnumber those with soil-carbon data. However, the generally low percentage of unmapped area and high percentage of map-unit area represented by data both suggest that major map-unit components are well represented. For example, with the PDSG linkage for Colorado, 80 of 150 series in the map area have no available data, but the geographic extent covered by no-data map units is only 15 percent, and the median map-unit area represented by data is 76 percent (table 4 ). 


\section{Suitability of Soil-Carbon Data for SOC Assessment}

The suitability of soil-carbon data for SOC geographic studies is largely defined by the answers to questions about the map scale and size of the study area, the geographic and temporal extent of the data, and soil taxonomy. Is the area of interest a small watershed, a county, or a large river basin? Pedon data used in carbon-mapping studies should be sufficient to describe the variability in soil carbon at the appropriate scale. Are the locations of pedon sampling sites well distributed across the landscape? Do these locations provide a spatially representative sampling of the landscape? How are the pedon data distributed through time? If there have been major decadal-scale changes in land use and most of the pedon data were collected before or after a major land-use change, how suitable are these data for regional assessment? Are changes in carbon storage occurring during the time period represented by the data? Ideally, the data set used for mapping should provide a consistent temporal snapshot; in actuality, few data sets achieve this goal. Are the pedon data keyed to soil series or only to a higher taxonomic level? The soil series is the most direct link to STATSGO and SSURGO. If serieslevel taxonomy is not available, then the data linkage must be at a higher taxonomic level—family, subgroup, great group, suborder, or, most generally, at the soil-order level. Some of these topics are discussed in the following sections.

\section{Map Scale}

Soil-attribute mapping using digital base maps such as STATSGO or SSURGO as a georeference can benefit from the use of scale-appropriate data. The STATSGO-based and SSURGO-based maps used in this report were produced by using the same site-specific data for soil carbon linked by series. Therefore, the differences between STATSGO and SSURGO soil-carbon maps of the same geographic area primarily are a function of the taxonomic differences between the two databases. However, there are inherent scales to the aggregate attribute data provided with STATSGO and SSURGO. Both the SIR and MUIR databases have built-in regional variability in soil-series properties (primarily based on slope) that accounts for differences in soil properties associated with erosional versus depositional landscape environments. Attribute values affected by this erosion/deposition split include those for soil carbon.

A model that incorporates regional variation in the environmental factors affecting series-level soil-carbon content could be developed for the S3C database. Variables that describe differences in landscape position, vegetation, and land-use history for land areas having the same soil series could be linked in the STATSGO/SSURGO data model and then used as "intra-series" or "subseries" links to the map units. In other words, instead of linking soil-carbon data to map-unit components at the soil-series level, separate data linkages based on these differences could be established for the same series. It is expected that the carbon content of soils in the same series will vary with the degree and type of land disturbance as well as with land-use history. An eroded Memphis silt loam under cultivation, for example, will likely have less carbon than an undisturbed Memphis silt loam under native hardwood cover. Similarly, a cultivated Sharkey clay probably will have less carbon than a Sharkey clay under native bottomland hardwood forest cover. Using this approach with site-specific soil-carbon data is problematic, however, because much of the desired ancillary data may not be available. Further subsetting of pedon data grouped by soil series will reduce sample sizes that, in many cases, already are too small to be representative of the series.

\section{Geographic and Temporal Coverage}

The pedon data used to populate STATSGO or SSURGO should be spatially distributed throughout the geographic area being mapped and provide a temporal snapshot of the landscape. A spatially representative set of samples for a particular series should provide a sample data set that proportionally describes the soil-carbon content of that series. Ideally, if 10 percent of the landscape occupied by Monona silt loam in western Iowa is native tallgrass prairie on slopes, then 10 percent of the Monona pedon samples should have been collected in this setting. The median carbon value for the "native prairie" subsample would then be linked to the Monona components of STATSGO or SSURGO map units in this environmental setting. In practice, there probably are no series with sufficient representative pedon data to allow subsampling across environmental settings. In this study, no subsampling was done because of the small series-level sample sizes-as mentioned earlier, only 5 percent of the series in the S3C database are represented by 10 or more pedons.

Temporal changes in soil-carbon content resulting from land disturbance and variation in climate and vegetation can be a large source of error in estimates of storage and inventory. If these estimates are based on a data set with a long time span, it is possible that regional differences in mapped carbon storage could be comparable to decadal-scale gains or losses in soil carbon within a region (Odell and others, 1984). The S3C database assembled for this study spans 96 years (1900-95) with 98 percent of the data collected post-1950 and 63 percent collected post-1980. Time spans for individual series range from 1 year to 68 years. For the series represented by one pedon ( 46 percent of the series in the database), sampling years span the entire 95-year period-thus soil series occurring within the same map unit could have been characterized many years apart. Landscape alterations due to intensive agriculture or severe erosion can result in large soil-carbon losses (Mann, 1986; Post and Kwon, 2000; Post and others, 2001). If these changes occurred for a series that was sampled predisturbance, SOC storage would be overestimated for map units with that series as a major component. 


\section{Soil Taxonomy}

STATSGO and SSURGO are taxonomic databases; therefore, the most direct linkage of soil-attribute data to the map units is taxonomic. Although the data linkage used in this study is at soil-series level, it is not clear that a low-level linkage is the most appropriate for mapping soil carbon. Linkages at higher taxonomic levels - such as family, subgroup, or great group, in combination with subsetting based on regional variation in geomorphology, vegetation, and climate - need to be tested and evaluated. One benefit to this approach would be larger sample sizes and potentially better statistical characterization of the soil with regard to carbon content. Larger map-unit coverage could also result from data linkage at a higher taxonomic level if, for example, the pedon data were classed to represent a family or a subgroup. Series not represented in the pedon database likely would be represented at the family or subgroup level.

Pedon data linked to STATSGO or SSURGO at a higher taxonomic level than soil series will be intrinsically classified by some of the variables that control soil-carbon sequestration, as many of the identifiers used at the family, subgroup, and great group levels relate to soil temperature, moisture, texture, and mineralogy (Soil Survey Staff, 1998, 1999). Additional classification based on landscape position, geomorphic setting, and current vegetation can provide further "process-based" grouping of site-specific soil-carbon data prior to mapping.

Even at the most general taxonomic level of soil order, soils are somewhat grouped along environmental gradients that relate to soil carbon. Mollisols are the predominant soils in Nicollet, Renville, and Sibley Counties, Minnesota (fig. 19A and 19B), with Alfisols, Entisols, and Inceptisols occurring along the Minnesota River and along the downstream reaches of its larger tributaries. Histosols (not mapped in this study) occur in small isolated pockets coincident with the depressional wetlands in the upland areas. Soils in Mitchell and Yancey Counties, North Carolina (fig. 19C and 19D), are predominantly Inceptisols on the ridges and upper slopes, Entisols along isolated smaller drainageways, and Ultisols on the lower slopes and larger drainageways. In Minnesota, mineral soils with the highest carbon content are the Mollisols (from 16 to $52 \mathrm{~kg} / \mathrm{m}^{2}$ SOC) (fig. 14A and 14C). Alfisols, Entisols, and Inceptisols developed in alluvium along the Minnesota River generally have carbon contents lower than the Mollisols. In North Carolina, the highest carbon soils are the Inceptisols on the ridges and upper slopes (from 10 to $32 \mathrm{~kg} / \mathrm{m}^{2} \mathrm{SOC}$ ) (fig. 16A-16C). Lower SOC values are associated with Ultisols in the valleys (from 4 to $10 \mathrm{~kg} / \mathrm{m}^{2}$ ) (fig. 16A). However, the highest SOC values for Inceptisols in North Carolina are intermediate when ranked on a storage continuum from Mollisols to Ultisols.

\section{Conclusions}

Terrestrial carbon sequestration can contribute as an offset to the anthropogenic increase in atmospheric $\mathrm{CO}_{2}$. Decisions about managing land use for carbon sequestration can benefit from an understanding of the controls on the processing and distribution of terrestrial carbon. One approach toward this understanding is the development of a carbon inventory based on accurate estimates of carbon storage. Because the soils are the largest and most stable long-term reservoir for terrestrial carbon, an accurate SOC inventory is a necessary baseline for measuring net changes in terrestrial carbon stocks.

GIS-based approaches to mapping soil carbon provide readily available methods for linking pedon-based SOC data to digital soil maps such as the USDA STATSGO and SSURGO databases. A direct link between the pedon data and the STATSGO or SSURGO map units allows one to regionalize limited quantities of pedon data in a manner consistent with results that could be obtained if systematic and regionally representative soil sampling was undertaken. Because the data linkage is based on soil taxonomy, many of the environmental controls on soil carbon are embedded in the linkage.

One of the strengths in the pedon-based approach to SOC mapping with STATSGO or SSURGO as the geographic base is the potentially large quantity of data that can be assembled for the task. The S3C database used in this study is comprised of several sources of data-the USDA-NRCS NSSC laboratory characterization database and extensive State databases for Arkansas, Illinois, and Louisiana. Several other large regional databases are currently being processed and standardized so they can be added to $\mathrm{S} 3 \mathrm{C}$, which will increase both the number of soil series represented by pedon data and the number of pedons per series. If sufficient pedon data are available for accurate characterization of the component series in the map area, then a more accurate soil-carbon map can be generated.

The linkage of pedon data to STATSGO and SSURGO provides a distinct advantage over the direct use of the STATSGO and SSURGO attribute data (SIR and MUIR databases) in producing an SOC map. The SIR/MUIR databases underepresent the series-level spatial variability in soil properties that may occur both geographically and with depth in the soil profile. Whereas a SIR/MUIR-based SOC map might be adequate for input to a global-scale model, a pedon-based SOC map can provide the regional detail required for local assessments and regional studies that relate SOC dynamics to climate, land use, and vegetation.

Weaknesses in both the pedon-based and SIR/MUIRbased approaches to mapping soil carbon include data deficiencies both at the sample level (missing data for pedon horizons or pseudo-pedon layers) and at the soil-series level (missing data for map-unit components). The most serious sample deficiencies are the lack of bulk-density data and the errors associated with accurate measurement of bulk density. Potential errors in SOC storage and inventory estimates resulting from inaccurate estimation or measurement of bulk density can be quite large. Variation in the total depth to which pedons are sampled, described, and characterized also contributes to sample-level error by reducing the number of pedons available for a given standard depth. At present, the S3C database contains 7,950 SOC values for the standard interval from 0 to $10 \mathrm{~cm}, 7,887$ for 0 to $20,7,697$ for 0 to 50 , and 7,321 for 0 to 


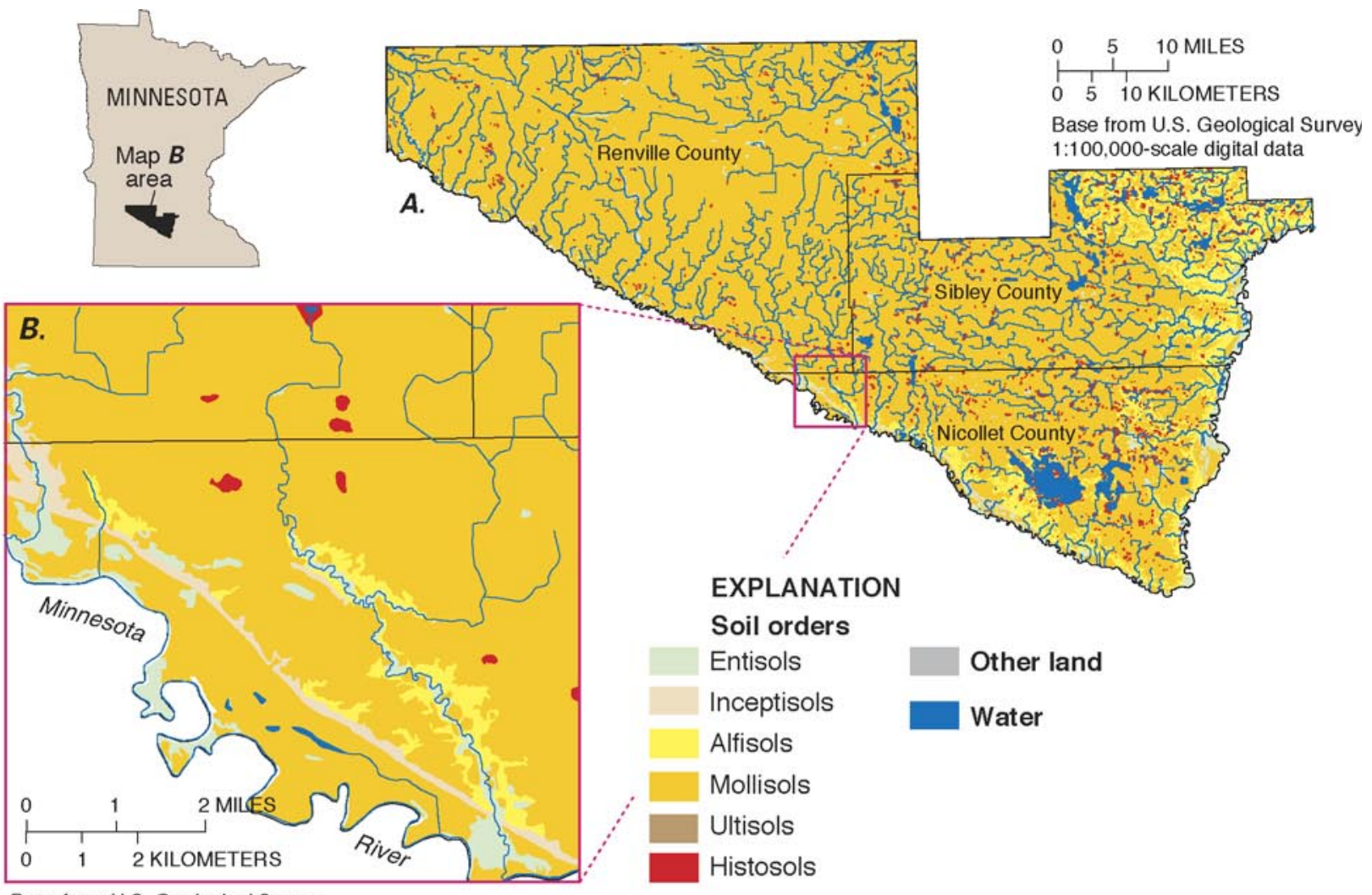

Geological Survey

1:100,000-scale digital data

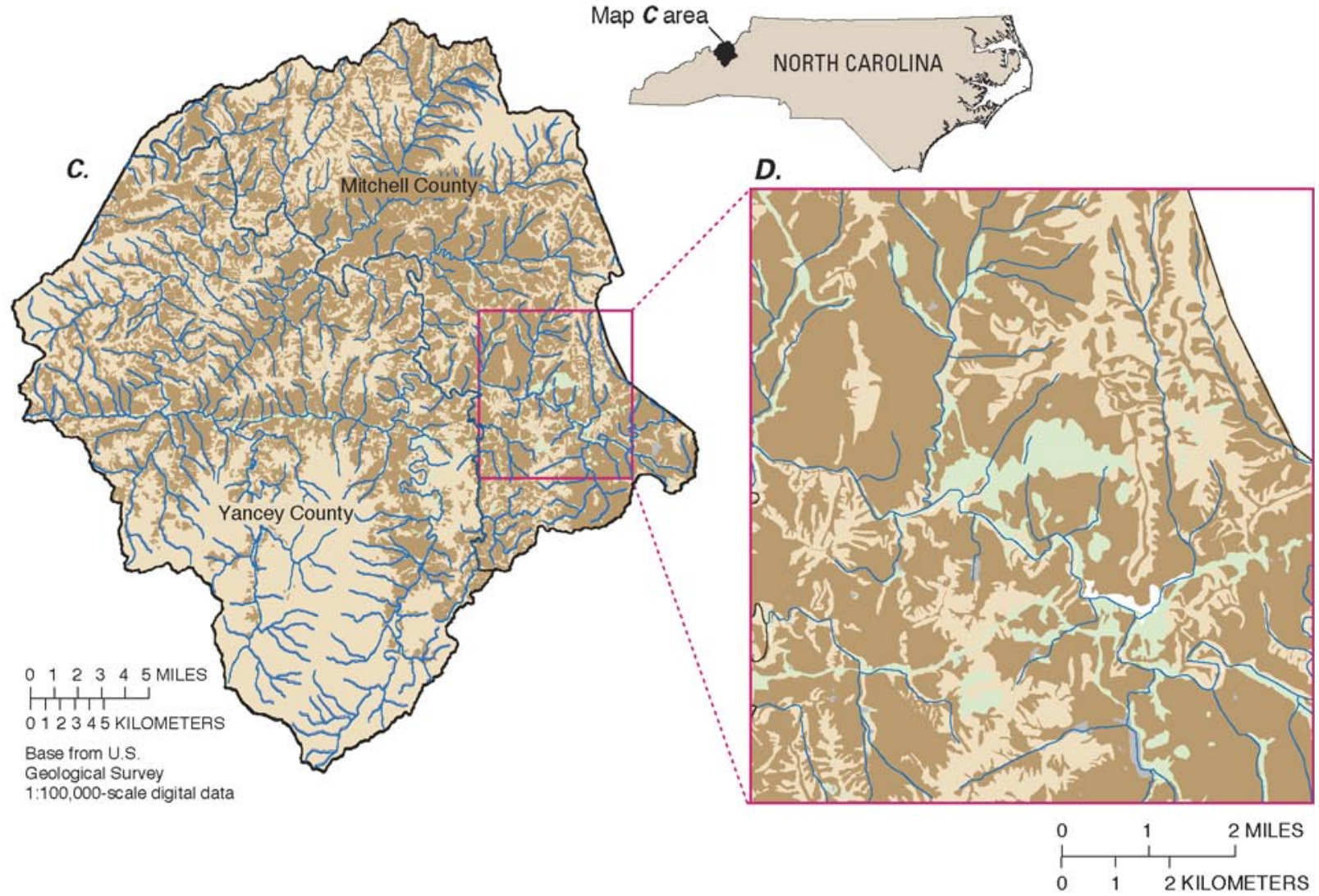

Figure 19. Geographic extent of soil orders based on SSURGO taxonomy. $A$ and $B$, Nicollet, Renville, and Sibley Counties, Minnesota; $B$ is area outlined in $A$. $C$ and $D$, Mitchell and Yancey Counties, North Carolina; $D$ is area outlined in $C$. 
100. Therefore, an SOC map for the surface meter of mineral soil in the MRB is based on 629 fewer pedons than a map for the surface 10 centimeters would be, an 8 percent loss of data. Series-level deficiencies include variable representation of soil series by pedon data and a complete lack of data for many series. In some cases, a series may be well characterized in some environmental settings but not in others. The Memphis silt loam and Sharkey clay were used as examples of this problem in earlier discussion. The cultivated settings for these series are relatively well characterized, whereas the native woodland settings are not. Data deficiencies for samples and soil series produce map-unit data gaps that can result in a reduction in either the number of map-unit components or the number of entire map units represented by data.

The suitability of existing pedon-data sources for SOC geographic studies is largely defined by the geographic and temporal extent of the data. Ideally, all of the soil series in the STATSGO/SSURGO map units should be represented by a sufficient number of pedons to characterize the carbon content of each series across all environmental settings. This endmember is a worthy goal of a soil-sampling network that could be designed and implemented to collect the data required for consistent long-term assessment. The pedon data used in such assessments should be sufficient to describe the variation in soil carbon at the appropriate scale and provide a temporal snapshot of storage and inventory. For those areas not mapped to series, or where pedons are not keyed to series, linkages of pedon data to STATSGO/SSURGO at higher taxonomic levels than the soil series should be explored, in combination with subsetting based on geomorphology, vegetation, and climate.

\section{References Cited}

Adams, J.M., Faure, H., Faure-Denard L., McGlade, J.M., and Woodward, F.I., 1990, Increases in terrestrial carbon storage from the Last Glacial Maximum to the present: Nature, v. 348, p. 711-714.

Alexander, T.G., and Robertson, J.S., 1970, Ascorbic acid as a reductant for inorganic phosphorus determination in Chang and Jackson fractionation procedure: Soil Science, v. 110, p. $361-362$.

Allison, L.E., 1965, Organic carbon, in Black, C.A., ed., Methods of Soil Analysis, Part 2: American Society of Agronomy, Monograph Series no. 9, p. 1367-1378.

Bachman, G.O., and Machette, M.N., 1977, Calcic soils and calcretes in the Southwestern United States: U.S. Geological Survey Open-File Report 77-794, 163 p.

Bailey, R.G., 1995, Description of the ecoregions of the United States: Accessed May 20, 2002, at URL http: //www.fs.fed.us/land/ecosysmgmt/ecoreg1_home.html.
Bailey, R.G., and Cushwa, C.T., 1981, Ecoregions of North America: Washington, D.C., U.S. Fish and Wildlife Service, FWS/OBS-81/29, map scale 1:12,000,000.

Bengtsson, L., and Enell, M., 1986, Chemical analysis, in Berglund, B.E., ed., Handbook of Holocene paleoecology and paleohydrology: New York, John Wiley and Sons, p. 423-451.

Blake, G.R., 1965, Bulk density, in Black, C.A., ed., Methods of soil analysis, Part 1: American Society of Agronomy, Monograph Series no. 9, p. 374-390.

Blecker, S.W., Yonker, C.M., Olson, C.G., and Kelly, E.F., 1997, Paleopedologic and geomorphic evidence for Holocene climate variation, short grass steppe, Colorado, USA: Geoderma, v. 76, p. 113-130.

Bliss, N.B., Waltman, S.W., and Petersen, G.W., 1995, Preparing a soil carbon inventory for the United States using geographic information systems, Chapter 23, in Lal, R., Kimble, J., Levine, E., and Stewart, B.A., eds., Soils and global change-Advances in soil science: Chelsea, Mich., Lewis Publishers, 440 p.

Bowman, Rudy, and Petersen, Mike, 1996, Soil organic matter levels in the Central Great Plains: U.S. Department of Agriculture Conservation Tillage Fact Sheet \#1-96: Accessed January 29, 2002, at URL http://www.akron.ars.usda.gov/ fs_soil.html.

Day, P.R., 1965, Particle fractionation and particle-size analysis, in Black, C.A., ed., Methods of soil analysis, Part 1: American Society of Agronomy, Monograph Series no. 9, p. $545-567$.

Eswaran, H., Van Den Berg, E., and Reich, P., 1993, Organic carbon in soils of the world: Soil Science Society of America Journal, v. 57, p. 192-194.

Fenneman, N.M., 1931, Physiography of Western United States: New York and London, McGraw-Hill Book Company, 534 p.

Fenneman, N.M., 1938, Physiography of Eastern United States: New York and London, McGraw-Hill Book Company, 714 p.

Goodale, C.L., Apps, M.J., Birdsey, R.A., Field, C.B., Heath, L.S., Houghton, R.A., Jenkins, J.C., Kohlmaier, G.H., Kurz, Werner, Liu, Shirong, Nabuurs, Gert-Jan, Nilsson, Sten, and Shvidenko, A.Z., 2002, Forest carbon sinks in the northern hemisphere: Ecological Applications, v. 12, p. 891-899.

Helsel, D.R., and Hirsch, R.M., 1992, Statistical methods in water resources-Studies in environmental science 49: New York, Elsevier, 522 p. 
IPCC [Intergovernmental Panel on Climate Change], 1995, Climate change 1995: The science of climate change, in Houghton, J.T., Meira Filho, L.G., Callender, B.A., Harris, N., Kattenberg, A., and Maskell, K., eds., Second Assessment of the IPCC: Cambridge, U.K., Cambridge University Press, 572 p.

IPCC, 2001, Climate change 2001: The scientific basis, in Houghton, J.T., Ding, Y., Griggs, D.J., Noguer, M., van der Linden, P.J., Dai, X., Maskell, K., and Johnson, C.A., eds., Third Assessment Report of the IPCC: Cambridge, U.K., Cambridge University Press, 892 p.

Jobbágy, E.G., and Jackson, R.B., 2000, The vertical distribution of soil organic carbon and its relation to climate and vegetation: Ecological Applications, v. 10, p. 423-436.

Kansas State University, 2002, Konza Prairie Soils (kzgis006): Konza Prairie Biological Station, Long Term Ecological Research Program: Accessed January 29, 2002, at URL http://climate.konza.ksu.edu/.

Mann, L.K., 1986, Changes in soil carbon storage after cultivation: Soil Science, v. 142, p. 279-288.

Odell, R.T., Melsted, S.W., and Walker, W.M., 1984, Changes in organic carbon and nitrogen of Morrow plot soils, 1904-1973: Soil Science, v. 137, p. 160-171.

Parker, J.L., Decker, G.L., Gray, L., and Muller, O., 1975, Soil survey of Carbon County area, Montana: U.S. Department of Agriculture, $137 \mathrm{p}$.

Pettry, D.E., and Switzer R.E., 1999, Sharkey soils in Mississippi: Mississippi Agricultural and Forestry Experiment Station Bulletin No.1057, Mississippi State University: Accessed April 14, 1999, at URL http://mafes.msstate.edu/ pubs/b1057.htm (currently http://msucares.com/pubs/ bulletins/b1057.htm).

Post, W.M., Izaurralde, R.C., Mann, L.K., and Bliss, Norman, 2001, Monitoring and verifying changes of organic carbon in soil: Climatic Change, v. 51, p. 73-99.

Post, W.M., and Kwon, K.C., 2000, Soil carbon sequestration and land-use change: Processes and potential: Global Change Biology, v. 6, p. 317-328.

Reheis, M.C., 1987, Soils in granitic alluvium in humid and semiarid climates along Rock Creek, Carbon County, Montana: U.S. Geological Survey Bulletin 1590-D, 71 p.

Schoeneberger, P.J., Wysocki, D.A., Benham, E.C., and Broderson, W.D., 1998, Field book for describing and sampling soils: U.S. Department of Agriculture, Natural Resources Conservation Service, National Soil Survey Center, Lincoln, Nebr., 177 p.
Schumacher, B.A., Day, W.J., Amacher, M.C., and Miller, B.J., 1988, Soils of the Mississippi River alluvial plain in Louisiana: Louisiana Agricultural Experiment Station Bulletin No. 796, Louisiana State University Agricultural Center, 275 p.

Seaber, P.R., Kapinos, F.P., and Knapp, G.L., 1994, Hydrologic unit maps: U.S. Geological Survey Water-Supply Paper 2294, 63 p.

Soil Survey Staff, 1951, Soil survey manual: U.S. Department of Agriculture, Soil Conservation Service, Agriculture Handbook 18, 503 p.

Soil Survey Staff, 1962, Identification and nomenclature of soil horizons in Soil survey manual: U.S. Department of Agriculture, Soil Conservation Service, supplement to Agriculture Handbook 18, p. 173-188.

Soil Survey Staff, 1975, Soil taxonomy, a basic system of soil classification for making and interpreting soil surveys: U.S. Department of Agriculture, Soil Conservation Service, Agriculture Handbook no. 436, 754 p.

Soil Survey Staff, 1986, National soil taxonomy handbook 430-VI, issue no. 8: U.S. Department of Agriculture, Soil Conservation Service, $55 \mathrm{p}$.

Soil Survey Staff, 1993, Soil survey manual, 2d ed.: U.S. Department of Agriculture, Natural Resources Conservation Service, National Soil Survey Center, Soil Survey Laboratory, Lincoln, Nebr., Agriculture Handbook 18, 410 p.

Soil Survey Staff, 1995, Soil Survey laboratory information manual: U.S. Department of Agriculture, Natural Resources Conservation Service, National Soil Survey Center, Soil Survey Laboratory, Lincoln, Nebr., Soil Survey Investigations Report no. 45, version 1.0, 305 p.

Soil Survey Staff, 1996, Soil survey laboratory methods manual: U.S. Department of Agriculture, Natural Resources Conservation Service, National Soil Survey Center, Soil Survey Laboratory, Lincoln, Nebr., Soil Survey Investigations Report no. 42, version 3.0, 693 p.

Soil Survey Staff, 1998, Keys to soil taxonomy, 8th ed.: U.S. Department of Agriculture, Natural Resources Conservation Service, $326 \mathrm{p}$.

Soil Survey Staff, 1999, Soil taxonomy, a basic system of soil classification for making and interpreting soil surveys, $2 \mathrm{~d}$ ed.: U.S. Department of Agriculture, Natural Resources Conservation Service, Agriculture Handbook no. 436, 870 p.

Soil Survey Staff, 2002, Official soil series descriptions: U.S. Department of Agriculture, Natural Resources Conservation Service, National Soil Survey Center, Lincoln, Nebr. Accessed January 16, 2002, at URL http//soils.usda.gov/ soils/technical/classification/osd/index.html. 


\section{A44 Soil-Carbon Storage and Inventory for the Continental United States}

U.S. Department of Agriculture, Natural Resources Conservation Service, 1994, State Soil Geographic (STATSGO) Data Base-Data use information: Miscellaneous Publication 1492, 39 p.

U.S. Department of Agriculture, Natural Resources Conservation Service, 1995, Soil Survey Geographic (SSURGO) Database-Data use information: Miscellaneous Publication $1527,31 \mathrm{p}$.

U.S. Department of Agriculture, Natural Resources Conservation Service, 1996, Soil Survey Laboratory Methods Manual: Soil Survey Investigations Report no. 42, version $3.0,716 \mathrm{p}$.

U.S. Department of Agriculture, Natural Resources Conservation Service, 2001a, State Soil Geographic (STATSGO) Database: Accessed September 1, 2001, at URL http: //www.ftw.nrcs.usda.gov/stat_data.html (currently http: //www.ncgc.nrcs.usda.gov/branch/ssb/products/statsgo/ index.html).
U.S. Department of Agriculture, Natural Resources Conservation Service, 2001b, Soil Survey Geographic (SSURGO) Database: Accessed September 1, 2001, at URL http: //www.ftw.nrcs.usda.gov/ssur_data.html. (currently http: //www.ncgc.nrcs.usda.gov/branch/ssb/products/ssurgo/ index.html).

U.S. Department of Agriculture, Natural Resources Conservation Service, 2001c, Map Unit Interpretations Record (MUIR) Database: Accessed September 1, 2001, at URL http://www.statlab.iastate.edu/soils/muir/ (currently http: //soils.usda.gov/survey/nmuir/index.html).

U.S. Department of Agriculture, Natural Resources Conservation Service, 2001d, National Soil Characterization Database: Accessed September 1, 2001, at URL http: //ssldata.nrcs.usda.gov/.

University of Illinois, 2001, Soil Characterization Laboratory Database: Accessed February 15, 2001, at URL http: //www.il.nrcs.usda.gov/soils/soil-lab.htm (currently http: //www.il.ncgc.nrcs.usda.gov/technical/soils/soil_lab.html). 
A46 Soil-Carbon Storage and Inventory for the Continental United States 